\title{
OVERCOMING RESISTANCE TO SONIC HEDGEHOG INHIBITION BY TARGETING p90 RIBOSOMAL S6 KINASE IN PEDIATRIC MEDULLOBLASTOMA
}

\author{
by \\ Mary Rose Pambid
}

B.Sc., The University of British Columbia, 2011

\begin{abstract}
A THESIS SUBMITTED IN PARTIAL FULFILLMENT OF THE REQUIREMENTS FOR THE DEGREE OF
\end{abstract}

MASTER OF SCIENCE

in

The Faculty of Graduate Studies

(Experimental Medicine)

THE UNIVERSITY OF BRITISH COLUMBIA

(Vancouver)

August 2013

(C) Mary Rose Pambid, 2013 


\begin{abstract}
Molecular subtyping has allowed for the beginning of personalized treatment in children suffering from medulloblastoma (MB). However, resistance inevitably emerges against these therapies, particularly in the Sonic Hedgehog $(\mathrm{SHH})$ subtype. We discovered that children with SHH subtype have inferior outcomes relative to other MB subtypes underscoring the need to identify new therapeutic targets.
\end{abstract}

High content screening of a 129 compound library identified agents that inhibited SHH MB growth. The lead molecular target was p90 ribosomal S6 kinase (RSK). Its levels were characterized by immunoblotting and qRT-PCR. Comparisons were made to human neural stem cells (hNSC). Impact of inhibiting RSK with the small molecule BI-D1870 or siRNA was assessed in growth assays (monolayer, neurosphere, and soft agar). NanoString was used to detect RSK in a cohort of 58 patients with MB. To determine BID1870 pharmacokinetics/pharmacodynamics, $100 \mathrm{mg} / \mathrm{kg}$ was I.P. injected into mice and tissues were collected at various time points.

Daoy, ONS76, UW228, and UW426 MB cells were exquisitely sensitive to BI-D1870 but unresponsive to SHH inhibitors. RSK inhibition had no effect on hNSCs. Antitumour growth corresponded with inactivated RSK in MB cells. Inhibiting RSK with siRNA or BI-D1870 suppressed growth, induced apoptosis, and sensitized cells to SHH agents. Notably, RSK2-4 was expressed in SHH patients as well as the other subtypes. In mice, BI-D1870 was well-tolerated and crossed the blood-brain barrier (BBB).

RSK inhibitors are promising because their target RSK is found in SHH MB patients. They also induce high levels of apoptosis in only MB cells. Importantly, BI-D1870 crosses the BBB, acting as a scaffold for the development of more long-lived RSK inhibitors. 


\section{PREFACE}

The work described was desgined by Dr. Sandra Dunn and myself. I performed, optimized, completed, and analyzed more than $90 \%$ of the experiments (including all imaging, flow cytometry, immunoblotting, siRNA and drug treatments) associated with this manuscript in its entirety. A version of Chapter 2 has been published. Mary Rose Pambid, Rachel Berns, Hans H. Adomat, Kaiji Hu, Joanna Triscott, Norbert Maurer, Natalia Zisman, Vijay Ramaswamy, Cynthia E. Hawkins, Michael D. Taylor, Christopher Dunham, Emma Guns, Sandra E. Dunn. Overcoming resistance to sonic hedgehog inhibition by targeting p90 ribosomal s6 kinase in pediatric medulloblastoma. Pediatr Blood Cancer, 2013.

Parts of the work presented in Chapter 2 were done in collaboration with the Centre for Drug Research and Development (CDRD), the Vancouver Prostate Centre, and SickKids Hospital. Dr. Norbert Maurer, Geoff Winters, and Natalia Zisman synthesized BI-D1870 at CDRD and performed solubility as well as formulation tests. Hans H. Adomat provided technical assistance and analysis with the development of the PK/PD studies. Dr. Vijay Ramaswamy, Dr. Michael D. Taylor, and Dr. Cynthia Hawkins provided the SickKids validation cohort for nanoString. 
TABLE OF CONTENTS

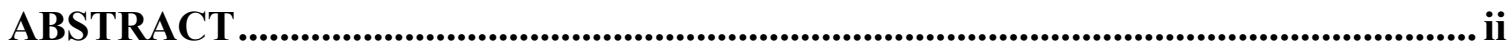

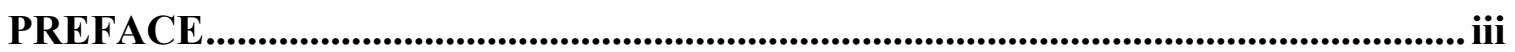

TABLE OF CONTENTS ............................................................................................... iv

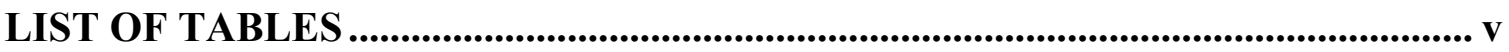

LIST OF FIGURES ……................................................................................................... vi

LIST OF ABBREVIATIONS ..................................................................................... vii

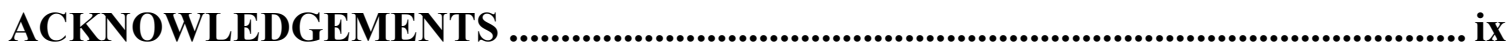

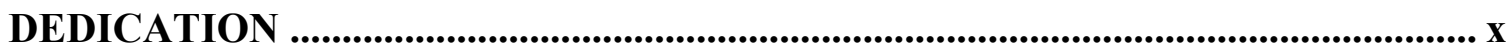

CHAPTER ONE: INTRODUCTION .................................................................. 1

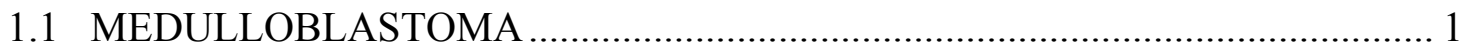

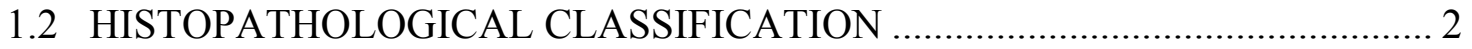

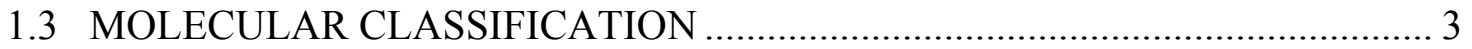

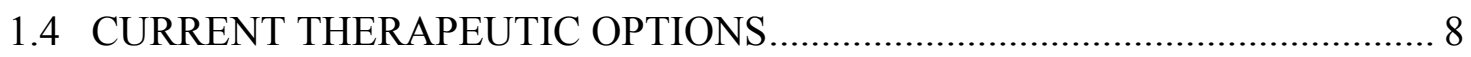

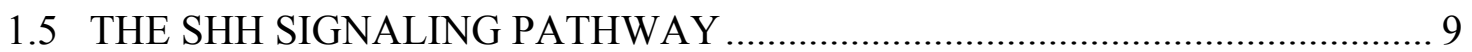

1.6 SHH MEDULLOBLASTOMA RESISTANCE ................................................. 10

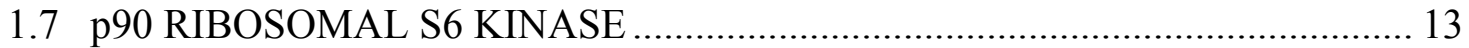

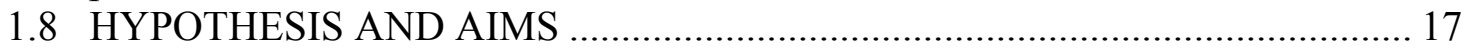

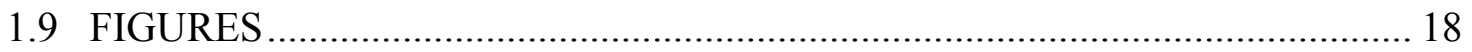

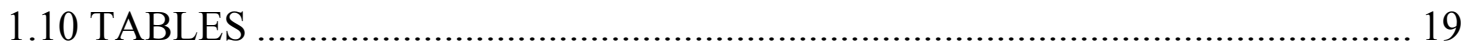

CHAPTER TWO: OVERCOMING RESISTANCE TO SONIC HEDGEHOG INHIBITION BY TARGETING P90 RIBOSOMAL S6 KINASE IN PEDIATRIC

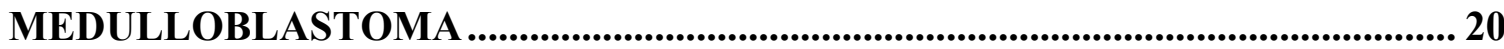

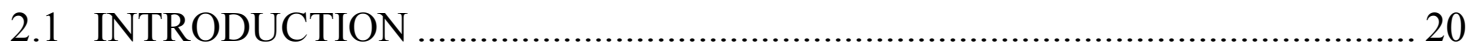

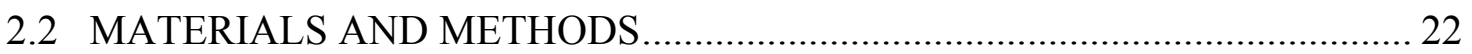

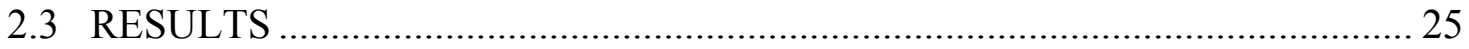

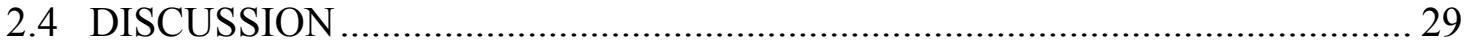

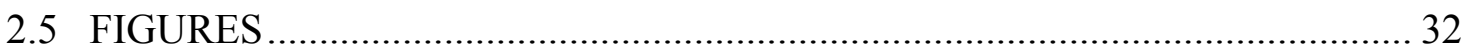

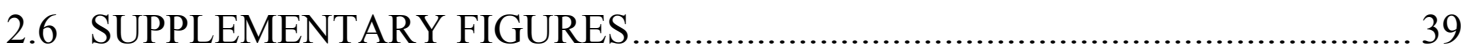

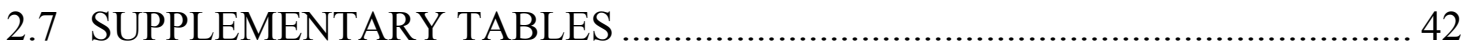

CHAPTER THREE: CLOSING REMARKS............................................................. 48

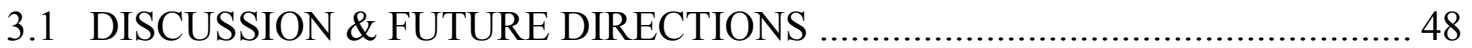

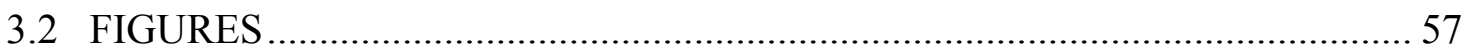

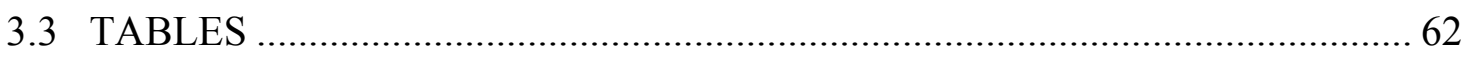

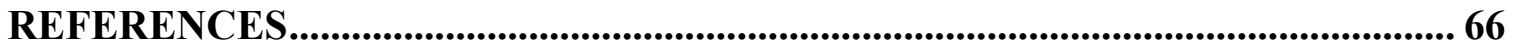




\section{LIST OF TABLES}

Table 1.1 Common characteristics of the four MB subtypes........................ 19

Supplementa1 Table 2.1 Summary of the pediatric MB patients from BCCH included in the Discovery cohort........................................................42

Supplementa1 Table 2.2 Summary of the pediatric MB patients from SickKids Hospital included in the Validation cohort.................................................43

Supplementa1 Table 2.3 Complete list of 129 compounds in the ChemieTek

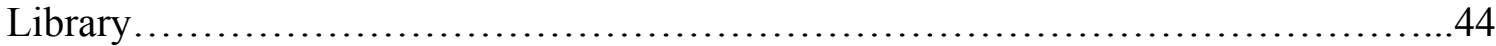

Table 3.1 ChemieTek screen of 129 small molecule inhibitors against SHH MB cell line Daoy and triple-negative breast cancer cell line SUM149......................62 


\section{LIST OF FIGURES}

Figure 1.1 The signaling pathways involved in the MB subtypes.....................18

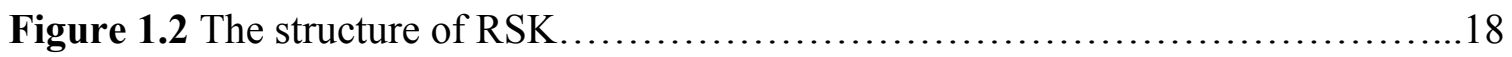

Figure 2.1 The foundation for focusing on SHH MB ................................

Figure 2.2 Identification of RSK as a novel target in resistant SHH MB cell lines.......33

Figure 2.3 Establishing the role of RSK in SHH MB cell growth......................34

Figure 2.4 Evaluation of the efficacy of BI-D1870 in SHH MB........................35

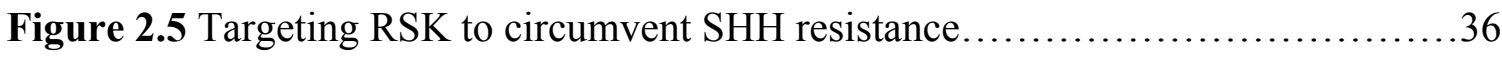

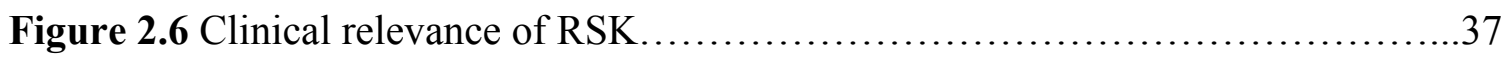

Figure 2.7 Profiling BI-D1870 for pre-clinical use ...............................38

Supplemental Figure 2.1 Characterization of SHH pathway components in MB cell

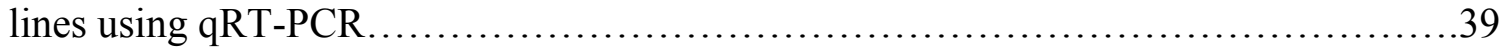

Supplemental Figure 2.2 Characterization of RSK3 and 4 in SHH MB cell lines via

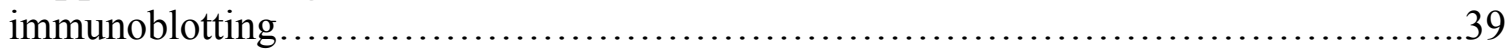

Supplemental Figure 2.3 Validation of RSK knockdown............................40

Supplemental Figure 2.4 Further effects of BI-D1870 on remaining SHH MB cell

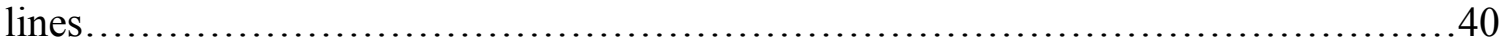

Supplemental Figure 2.5 Metabolite concentrations relative to BI-D1870 in plasma...41

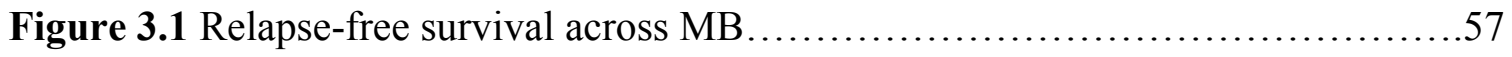

Figure 3.2 Effects of silencing YB-1 in SHH MB...............................58

Figure 3.3 BI-D1870 and the DNA damage response.............................58

Figure 3.4 IHC optimization for future RSK inhibitor studies......................59

Figure 3.5 The efficacy of BI-D1870 in other MB subtypes........................60

Figure 3.6 Broad implications of RSK inhibitors in other cancers.....................62 


\section{LIST OF ABBREVIATIONS}

\begin{tabular}{|c|c|}
\hline $\mathrm{AGC}$ & Protein kinases A, G, and C \\
\hline APC & Adenomatous polyposis coli \\
\hline ATP & Adenosine triphosphate \\
\hline ATR & Ataxia telangiectasia mutated RAD3-related protein \\
\hline $\mathrm{BBB}$ & Blood-brain barrier \\
\hline BMI1 & B lymphoma Mo-MLV insertion region 1 homolog \\
\hline BSA & Bovine serum albumin \\
\hline $\mathrm{CHK}$ & Checkpoint kinase \\
\hline CLS & Coffin-Lowry Syndrome \\
\hline CSI & Cranio-spinal irradiation \\
\hline CTKD & C-terminal kinase domain \\
\hline DA & Dalton \\
\hline DAPI & 4',6-Diamidino-2-phenylindole \\
\hline DMEM & Dulbeco's modified essential medium \\
\hline DNA & Deoxyribonucleic acid \\
\hline DDR & DNA damage response \\
\hline EGFR & Epidermal growth factor receptor \\
\hline EGL & External granular layer \\
\hline ERK & Extracellular signal-regulated kinase \\
\hline FBS & Fetal bovine serum \\
\hline FGF & Fibroblast growth factor \\
\hline GBM & Glioblastoma multiforme \\
\hline GLI & Glioma-associated oncogene homologue \\
\hline GCP & Granular cell precursors \\
\hline GPCR & G-protein coupled receptor \\
\hline GSK3 & Glycogen synthase kinase 3 \\
\hline GY & Gray \\
\hline HNSC & Human neural stem cells \\
\hline IGL & Internal granular layer \\
\hline $\mathrm{IHC}$ & Immunohistochemistry \\
\hline IP & Intra-peritoneally \\
\hline $\mathrm{LC} / \mathrm{A}$ & Large cell/anaplastic \\
\hline $\mathrm{LC} / \mathrm{MS}$ & Liquid-chromatography mass-spectrometry \\
\hline LEF & Lymphoid enhancer factor \\
\hline LFS & Li-Fraumeni Syndrome \\
\hline LRL & Lower rhombic lip \\
\hline MAPK & Mitogen-activated protein kinase \\
\hline $\mathrm{MB}$ & Medulloblastoma \\
\hline MBEN & Medulloblastoma with extensive nodularity \\
\hline MDR-1 & Multi-drug resistance-1 \\
\hline MEK & Mitogen-activated protein kinase kinase \\
\hline MLL & Multi-lineage leukemia \\
\hline
\end{tabular}




$\begin{array}{ll}\text { MTH } & \text { Molecular Trojan horse } \\ \text { NTKD } & \text { N-terminal kinase domain } \\ \text { PARP } & \text { Poly (ADP-ribose) polymerase } \\ \text { PBS } & \text { Phosphate buffer saline } \\ \text { PD } & \text { Pharmacodynamic } \\ \text { PDK } & \text { 3'-phosphoinositide-dependent kinase-1 } \\ \text { PI3K } & \text { Phosphoinositide 3-kinase } \\ \text { PK } & \text { Pharmacokinetic } \\ \text { PLK } & \text { Polo-like kinase } \\ \text { PNET } & \text { Primitive neuroectodermal tumour } \\ \text { PTCH } & \text { Patched receptor } \\ \text { qRT-PCR } & \text { Quantitative real-time polymerase chain reaction } \\ \text { RIPA } & \text { Radioimmunoprecipitation } \\ \text { RSK } & \text { p90 ribosomal S6 kinase } \\ \text { SCNA } & \text { Somatic copy number abberation } \\ \text { SER } & \text { Serine } \\ \text { SHH } & \text { Sonic hedgehog } \\ \text { shRNA } & \text { Short hairpin RNA } \\ \text { siRNA } & \text { Small interfering RNA } \\ \text { SMO } & \text { Smoothened receptor } \\ \text { SUFU } & \text { Suppressor of fused } \\ \text { TBP } & \text { TATA-box binding protein } \\ \text { TCF } & \text { T-cell factor } \\ \text { THR } & \text { Threonine } \\ \text { TMA } & \text { Tissue microarray } \\ \text { TMZ } & \text { Temozolomide } \\ \text { TNBC } & \text { Triple-negative breast cancer } \\ \text { TSG } & \text { Tumour suppressor gene } \\ \text { WHO } & \text { World Health Organization } \\ \text { WNT } & \text { Wingless type } \\ \text { YB-1 } & \text { Y-box binding protein-1 } \\ & \end{array}$




\section{ACKNOWLEDGEMENTS}

This thesis was written on behalf of many individuals who have contributed to it in many ways and deserve recognition for their support.

To Sandi, thank you for giving me the opportunity to grow academically under your inspiring tutelage for the past four years. You always find the silver linings during turbulent scientific weather.

My labmates have been the catalyst towards a fulfilling academic career. To Alastair, you nurtured my inquisitive nature by allowing me to work alongside you. I will cherish the scientific foundation you helped me solidify. To Cathy, thank you for your proverbial wisdom when I needed it most. I will never forget the faith you had in me when I was handling my first primary sample. To Anna, you have been a fountain of invaluable information and a source of heartwarming laughter. Thank you for your amazing editing and baking skills. To Rachel, I could not have asked for a better student to mentor. Thank you for being a quick learning, caffeine-fueled colleague. To Kaiji, thank you for scanning plate after plate - literally moving mountains. To Joanna, thank you for being the NanoString pioneer. To Abbas and Natalie, it was a pleasure working with you. To the Dunn Lab originals - Arezoo, James, Jennifer, Jessie, Karen, Kristen, Mel - thank you for your welcoming atmosphere and brilliant ambition.

To my supervisory committee, Dr. Emma Guns and Dr. Christopher Dunham, thank you for introducing me to your fields of expertise. To Hans, thank you for your endless wisdom and guidance in the world of LC/MS. To Mani, Mei, and Mohamed, thank you for the enjoyable experiences of microsurgery. To Brenda and Cornelia, thank you for always being prompt and helpful. I would like to thank the Hannah's Heroes Foundation and Mitacs Internship Program for their gracious financial support and friendship.

To my family, thank you for your love and endless encouragement. 


\section{DEDICATION}

To my family. 


\section{CHAPTER ONE: INTRODUCTION}

\subsection{MEDULLOBLASTOMA}

Cancer is a disease of uncontrolled cell growth manifesting as a seemingly inextinguishable force, which drains the life out of its host. This deregulated proliferation is the result of inherited genetic aberrations, exposure to extraneous mutagens, and/or chromothripsis distorting homeostatic mechanisms (Forment et al., 2012; Hanahan and Weinberg, 2011). Its name is derived from the Greek term "karkinos" or crab. Much like crabs, cancer hides undetected and eventually spreads until pain is felt. Once identified, several groups sought to understand and eliminate it. In 2011, Hanahan and Weinberg documented an updated succinct catalogue of cancer hallmarks: 1) sustaining proliferative signaling, 2) evading growth suppressors, 3) activating invasion and metastasis, 4) enabling replicative immortality, 5) inducing angiogenesis, 6) resisting apoptosis, 7) avoiding immune destruction, and 8) deregulating cellular energetics (Hanahan and Weinberg, 2011). International efforts have identified cellular pathways that, when distorted, promote these neoplastic hallmarks.

Cancer does not discriminate between adults and children. As life is extended due to advances in medicine and technology, mutations in oncogenes inevitably accumulate as people age. For children, cancer is a disease of distorted developmental systems (Scotting et al., 2005). Children are in stages of rapid growth and one oncogenic mutation in proliferative tissues leaves opportunity for cancer to creep in. Brain cancer is the second leading cause of cancer-related death in children after leukemia (Siegel et al., 2013). There are several varieties of brain cancer depending on its location in the brain and central nervous system. Medulloblastoma (MB) is the most common malignant brain tumour. It affects $30 \%$ of children with brain tumours (Kieran et al., 2010; Northcott et al., 2012a). MB does occur rarely in adults at a rate of $0.4 \%-1 \%$ (Bartlett et al., 2013; Kieran et al., 2010). 
According to the Childhood Oncology Group, which encompasses 220 institutions engaged in clinical-translational research, approximately $400-450$ new cases of pediatric MB (infants to 21 years of age) are diagnosed annually in North America (Gajjar et al., 2012). MB is a primitive neuroectodermal tumour (PNET) that is given the worst World Health Organization (WHO) designation of Grade IV (Louis et al., 2007). It is a posterior fossa tumour originating in the cerebellum and the fourth ventricle, thus creating intracranial pressure. This in turn induces sudden bouts of vomiting, headaches, impaired vision, and ataxia. During the spread of $\mathrm{MB}$, it obliterates the fourth ventricle and disseminates into the craniospinal fluid (Bartlett et al., 2013). This further complicates treatment as a metastatic diagnosis is inevitably incurable.

\subsection{HISTOPATHOLOGICAL CLASSIFICATION}

With the shift towards personalized medicine and targeted therapies, diagnostic and prognostic tools are becoming more and more important. The most common prognostic factors for survival are age, presence of metastasis, and extent of resection $\left(\geq 1.5 \mathrm{~cm}^{2}\right)$ (Packer and Vezina, 2008). Histology is mostly used to confirm that a patient has MB and recently to further subdivide them into subtypes. The following four histological variants - classic, nodular desmoplastic, large cell/anaplastic (LC/A), and MB with extensive nodularity (MBEN) - of which only LC/A histology is used for some cases to stratify into various treatment regimes (Louis et al., 2007; Northcott et al., 2011). Classic histology is composed of small, round, high nuclear content tumour cells, which appear undifferentiated, but stain positive for neuronal markers (Samkari et al., 2012). Nodular desmoplastic MB consist of pale areas with patterns of neuronal differentiation surrounded by densely packed hyperchromatic cells resulting in desmoplasia. Previous work has suggested desmoplastic nodular has a better prognosis than classic variants (Ellison et al., 2011), while MBEN has the best prognosis. In contrast, LC/A usually has the worst prognosis and marks patients with high-risk disease (Ellison et al., 2011). LC/A has two appearances: large cell and anaplastic. They are classified as one histology due to overlap of the two appearances in the same tumour. Large cell histology appears as cells with large nuclei, prominent nucleoli, and a visible cytoplasm. Anaplastic histology, 
which predominates over large cell histology, presents as cells with dark pleiomorphic nuclei and cell wrapping. These histological subtypes can also present with either myogenic (medullomyoblastoma) or melanotic differentiation (melanocytic MB).

\subsection{MOLECULAR CLASSIFICATION}

Although there are difficulties with the histopathological method of stratification, there has been an explosion of research indicating that MB is, in fact, extremely heterogeneous (Cho et al., 2011; Kool et al., 2012; Northcott et al., 2011; Thompson et al., 2006). With the advent of array-based transcriptional profiling of large cohorts of primary MB, it can be divided into four subtypes: WNT, Sonic Hedgehog (SHH), Group 3, and Group 4. These gene signatures correlate with a reliable prognosis.

Gene expression microarrays require large amounts of high-quality RNA from frozen tumour tissue and are expensive. Formalin-fixed paraffin embedded tissues are typically the materials available from patients, which are not suitable for these microarrays. Immunohistochemistry (IHC) as per Northcott et al. was toted as a means of classifying by subtype, but subjectivity and antibody selectivity have limited utility (Ellison et al., 2011). Recently, the nanoString nCounter system has emerged as a new and faster way to classify tumours into their subtypes (Table 1.1; Northcott et al., 2012c). This nonenzymatic method uses sequence-specific probes to digitally measure mRNA abundance for each subtype within a given sample. There are 5-6 genes used in the custom codeset to separate each subtype (Northcott et al., 2012c).

\section{WNT Subtype}

The WNT subtype represents $10 \%$ of MB cases and is evenly distributed among the genders (Kool et al., 2012). The Clifford group has divided WNT into two subgroups, but have yet to publish this data (Clifford et al., 2013). Individuals with Type II Turcot Syndrome have a genetic predisposition for developing WNT MB (Hamilton et al., 1995; Taylor et al., 2000). Turcot Syndrome is characterized by germline mutations in the tumour suppressor gene (TSG) APC. APC forms a complex with Axin, GSK3, and CK1. 
Normally, this complex phosphorylates $\beta$-catenin for degradation in the absence of Wnt ligand (Fig. 1.1). CTNNB1 (ß-catenin) is the most common somatic activating point mutation in the downstream component of the WNT pathway, which drives this subtype (Clifford et al., 2006; Eberhart et al., 2000; Zurawel et al., 1998). B-catenin mutants are resistant to degradation and accumulate in the nucleus where they interact with TCF/LEF transcription factors (T-cell and lymphoid enhancer factors). The TCF/LEF repression is relieved and Wnt target genes such as Cyclin D1 and c-MYC are transcribed. These patients are often heterozygous carriers of the TSG TP53 (p53) (Lindsey et al., 2011; Pfaff et al., 2010).

Histone modifiers, $D D X 3 X$ (DEAD-box RNA helicase), MLL2 (mixed lineage leukemia 2), and the chromatin-associated gene, SMARCA4, have been identified as somatically mutated (Northcott et al., 2009). $D D X 3 X$ is crucial for maintaining lower rhombic lip (LRL) progenitors, which give rise to WNT tumours (Gibson et al., 2010; Robinson et al., 2012). Monosomy 6 is exclusive to pediatric WNT MB. This subtype has no significant regions of somatic copy number aberrations (SCNA) (Northcott et al., 2012b). The custom nanoString codeset encoding WNT includes WIF1, TNC, GAD1, DKK2, and EMX2 (Northcott et al., 2012c).

There are several murine models that have been created to recapitulate the progression of human WNT tumours, which have assisted in identifying LRL as the origin of this subtype (Gibson et al., 2010; Robinson et al., 2012). WNT MB has classic histology, which coincides with the observation that $95 \%$ of patients with this subtype survive (Ellison et al., 2005). Regardless of metastatic status, WNT patients typically have excellent prognoses (Kool et al., 2012). Because of this finding, metastasis as a prognostic marker is under scrutiny. Currently, a reduction in therapy has been the subject of debate to avoid negative side effects of treatment.

\section{SHH Subtype}

The SHH subtype accounts for $30 \%$ of MB cases, presenting mostly in infancy and adulthood (Kool et al., 2012). However, it does occur in children as demonstrated by 
cohorts from BC Children's Hospital $(\mathrm{BCCH})$ and SickKids Hospitals. Individuals with Gorlin syndrome are susceptible to basal cell carcinoma and MB (Taylor et al., 2000). Gorlin syndrome is a germline mutation in the SHH pathway TSG PTCH1 (Patched1) (Pietsch et al., 1997). Germline mutations also occur in the SHH pathway TSG SUFU (Suppressor of Fused) (Brugieres et al., 2012; Taylor et al., 2002). Additionally, there are SCNA of target genes in the transcription factors MYCN and GLI2 as well as PI3K subunits (Cho et al., 2011; Northcott et al., 2012b; Thompson et al., 2006).

Patients suffering from Li-Fraumeni syndrome (LFS) have germline mutations in TP53 and fall victim to several cancers including SHH MB. LFS-SHH MB are implied to occur through the process of chromothripsis, which is characterized as the spontaneous rearrangement of chromosomes (Rausch et al., 2012). Thus, DNA-damaging agents should be avoided in treating these patients, as there will be high risk of secondary malignancies. Tetraploidy is also common when chromothripsis happens leading to chemo- and radio-therapy resistance (Castedo et al., 2006). One way to combat tetraploidy is to use kinesin inhibitors. PPM1D (a protein that is known to inactivate p53) was exclusively amplified and can specifically drive SHH MB (Doucette et al., 2012; Mendrzyk et al., 2005).

Mutational analysis has revealed that $D D X 3 X$ and $M L L 2$ are common mutations in this subtype (Northcott et al., 2012a). Other histone modifiers were found truncated, thus leading to a disruption in the histone code and promoting tumourigenesis. There are frequent deletions in chromosome $9 \mathrm{q}$ and 10q (Kool et al., 2012). The custom nanoString codeset encoding SHH includes PDLIM3, EYA1, HHIP, ATOH1, and SFRP1 (Northcott et al., 2012c).

In terms of origins of SHH MB, mouse models such as Ptch1 ${ }^{+/}$and Smoothened (SMO) overexpressing mice have demonstrated that granular neural precursors in the external granular layer (EGL) are responsible as well as neural stem cells of the subventricular zone (SVZ) are responsible for SHH MB (Goodrich et al., 1997; Hatton et al., 2008; Schuller et al., 2008; Yang et al., 2008). According to the Kool group, SHH has the worst 
prognosis in children. Like WNT, metastasis is rare at diagnosis (Kool et al., 2012). When it does recur, it typically occurs in the local tumour bed. SHH MB displays desmoplastic nodular and classic histology, but can appear as LC/A. Because the integral components of the SHH pathway are known, antagonists have been created against these parts, which have advanced into clinical trials.

\section{Group 3 Subtype}

The last two subtypes are not well characterized, as driver pathways have not yet been identified. Group $3 \mathrm{MB}$ has the worst outcome comprising a quarter of all MB cases, occurring mostly in males with LC/A histology (Kool et al., 2012). Metastasis is identified at diagnosis in 50\% of cases (Kool et al., 2012). This type commonly has leptomeningeal spread (Ramaswamy et al., 2013). There are several chromosomal gains and losses including isochromosome 17 (Northcott et al., 2012a). Histone modifiers such as EZH2 are mutated and overexpressed in this subtype (Northcott et al., 2009). Group 3 has amplified MYC as well as PVT1-MYC fusions, which encode microRNAs such as miR-1204-1207 (Northcott et al., 2012b). Targeting transcription factors is difficult, thus MYC inhibitors have yet to be approved for clinic. The Cho group has identified proteasome, aldehyde dehydrogenase, and histone deacetylase inhibitors as well as neuroactive ligand receptor agonists from a screen of compounds ( $Y u$ et al., 2013). The most striking finding is the discovery of the inhibitor JQ1, which targets bromodomains protein regions, which recognize acetylated lysines (Bandopadhayay et. al, 2013).

Tetraploidy is abundant in this subtype, allowing for chemo- and radio-resistant tumours. The custom nanoString Group 3 codeset includes IMPG2, GABRA5, EGFL11, NRL, MAB21L2, and NPR3 (Northcott et al., 2012c). Recently, FOXG1 and FSTL5 have been identified as two markers of poor prognosis in Group 3 and Group 4 subtypes (Manoranjan et al, 2013; Remke et al, 2011). MYC-driven mouse models have been designed mimicking Group 3 MB; however, they are TP53 null, which do not reflect human Group 3 tumours (Kawauchi et al., 2012; Pei et al., 2012). 


\section{Group 4 Subtype}

Group 4 is the most common MB (35\%) with a propensity to arise in males (Kool et al., 2012). Metastasis occurs in $30 \%$ of cases usually in the frontal lobe later after diagnosis (Ramaswamy et al., 2013). Classic histology and LC/A have been seen in this subtype. MYCN and CDK6 are amplified (Cho et al., 2011; Northcott et al., 2011). There are gains of chromosome 4 and loss of one X chromosome in females (Kool et al., 2012). Histone modifiers and TSG KDM6A are commonly mutated in this subtype (Northcott et al., 2012a). These genes along with the amplified EZH2 have been proposed to cooperate to maintain stem cells by repressing expression of lineage-specific genes. A solid Group 4 marker is that of the tandem duplicated SNCAIP (synphilin1) (Northcott et al., 2012b). Tetraploidy is also present in this subtype, fueling resistance to chemo-/radio-therapy. The custom nanoString codeset encoding Group 4 includes KCNA1, EOMES, KHDRBS2, RBM24, UNC5D, and OAS1 (Northcott et al., 2012c). No representative mouse model has been confirmed for this subtype. However, there has been a N-MYC mouse model, which can be temporally regulated to form SHH or non-SHH tumours (Swartling et al., 2012).

All subtypes of $\mathrm{MB}$ require a more thorough understanding of their underlying complexity to design compounds that will ultimately eliminate them. With the paradigm shift towards targeted therapies and personalized medicine, there has been a surge of attention towards developing specific inhibitors of pathways underlying MB. One of the major challenges of this endeavour is the blood-brain barrier (BBB). Evolution has imparted to humans the BBB to exclude toxins and bacteria from infecting the brain. The $\mathrm{BBB}$ is composed of tight endothelial junctions and specific transport systems (Cecchelli et al., 2007; Loscher and Potschka, 2005). The main efflux pumps are ATP-driven including P-glycoprotein (P-gp), breast cancer resistance protein (ABCG2), and multidrug resistance related proteins (MRP1) (Mahringer et al., 2011). Fortunately, the SHH subtype has had inhibitors engineered to penetrate the BBB and exert their effects on tumours in clinical trials. 


\subsection{CURRENT THERAPEUTIC OPTIONS}

Worldwide, the typical treatment regimen for MB is a combination of cranio-spinal irradiation (CSI; in children $\geq 3$ years of age), maximum safe resection, and chemotherapy. Individuals are stratified into standard- and high-risk patients based on age, presence of metastasis, and $\geq 1.5 \mathrm{~cm}^{2}$ residual tumour. In the past, CSI was given at 36 Gy leading to complications such as stroke and dramatic neurocognitive problems and therefore is now given at $24 \mathrm{~Gy}$. Here at $\mathrm{BCCH}$ and a few other institutions, a more conservative view is taken on radiation where it is only given to children $\geq 6$ years of age (8 years old if other comorbidities).

Chemotherapy is available as three different Head Start protocols. Head Start I consists of cisplatin, vincristine, etoposide, and cyclophosphamide. Head Start II has improved response rates compared to the first protocol. It includes 5 cycles of the aforementioned chemotherapeutics and methotrexate followed by autologous stem cell transplant with thiotepa, carboplatin, and etoposide. Cisplatin and cyclophosphamide cross-link DNA, thus inducing apoptosis. Vincristine stabilizes tubulin, preventing cells from dividing. Etoposide prevents religation of DNA strands during replication. Methotrexate inhibits DNA, RNA, and protein synthesis. Head Start III has intensive cycles 1, 3, and 5 and less intensive cycles 2 and 4 with the addition of temozolomide (TMZ). TMZ is a widely used oral alkylating agent for glioblastoma multiforme, which induces DNA damage, leading to apoptosis. Standard- and high-risk patients are treated similarly. The major difference is that high-risk patients are given higher doses of CSI and are likely to be enrolled in Head Start III (Bartlett et al., 2013; Samkari et al., 2012). At BCCH, Head Start II is more intensive and used for most cases while Head Start III is used for desmoplastic nodular MB. Preliminary data from $\mathrm{BCCH}$ has shown that patients treated with chemotherapy only have an overall survival of $69 \%$ (unpublished).

These treatments are quite aggressive amounting to detrimental life-long impairments including neurocognitive/endocrine deficits, visual/auditory impairments, and seizures. Posterior fossa syndrome can occur as a side effect of surgery, which is characterized by speech impairment, mutism, hypotonia, ataxia, and emotional lability (Marks and Packer, 
2012). However, today approximately $70 \%$ of MB patients survive conventional treatment compared to the 1970s when survival rates were a dismal 50\% (Marks and Packer, 2012; Northcott et al., 2012a). Also, it is important to consider functional longterm outcomes. Here at $\mathrm{BCCH}, 57 \%$ of infants survive more than 5 years and $30 \%$ of these patients continue to attend regular school or have a skilled job (Pillai et. al, 2012).

For children that relapse and present with secondary tumours, there is no standard procedure (Samkari et al., 2012). Repeated cycles of CSI and TMZ have been used to treat relapse cases with an abysmal three-year survival rate of 22\% (Massimino et al., 2013). The treatments administered damage and mutate DNA potentially leading to secondary tumours (Marks and Packer, 2012). Thus, there is an impetus for the scientific community to suggest a better alternative. SHH MB has inhibitors towards it, but resistance still emerges.

\subsection{THE SHH SIGNALING PATHWAY}

Before describing the inhibitors against SHH MB, a brief overview of the signaling cascade is required. As aforementioned, SHH MB is driven by the SHH pathway (Fig. 1.1). The first speculation that MB is driven by this particular cascade came about when patients with Gorlin Syndrome were diagnosed with MB, basal cell carcinoma, and rhabdomyosarcoma (Taylor et al., 2000). Gorlin syndrome is an autosomal dominant condition associated with germline loss of one copy of the tumour suppressor gene, PTCH1 (Pietsch et al., 1997).

Normally, this pathway is expressed and actively promotes proliferation, differentiation, and migration during embryogenesis, but shuts off postnatally (Polkinghorn and Tarbell, 2007). SHH works in concert with several signals such as the bone morphogenetic proteins (BMPs; Bastida et al., 2009; Ng and Curran, 2011). BMPs negatively regulate SHH signaling indirectly and induce differentiation (Bastida et al., 2009). There are three hedgehog ligands: Indian, Desert, and Sonic. SHH is the most prominent in cells and the most-well documented (Shahi et al., 2012). The HH ligands form a gradient, ultimately 
acting as a morphogen during the formation of the nervous system (Fuccillo et al., 2006). They are also important for oligodendrocyte formation, embryonic proliferation, and maintaining neural stem cell pools in adults.

SHH starts off as $45 \mathrm{kDa}$ and has autocatalytic activity cleaving into $20 \mathrm{kDa}$-terminal SHH and $25 \mathrm{kDa}$ C-terminal SHH (Shahi et al., 2012). The N-terminal SHH protein product binds to the 12-pass transmembrane receptor PTCH1, relieving its inhibitory action as an efflux pump on the 7-pass transmembrane G-protein coupled receptor SMO (Fig. 1.1). Unleashed SMO changes conformation and translocates into the cytoplasm. SMO promotes the dissociation of SUFU from the downstream effector complex. This complex is composed of the GLI (glioma-associated oncogene homolog) Zinc finger transcription factors, kinesin-like protein Costal, and Ser/Thr kinase Fu. There are three GLI isoforms: GLI1, 2, and 3. GLI3 acts as a repressor, while the other GLIs act as activators (Shahi et al., 2012). GLI2/3 suppress GLI3 cleavage into a truncated repressor after SHH stimulation. GLI1/2 translocate into the nucleus, binding to their target genes: GLI1, PTCH1, HHIP, IGF2, BMI1, BCL2, CCND1, and MYCN (Shahi et al., 2012).

\subsection{SHH MEDULLOBLASTOMA RESISTANCE}

When the Hedgehog signaling pathway is deregulated, cancers arise in brain, lung, mammary glands, prostate, and skin due to upregulation of target genes (Lin and Matsui, 2012). HHIP encodes hedgehog interacting protein, which acts as an endogenous antagonist to the hedgehog ligands. Proliferation is fueled by IGF2 and CCND1. Evasion of apoptosis occurs through down-regulation of the anti-apoptosis protein BCL2. MYCN is involved with both proliferation and survival, while BMI1 (B lymphoma Mo-MLV insertion region 1 homolog) regulates cell cycle inhibitor genes.

Constitutive activation of the SHH pathway leads to cancer progression. This may happen either by a ligand-dependent or ligand-independent manner (Lin and Matsui, 2012; Sahebjam et al., 2012). In the ligand-dependent mode of activation, SHH is either produced by the microenvironment or nearby cancer cells. They can signal in an 
autocrine or paracrine fashion. This excess of ligand allows for hyperactivation of the pathway, leading to cancer. The second mechanism is through mutations in components of the pathway resulting in activation regardless of ligand presence. For example, mutations in the tumour suppressors $S U F U$ or $P T C H 1$ can lead to cancer (Brugieres et al., 2012). Point activating mutations in $S M O$ can also lead to cancer. Additionally, there has been evidence of $G L I$ amplifications; however their activity is undetermined (Buonamici et al., 2010).

In the context of the cerebellum, Purkinje cells secrete hedgehog ligand stimulating granular cell precursors (GCPs) to proliferate. These GCPs grow and eventually migrate from the external granular layer into the internal granular layer (Polkinghorn and Tarbell, 2007). However, dysregulated SHH signaling in GCPs results in uncontrolled proliferation, detrimentally leading to MB. Mouse models resembling human SHH MB have been established suggesting a cell of origin for this subtype. To name a few, the $\mathrm{Ptchl}^{+/-}$and SMO over-expressing transgenic mice are reliable tools (Goodrich et al., 1997; Hatton et al., 2008). In mice, SHH MB is derived from cerebellar granule neuron precursors of the EGL (Schuller et al., 2008) and cochlear nuclei (Grammel et al., 2012), and neural stem cells in the SVZ (Yang et al., 2008).

Based on analysis of approximately 65 primary MB samples from $\mathrm{BCCH}$, the $\mathrm{SHH}$ subtype has an equally dismal prognosis as the Group 3 subtype (Lee et al., 2013). This is in agreement with the Kool group's findings that outlined that pediatric SHH MB does as poorly as Group 3 MB (Kool et al., 2012). There have been concertive efforts to develop HH pathway antagonists for therapeutic use. The first naturally occurring SMO inhibitor was identified when cyclopic lambs were born after the ingestion of the corn lily Veratrum californicum (Lin and Matsui, 2012). However, its limited oral bioavailability and acid sensitivity outweighed its anti-tumour activity. The anti-fungal agent, itraconazole, is currently in clinical trials after being identified as a SHH inhibitor through a drug screen (Kim et al., 2013). 
Currently, there are five SMO inhibitors in clinical trials: vismodegib (GDC-0449), NVPLDE225, IPI-926, PF-0449913, and XL-139 (Lin and Matsui, 2012; Ng and Curran, 2011; Sahebjam et al., 2012). These inhibitors have shown promise in clinical trials of MB. Despite the early successes, they all have toxicities (Lin and Matsui, 2012; Ng and Curran, 2011). Treatement with vismodegib, IPI-926, XL-139 and NVP-LDE225 lead to nausea, muscle spasms, and fatigue. PF-044913 causes alopecia, nausea, vomiting, joint pain, and a distorted sense of taste.

It is important to note that most of these clinical studies have been tested on adults rather than children. As such, the effects of these inhibitors are unknown in children.

Developmental toxicity is a huge concern. Preclinical murine studies have revealed that SMO inhibitors caused permanent defects in bone growth (Kimura et al., 2008). This could not be compensated for using parathyroid hormone-related protein, which functions to maintain chondrocyte proliferation. Furthermore, HH signaling is in cooperation with WNT and BMPs (Yuasa et al., 2002; Bastida, 2009). These pathways are all involved in correct patterning and morphogenesis of tissues. The distortion of these pathways could lead to undesirable consequences.

Resistance is a lethal reality that must be faced when treating MB. The first case to be reported was in a 26-year-old man with metastatic MB. After 3 months, his tumours stopped responding to GDC-0449 and were growing rapidly (Rudin et al., 2009). His primary and relapsed tumours were sequenced identifying an amino acid substitution rendering GDC-0449 incapable of binding to SMO (Yauch et al., 2009). Murine models resistant to GDC-0449 soon followed suit, verifying that SMO resistance occurred due to single amino acid mutations (Buonamici et al., 2010). Further murine models resistant to NVP-LDE225 led to the identification of point mutations in SMO that prevented this compound from binding (Buonamici et al., 2010). Chromosomal changes were also assessed to account for resistance using sensitive and resistant tumours. GLI2 was amplified in 50\% of $\mathrm{PTCHI}^{+/} / \mathrm{TP} 53^{-/-}$tumours (Buonamici et al., 2010). The SMO mutations and GLI2 amplifications were mutually exclusive. 
Methods to counteract these resistance mechanisms have been to target different components of the SHH pathway or to identify novel pathways that contribute to resistance. GLI inhibitors are available for in vitro testing including GANT61 and GANT58 (Lauth et al., 2007). These two inhibitors block GLI transcriptional activity. The HPI-1 to -4 are also GLI inhibitors with different mechanisms of action (Hyman et al., 2009). HPI-2 and HPI-3 inhibit GLI2 conversion into a fully functional transcription factor. HPI-4 disrupts ciliary processes needed for GLI activity. Arsenic trioxide is another way to disrupt SHH signaling by destabilizing GLI (Kim et al., 2013).

A novel pathway that has been identified to overcome resistance is the PI3K pathway. The Buonamici group analyzed gene-expression signatures of resistant mouse tumours, which showed increased PI3K signaling. Using a combination of NVP-LDE225 and the PI3K inhibitor NVP-BEZ235, they were able to eliminate resistant cells (Buonamici et al., 2010). Despite this new target, this will only delay further resistance. There is a crucial need to find alternative pathways, which will eliminate MB.

\section{7 p90 RIBOSOMAL S6 KINASE}

The mitogen-activated protein kinase (MAPK) pathway is responsible for normal cell proliferation, differentiation, and survival (Fig. 1.1; Anjum and Blenis, 2008; Cargnello and Roux, 2011). Receptor tyrosine kinases are stimulated by ligand, dimerize, and autophosphorylate tyrosine residues. Grb2 and SOS are recruited and phosphorylate membrane-bound GTPase Ras. A series of phosphorylation events occur in the order of Ras, Raf, and finally ERK. ERK regulates several substrates including p90 ribosomal S6 kinase (RSK). Aberrant signaling of this pathway fuels the development and sustenance of cancers such as breast, skin, pancreatic, and prostate cancer (Ray-David et al., 2012). RSKs are a family of Ser/Thr kinases that are downstream of the MAPK pathway (Anjum and Blenis, 2008). It is comprised of four human isoforms: RSK1 (RPS6KA1), RSK2 (RPS6KA3), RSK3 (RPS6KA2), and RSK4 (RPS6KA6). They share roughly 80\% sequence homology (Romeo et al., 2012). 
RSK is unique for it has evolved to have two kinase domains fused together with a linker region (Fig. 1.2). The C-terminal kinase domain (CTKD) is part of the CAMK family $\left(\mathrm{Ca}^{2+} /\right.$ calmodulin-dependent protein kinase) while the N-terminal kinase domain (NTKD) is a member of the AGC family (protein kinase A, G, and C). The activation of RSK is a highly orchestrated event (Fig. 1.2). It has six phosphorylation sites, four of which are crucial for its activity: $\operatorname{Ser}^{221}, \mathrm{Ser}^{363}, \mathrm{Ser}^{380}, \mathrm{Thr}^{573}$ (Romeo et al., 2012). Following stimulation by mitogens, hormones, neurotransmitters, and other stimuli, ERK docks on the CTKD of RSK and phosphorylates $\mathrm{Thr}^{573}$. The activated CTKD autophosphorylates $\mathrm{Ser}^{380}, \mathrm{Ser}^{363}$, and $\mathrm{Thr}^{359}$ in the linker region, thus creating a docking site for PDK1. This constitutively active PDK1 phosphorylates $\mathrm{Ser}^{221}$ in the NTKD and dissociates. RSK becomes stabilized in an active conformation and is fully engaged for phosphorylation of target cytoplasmic and nuclear substrates.

Following stimulation, RSK phosphorylates its substrates at this consensus motif: Arg-XArg-X-X-pSer/Thr (Romeo et al., 2012). Isoform specific functions have yet to be fully understood. Both RSK1 and 2 have been documented to phosphorylate targets important for proliferation, transcriptional/translational regulation, survival, and apoptosis. RSK1 and 2 both phosphorylate and inactivate DAPK, which is a tumour suppressor. They also play a role in stimulating motility and invasion. The Roux group outlines a more comprehensive list of RSK isoform substrates in this review (Romeo et al., 2012). RSK3 has been suspected to be a tumour suppressor in ovarian cancer, but warrants more investigation before any conclusions are drawn (Bignone et al., 2007). RSK4 is also under scrutiny for being either an oncogene or tumour suppressor (Sun et al., 2012). Recently, RSK3/4 have been identified as a compensatory mechanism for PI3K resistance (Serra et al., 2013).

\section{Physiological Expression}

RSK expression during development has been investigated using embryonic murine model (Zeniou et al., 2002). RSK3 is highly expressed during early stages of 
development, while RSK1 is expressed during the latter stages. Postpartum, RSK1 then temporally shuts off. In a study using murine cortical precursors, RSK2 is highly expressed and then temporally silenced at around postnatal day 2 (Dugani et al., 2010). According to murine models, RSK2 knockout mice have impaired cognitive functions and poor coordination (Zeniou et al., 2002). This is the phenotype exhibited in humans with Coffin-Lowry Syndrome (CLS) caused by heterogeneous loss-of-function mutations in the RSK2 gene. CLS is a hereditary X-linked dominant disorder, which manifests as mental retardation, small stature, and distinct facial features (Pereira et. al, 2010). Mice without RSK4 had X-linked mental retardation. RSK1, 2, and 3 triple knockout mice were viable, but no phenotype has been associated with them (Romeo et al., 2012).

Within the adult body, RSK1-3 mRNA are ubiquitously expressed throughout tissues (Zeniou et al., 2002); however, RSK4 is not. RSK1 mRNA is mostly found in the kidney, lung, and pancreas. RSK2 and 3 mRNA are detected in skeletal muscle, heart, and pancreas. In the brain, RSK1 mRNA is in the granular cell layer of the cerebellum. RSK2 mRNA is in the neocortex, hippocampus, and cerebellum. RSK3 is in the cerebral cortex, dentate gyrus, and the amygdala. Although RSK1-3 mRNA are expressed in the brain, their actual translation and activity have not been determined.

\section{Inhibitors}

RSK2 is the most closely associated with cancer and RSK1 has also been well established in several cancers. There are available inhibitors for in vitro work, but none have advanced to clinical trials as of yet. Staurosporine and compounds similar to it are potent inhibitors of RSK, but have off-target effects due to inhibition of several other kinases. The first specific RSK inhibitor to be identified was kaempferol-glycoside SL0101, a natural product from tropical plants. It exerts its ATP competitive effect by binding to the NTKD of RSK (Nguyen, 2008). Despite its promising anti-growth effects, it has severe solubility limitations, a half-life of less than $30 \mathrm{~min}$., and a poor pharmacokinetic (PK) profile (Mrozowski et al., 2012). Recent studies have chemically modified SL0101 producing analogs with either increased stability or increased potency (Hilinski et al., 
2012; Mrozowski et al., 2012). The analogs with increased stability have yet to be tested in vivo. The other analogs did not achieve a significantly higher potency due to poor cell permeability (Mrozowski et al., 2012).

FMK is another RSK inhibitor, which irreversibly binds to the CTKD. The RSK2 inhibitor, BIX 02565, is potent, but unfortunately also targets adrenergic receptors, ultimately having detrimental effects on the cardiovascular system (Fryer et al., 2012). The Fryer group went on to identify Compound 15, which had much higher potency and no effect on the cardiovascular system. There are also off-patent compounds that are commercially available, which target RSK. However, high concentrations are needed to exert an effect. Luteolin and quercetin are both flavonoids that inhibit RSK by changing its NTKD conformation (Reipas et al., 2013; Utepbergenov and Derewenda, 2013).

Another reversible RSK inhibitor of interest is the dihydropteridinone, BI-D1870 (Sapkota et al., 2007). It is a synthetic inhibitor that binds to the NTKD of RSK. It does not inhibit MAPK upstream effectors, but potently inhibits phosphorylation of RSK substrates. Its pharmacokinetic profile is unknown, but it has shown promise against several cancers including breast cancer (Stratford et al., 2012).

\section{Crosstalk between RSK and SHH Pathways}

The MAPK pathway has been demonstrated to work in tandem with the SHH pathway.

The first clue that the MAPK and SHH pathways converge and cooperate to promote cell proliferation was demonstrated in neocortical stem cells. In oncogenic studies, cotransfection of GLI and EGFR led to increased soft agar colony formation (Schnidar et al., 2009). However, co-transfection with other signaling pathways such as the PI3K/AKT pathway did not have any effect on tumourigenic capacity. The first links between the MAPK and SHH pathways were cemented in these instrumental findings in 2009 (Mangelberger et al., 2012). 
Three years later, a direct link was established between GLI and RSK in melanoma (Liu et al., 2012). The Liu group looked further down the MAPK cascade and honed in on MEK. They transfected constitutively active MEK and found that GLI expression increased. They posited that MEK is protecting GLI from degradation. They found that RSK2 expression increased GLI expression; however, it was not a direct interaction. RSK2 phosphorylates GSK3ß rendering it unavailable to tag GLI for degradation (Liu et al., 2012). This is one potential mechanism for crosstalk between the SHH and RSK pathways.

\subsection{HYPOTHESIS AND AIMS}

There is a dire need for new pathways to target, other than the SHH pathway, for $\mathrm{SHH}$ MB. Using a pharmacological screen of 129 small molecule inhibitors most of which are in clinical trials against SHH MB cell lines, RSK inhibitors were effective against cells of this subtype. This project focuses on the promise of RSK inhibitors to circumvent resistance.

Hypothesis: Inhibiting RSK will overcome resistance to SHH MB.

Aim I: To elucidate the role of RSK in SHH MB cell growth.

Aim II: To determine the efficacy of the RSK inhibitor BI-D1870 against this subtype. 


\subsection{FIGURES}

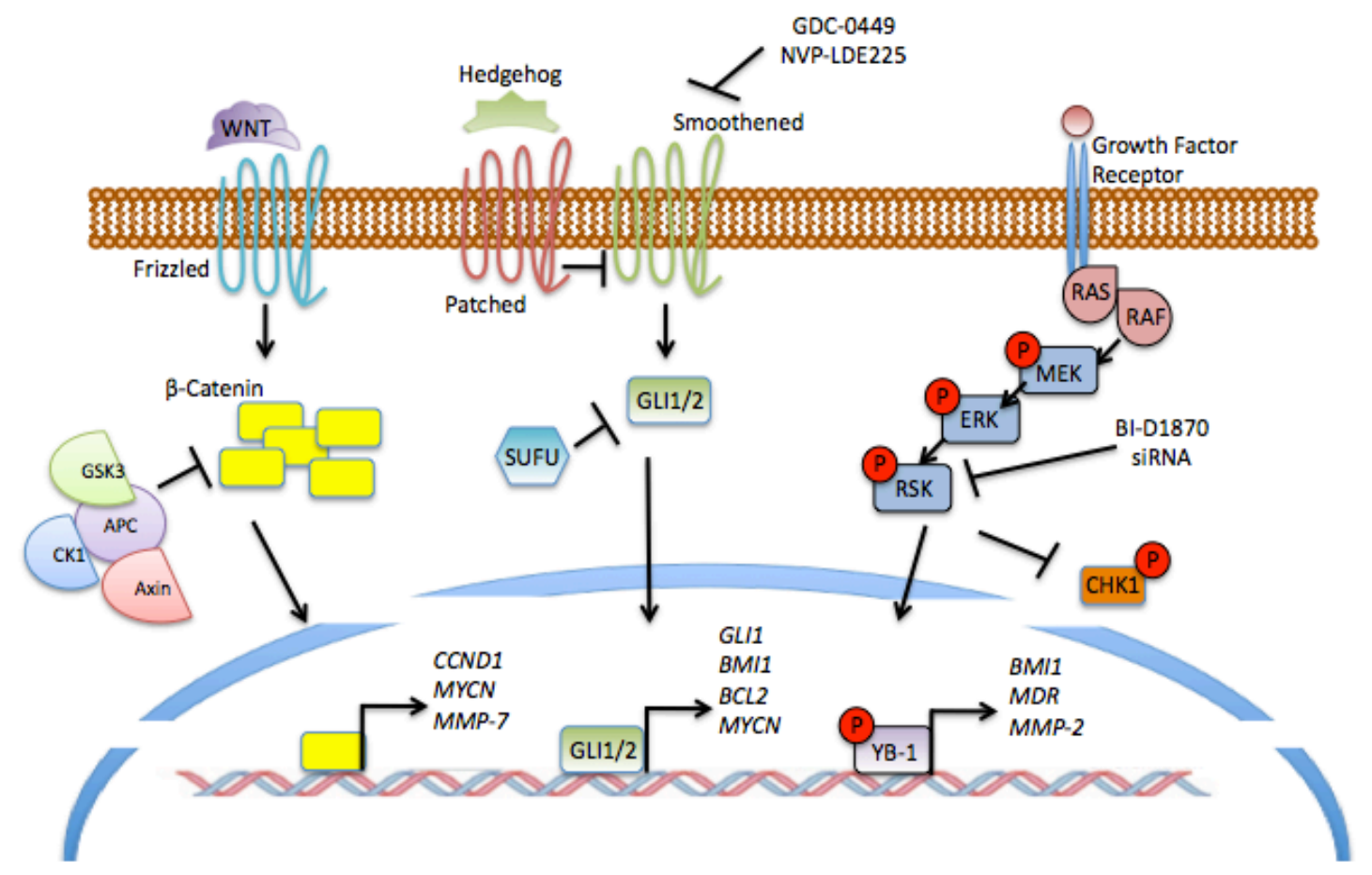

Figure 1.1 The signaling pathways involved in the MB subtypes. The WNT pathway consists of WNT ligand binding to Frizzled, leading to nuclear translocation of B-catenin to activate transcription of target genes (left). For the SHH subtype, SHH ligand binds to $\mathrm{PTCH}$, allowing SMO to signal GLI to enter the nucleus for transcription (center). The MAPK pathway is stimulated by growth factors leading to RSK phosphorylating transcription factors to carry out pleiotropic functions. Adapted from Manoranjan et al, Pediatric Research 2012.

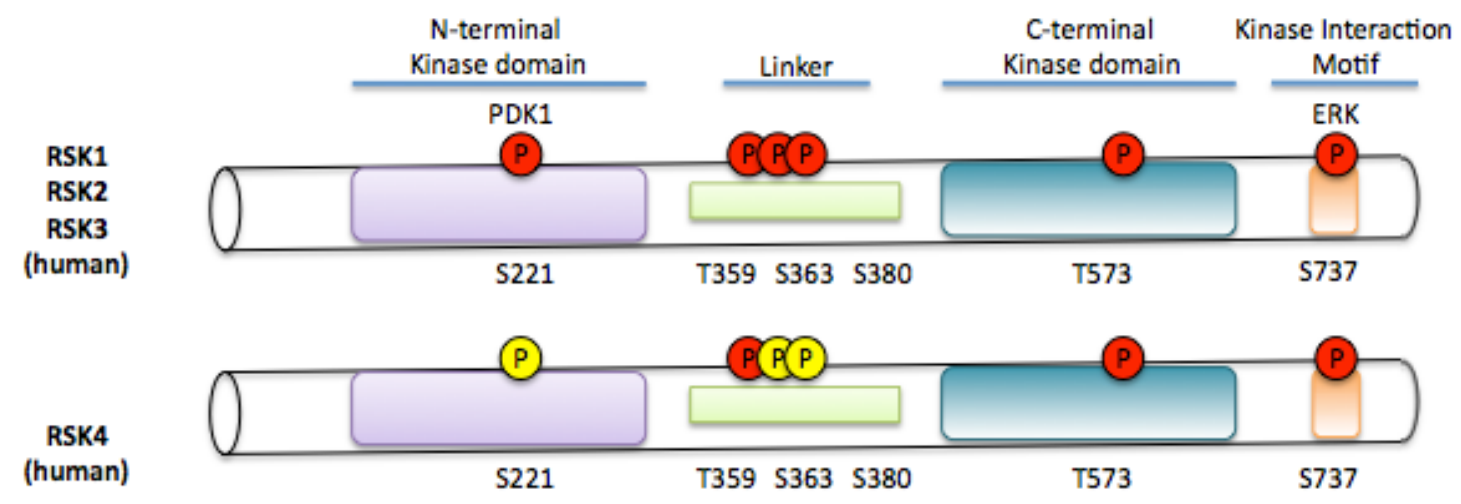

Figure 1.2 The structure of RSK. All four RSK isoforms have two kinase domains and a linker region. RSK1-3 have the same phosphorylation pattern whereas RSK4 is constitutively phosphorylated at three sites (indicated in yellow). Adapted from Romeo et al, Biochemical Journal 2012. 


\subsection{TABLES}
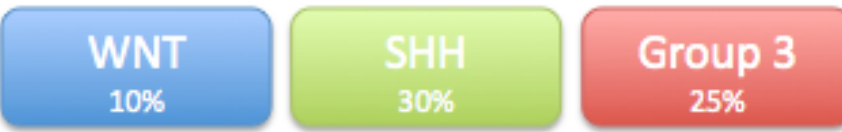

\section{Group 4}

$35 \%$

\begin{tabular}{|c|c|c|c|c|}
\hline Gender Ratio ( $0^{7}:$ 우) & $1: 1$ & $1.5: 1$ & $2: 1$ & $3: 1$ \\
\hline Age Distribution & Childhood & $\begin{array}{l}\text { Infants/Childhood/ } \\
\text { Adults }\end{array}$ & Infants/Childhood & Childhood \\
\hline Histology & Classic & $\begin{array}{c}\text { Classic }>\text { desmoplastic/nodula } \\
\quad>\text { LCA }>\text { MBEN }\end{array}$ & ar Classic $>$ LCA & Classic \\
\hline Metastasis & $5-10 \%$ & $15-20 \%$ & $40-45 \%$ & $35-40 \%$ \\
\hline $\begin{array}{l}\text { Predominant Driver } \\
\text { Genes }\end{array}$ & $\begin{array}{l}\text { CTNNB1 } \\
\text { DDX3X }\end{array}$ & $\begin{array}{l}\text { PTCH1 } \\
\text { TP53 }\end{array}$ & $\begin{array}{l}\text { MYC } \\
\text { PVT1 }\end{array}$ & $\begin{array}{l}\text { KDM6A } \\
\text { SNCAIP }\end{array}$ \\
\hline
\end{tabular}

Table 1.1 Common characteristics of the four MB subtypes. Adapted from Northcott et al, Nature Reviews 2013. 


\section{CHAPTER TWO: OVERCOMING RESISTANCE TO SONIC HEDGEHOG INHIBITION BY TARGETING P90 RIBOSOMAL S6 KINASE IN PEDIATRIC MEDULLOBLASTOMA}

\subsection{INTRODUCTION}

Tumours of the central nervous system are the second-leading cause of cancer-related death in children (Siegel et al., 2013). Of the several tumours that occur in the brain, medulloblastoma (MB) is the most common malignant type and arises in the cerebellum (Northcott et al., 2012a). The current standard of care is maximum safe resection, chemotherapy, and craniospinal irradiation ( $\geq 3$ years of age) - all of which are extremely detrimental to the developing systems of children (Dhall et al., 2008; Gajjar et al., 2012). Although $80 \%$ of patients survive, they can be left with impairments that result in a poor quality of life (Dhall et al., 2008; Northcott et al., 2012a; Pollack and Jakacki, 2011). Another challenge in treating $\mathrm{MB}$ is the blood-brain barrier (BBB), which restricts the passage of molecules such as inhibitors (Loscher and Potschka, 2005). Thus, there is a need to establish novel, less aggressive therapies to rid children of this devastating disease.

With the advances in molecular profiling, MB has been divided into four distinct subtypes: WNT, Sonic Hedgehog (SHH), Group 3, and Group 4 (Kool et al., 2012; Northcott et al., 2012a; Northcott et al., 2012c; Pollack and Jakacki, 2011). WNT has the best prognosis, while Group 3 has the worst prognosis. SHH and Group 4 have intermediate prognoses. However, we noticed particularly poor prognosis among children with SHH tumours based on our analyses of approximately 65 samples from BCCH whereas the SickKids validation cohort of 55 cases showed Group 3 with the worst prognosis (Fig. 2.1A; Supplemental Tables 2.1 and 2.2). Discrepancies may be accounted for when considering that different institutions use different treatment protocols. 
This study focuses on the SHH subtype, which is the best characterized in terms of origin (Gibson et al., 2010; Schuller et al., 2008; Swartling et al., 2012; Yang et al., 2008). This $\mathrm{MB}$ is often the manifestation of dysregulated proliferative signals in the SHH pathway as first implicated in individuals with Gorlin Syndrome (Evans et al., 1991). This inherited genetic predisposition to basal cell carcinoma or MB is a result of loss of tumour suppressor Patched (PTCH). Normally, SHH is important for the formation of the human nervous system during embryogenesis and maintenance of stem cells postnatally (Fuccillo et al., 2006). SHH ligand binds to the 12-pass transmembrane receptor PTCH, relieving its inhibitory action on the 7-pass transmembrane protein Smoothened (SMO) (Kim et al., 2009). Unleashed, SMO promotes translocation of GLI transcription factors into the nucleus to bind to their target genes: GLI1, PTCH1, MYC, BCL2.

Currently, there are four SMO inhibitors in Phase I/II clinical trials: GDC-0449 (Vismodegib; Genentech), NVP-LDE225 (Novartis), IPI-926 (Infinity), and XL-139 (BMS/Exelis) (Sahebjam et al., 2012). GDC-0449 was the first SMO inhibitor to show promise in metastatic MB; however, resistance developed within months (Rudin et al., 2009). A common phenomenon with SMO inhibitors is that resistance emerges due to amplifications and point mutations (Buonamici et al., 2010; Dijkgraaf et al., 2011; Yauch et al., 2009). Also, SMO inhibitors have been shown to induce bone malformations in mice (Kimura et al., 2008). Therefore, alternative pathways require exploration to eliminate SHH MB.

In this study, we identified p90 ribosomal S6 kinase (RSK) as a crucial target for SHH MB. RSK is a family of serine/threonine kinases and is located downstream of the MAPK pathway (Romeo et al., 2012). Normally, RSK is expressed in the cerebellum during embryogenesis and shut off postnatally (Dugani et al., 2010; Zeniou et al., 2002). Aberrant RSK signaling is integral for several cancers such as breast cancer and melanoma (Ray-David et al., 2012; Stratford et al., 2012). We sought to establish its importance in SHH MB with our four cell lines (Fig. 2.1B). Additionally, we examined the potential of RSK inhibitors as a future therapy against recurrent SHH MB by 
determining the pharmacokinetics/pharmacodynamics (PK/PD) of the RSK inhibitor, BID1870.

\subsection{MATERIALS AND METHODS}

\section{Cell Culture and Treatments}

Daoy (ATCC, Manassas, VA), ONS76, UW228, and UW426 (gifts from Dr. S. Singh, McMaster University, Toronto, ON) were cultured in 10\% FBS and Dulbecco's DMEM. Normal human neural stem cells (hNSC) were cultured according to Gibco protocol.

Small molecule inhibitors were synthesized, purity checked, and obtained from ChemieTek (Supplemental Table I). Larger amounts of BI-D1870 were synthesized by the Centre for Drug Research and Development in Vancouver, BC. Cells were seeded (3,000 cells/well) into 96-well plates (BD; Becton Dickinson, Franklin Lakes, NJ) overnight. They were treated with $1 \mu \mathrm{M}$ and $10 \mu \mathrm{M}$ for $72 \mathrm{~h}$ followed by Hoechst 33342 staining (Sigma-Aldrich, Oakville, ON) and analyzed by ArrayScan high-content screening system (Thermo Fisher Scientific, Pittsburgh, PA).

\section{Neurosphere assay}

Cells were plated 20,000 cells/well into ultra-low attachment 6-well plates (Corning, NY) in Neurocult media with supplements and spheres counted after 7 days. For serial passaging, neurospheres were dissociated using the Neurocult Chemical Dissociation Kit (Stem Cell Technologies, Vancouver, BC). For drug treatments, SHH MB cell lines were seeded into media containing vehicle or $2.5 \mu \mathrm{M}$ BI-D1870. For siRNA, Daoy cells were treated with siRNA in monolayer for 2 days and transferred to neurospheres.

\section{Quantitative real-time PCR}

RNA extraction, cDNA synthesis, and real-time PCR were performed as previously described for all cell lines cultured in monolayer and as neurospheres using FAM-labeled Taqman Assay-On-Demand probes, RSK1, RSK2, SHH, GLI1, GLI2, BMI-1, BCL2, and 
Cyclin D1, normalized to TBP (Life Technologies, Burlington, ON) (Astanehe et al., 2009).

\section{Immunoblotting}

Cells were lysed in RIPA buffer and immunoblotting was performed as described previously (Wu et al., 2006). Primary antibodies were used at 1:1,000: RSK1, RSK4

(Santa Cruz, Dallas, TX); RSK2, RSK3, RSK1-3, P-YB-1 ${ }^{\text {S102 }}$, PARP, pan-actin (Cell Signaling, Danvers, MA); P-RSK1/2 ${ }^{\mathrm{S} 221 / 227}$ (Life Technologies); YB-1 (Abcam, Toronto, $\mathrm{ON}$ ); and vinculin (Sigma-Aldrich).

\section{siRNA transfections}

Cells (3,000 cells/well in 96-well plates) were transfected for $96 \mathrm{~h}$ with $20 \mathrm{nM}$ siRNA to RSK1 (Hs_RPS6KA1_10, SI02223067), RSK2 (Hs_RPS6KA3_5, SI00288190), or control (AllStars negative control siRNA, 1027280) from Qiagen using Lipofectamine RNAiMAX (Life Technologies).

\section{Anchorage-independent growth assays}

Daoy cells were seeded at 20,000 cells/well in agar as previously described (Finkbeiner et al., 2009). For knockdown experiments, RSK isoforms were silenced with siRNA for 48 $\mathrm{h}$ in monolayer and transferred into the soft agar assay. For BI-D1870 treatments, the top layer contains DMSO, $0.5 \mu \mathrm{M}, 1 \mu \mathrm{M}$, or $2.5 \mu \mathrm{M}$ BI-D1870. Agar was re-fed with media including drug once per week. The threshold size for colonies was $50 \mu \mathrm{m}$.

\section{Flow cytometric analysis of apoptosis}

Daoy cells were treated with DMSO, $1 \mu \mathrm{M}$, or $2.5 \mu \mathrm{M}$ BI-D1870 for $72 \mathrm{~h}$ and stained with Annexin V (BD Biosciences, Mississauga, ON) for flow cytometry on a FACSCalibur (BD Biosciences). Data was analyzed using FlowJo Software.

\section{NanoString nCounter Gene Expression Analysis and Patient Subtyping}

Through collaboration with Dr. Michael Taylor, we obtained 62 MB patient samples from Sick Kids hospital, Toronto, ON. Normal cerebellum and 4 additional MB samples 
were collected from BCCH, Vancouver, BC. RNA was extracted from FFPE tissue scrolls using Qiagen RNeasy FFPE kit (Valencia, CA). Nanodrop spectrometry and a 2100 Bioanalyzer (Agilent Technologies, Mississauga, ON) were used to assess RNA quality.

Exactly 200 ng RNA per patient was run using NanoString nCounter Gene Expression analysis located at the Centre for Translational and Applied Genomics (BC Cancer Agency, Vancouver, BC). A custom codeset was designed which included $22 \mathrm{MB}$ subtyping gene probes (Northcott et al., 2012c) and additional genes - RSK1 (RPS6KA1; NM_002953.3), RSK2 (RPS6KA3; NM_004586.2), RSK3 (RPS6KA2; NM_021135.4), RSK4 (RPS6KA6; NM_014496.1), GLI1 (NM_005269.1), GLI2 (NM_005270.3), and SOX2 (NM_003106.2). This codeset was synthesized by NanoString Technologies (Seattle, WA) and all protocols outlined by this company were followed regarding sample preparation, hybridization, detection, and data normalization.

R statistical programming version 2.15.2, and R package pamr (PAM) version 2.23 was used for gene expression based MB subgroup assignment as previously described (Northcott et al., 2012c). Cluster version 3.0 and Java TreeView version1.1.6r2 were used for unsupervised hierarchical clustering with average linkage to generate heatmaps of gene expression.

\section{Pharmacokinetics/Pharmacodynamics}

Intraperitoneal (I.P.) injections of BI-D1870 (5 mg/mL stock dissolved in 1.5\% Solutol $\mathrm{H} 15$ with milling at CDRD) were administered at final concentrations of $50 \mathrm{mg} / \mathrm{kg}$ or 100 $\mathrm{mg} / \mathrm{kg}$ in male CD-1 mice ( $\mathrm{n}=3$; Harlan Laboratories, Indianapolis, $\mathrm{IN}$ ) in order to determine drug tolerability. For the PK study, it was determined that $100 \mathrm{mg} / \mathrm{kg}$ was not toxic and was therefore administered to mice which were then euthanized after 1, 2, 4, 6, and $24 \mathrm{~h}$. Liver, spleen, kidney, lungs, and brain were harvested and snap frozen. Blood (approximately $1 \mathrm{~mL}$ ) was collected via cardiac puncture into tubes containing anticoagulant and centrifuged at $1,000 \mathrm{xg}$ for $5 \mathrm{~min}$ at $4^{\circ} \mathrm{C}$ to isolate plasma. Both plasma and tissue samples were stored at $-80^{\circ} \mathrm{C}$ until extraction for analysis by liquid 
chromatography/mass spectrometry (LC/MS; Vancouver Prostate Center, Vancouver, $\mathrm{BC})$.

Serum samples were processed for LC/MS by liquid-liquid extraction using acetonitrile. Tissue samples (approximately $50 \mathrm{mg}$ ) were homogenized in Precellys Lysing tubes and ultrapure $\mathrm{H}_{2} \mathrm{O}(100 \mu \mathrm{l} / \mathrm{mg}$ tissue). Specific volumes of $\mathrm{NaOH}$ and internal standard were added to homogenates. Calibration and quality control samples were run with analytes. Liquid-liquid extraction using ethyl acetate was carried out. Internal standards used for LC/MS analysis were MDV3100 for serum and Compound 4, which has a similar structure to that of BI-D1870, for tissues (Fig. 2.7F). A solution of $0.1 \%$ formic acid $/ 67 \%$ methanol was used to reconstitute extracts for LC/MS.

\section{Statistical analysis}

Independent experiments $(\mathrm{n}=3)$ were performed for qRT-PCR and cell viability analyses. Data are reported as mean \pm standard deviation. Significance was examined using a paired Student's $t$-test, where ${ }^{*} P<0.05,{ }^{*} P<0.01$.

\subsection{RESULTS}

\section{Identification of A Novel Target for SHH MB}

Our group previously characterized the pediatric MB cell lines, Daoy, ONS76, UW228, and UW426, as being best assigned to the SHH subtype via NanoString (Fig. 2.1B). Interestingly, we found the Daoy cell line was not responsive towards SMO inhibitors, GDC-0449 and NVP-LDE225 (Fig. 2.2A). Observing that Daoy cells were resistant to these inhibitors, we tested them on the remaining three SHH cell lines. Astonishingly, we found that they were also resistant to SMO inhibitors (Fig. 2.2B). These four cell lines express SHH pathway components and serve as our resistant model (Supplemental Fig. 2.1). 
To combat resistance in SHH MB, we screened the ChemieTek library for novel targets (Fig. 2.2A;Supplemental Table 2.3). We applied the following criteria to narrow down the list from 129 small molecule inhibitors to one: 1) efficacy at $1 \mu \mathrm{M}, 2)$ potential to cross the BBB, and 3) novelty. From this screen, we identified three compounds, which showed potential inhibitory activity; however, two of these have been previously tested against MB. We therefore focused on BI-D1870, a small molecule pan RSK inhibitor. BID1870 was extremely effective against the Daoy cell line at low concentrations and it has not previously been tested against MB. Further, the backbone of BI-D1870 is identical to that of Polo-Like Kinase inhibitors, BI6727 and BI2536, which have been shown to decrease tumour burden and prolong lifespan in glioblastoma multiforme (GBM) mouse models (Lee et al., 2012). BI-D1870 is smaller than PLK inhibitors, indicating that it has high potential to traverse the BBB.

Using immunoblotting, we assessed protein levels of RSK in all SHH cell lines. Notably, the hNSCs do not express RSK1 or 2 protein (Fig. 2.2C). More importantly, activated RSK and its phosphorylated substrate Y-box binding protein-1 (YB-1) (Stratford et al., 2008) was dramatically higher in all four MB cell lines compared to hNSCs. We speculate that these cells are functionally dependent on RSK, leading to resistance. The remaining isoforms, RSK3 and RSK4, are not expressed in these cells (Supplemental Fig. 2.2).

\section{Characterization of the role of RSK in SHH MB}

To ascertain the functional importance of RSK and to validate the specificity of BID1870, we silenced isoforms 1 and 2 with siRNA (Supplemental Fig. 2.3). There was a decrease in cell viability in monolayer after 7 days following RSK inhibition (Fig. 2.3A). Since silencing both isoforms together led to the most growth inhibition, we analyzed the treated Daoy cells for apoptosis. Using Annexin V and flow cytometry, we found that maximum induction of apoptosis occurred after 7 days compared to 3 days (Fig. 2.3B). RSK inhibition prevented Daoy colony formation in soft agar by approximately $100 \%$ (Fig. 2.3C). In addition, RSK inhibition suppressed tumour sphere formation (Fig. 2.3D). 


\section{BI-D1870 Induces Apoptosis in SHH MB}

Once we established that RSK is an integral component to SHH MB survival, we inhibited RSK activity via BI-D1870. This is a reversible ATP-competitive inhibitor that prevents RSK from phosphorylating its targets (Sapkota et al., 2007). To determine the optimal dose to inhibit RSK in the cell lines, we tested a range of BI-D1870 concentrations for $72 \mathrm{~h}$ (Fig. 2.4A). The minimum concentration that elicited a significant response was at $2.5 \mu \mathrm{M}$. Notably, there are no toxicity issues with hNSCs at this concentration. To assess that BI-D1870 elicited its inhibitory growth effects through modulating RSK function, we used immunoblotting and showed a decrease in phosphoYB-1 ${ }^{\mathrm{S} 102}$ post-treatment in the Daoy cells (Fig. 2.4B).

To detect apoptosis, we observed significant PARP cleavage after $72 \mathrm{~h}$ in treated cells. We also applied the Annexin V assay, which measures early stages of apoptosis (Fig. 2.4C). We saw maximal amount of apoptosis, $89.6 \%$, indicated by a rightward shift in Annexin V at 72 h. BI-D1870 not only inhibits monolayer growth, but also prevents the formation of colonies (Fig. 2.4D). Upon low dosing of BI-D1870, we were able to significantly prevent colony formation at as low as $0.5 \mu \mathrm{M}$. Continuing with the idea that RSK is essential for self-renewal, we inhibited RSK activity with $2.5 \mu \mathrm{M}$ BI-D1870 in all cell lines. We found the spheres were significantly depleted in particular following serial passaging, thus indicating a role for RSK in self-renewal (Fig. 2.4E;Supplemental Fig. 2.4A).

One of the main difficulties of treating MB is resistance to conventional therapy such as vincristine and etoposide. Typically, new drugs are given in combination with standard chemotherapy. BI-D1870 was used in combination with these drugs to assess whether together they can overcome conventional drug resistance. As shown in Fig. 2.4F and Supplemental Fig. 2.4B, we found that together, there is an enhanced effect on growth inhibition compared to chemotherapy alone. 


\section{Circumventing SMO Resistance By Targeting RSK}

To determine the underpinnings of SMO inhibitor resistance and the role of RSK, we silenced RSK1/2 and found that the downstream transcription factors, GLI1/2 were both decreased regardless of the presence of autocrine SHH ligand (Fig. 2.5A). BMI-1 (chromatin modifier) and BCL2 (anti-apoptotic protein) transcripts both decreased. Cyclin D1 transcript did not decrease, perhaps due to activation by other pathways. Next, we treated Daoy cells with $1 \mu \mathrm{M}$ BI-D1870 in conjunction with SMO inhibitors to assess whether this would sensitize resistant cells. We found a significant inhibition of growth following treatment with RSK and SMO inhibitors, thus indicating that cells became sensitive to the SMO inhibitors (Fig. 2.5B). We propose that RSK is activating GLI1/2 independent of ligand status, thus driving the SMO inhibitor resistant phenotype (Fig. 2.5C). RSK inhibitors are a potential way to overcome SMO inhibitor resistance.

\section{RSK is Most Prevalent in SHH MB Patient Samples}

Once we demonstrated that RSK plays important roles in SHH MB cell lines, we ventured to establish its clinical relevance. In a cohort of patients from SickKids Hospital, we found that RSK2-4 are tightly correlated with SHH genes (Fig. 2.6A). The stem cell gene, SOX2, was highly expressed in $\mathrm{SHH}$ subtype $(\mathrm{P}=0.018)$. SOX2 is associated with self-renewal and correlated with SHH MB (Ahlfeld et al., 2013). RSK2 correlated with SOX2 (Spearmans Rho=0.556, P=1.04E-6), GLI1 (Spearmans $\mathrm{Rho}=0.493, \mathrm{P}=2.2 \mathrm{E}-5$ ), and GLI2 (Spearmans Rho=0.486, $\mathrm{P}=3.02 \mathrm{E}-5)$. This was not the case for RSK1. Likewise, RSK2-4 were consistently higher in MB patients compared to normal cerebellum (Fig. 2.6B-E). Ultimately, this indicates that RSK is closely associated with the SHH MB subtype.

\section{PK/PD Evaluation of BI-D1870 in Mice}

Given the activity of BI-D1870 against MB in vitro, we determined its $\mathrm{PK} / \mathrm{PD}$ profile in mice. We formulated BI-D1870 in buffer and H15, which would stabilize BI-D1870 over $18 \mathrm{~h}$. H15 is a cornstarch derivative that can be taken orally and allows for excellent GI uptake. BI-D1870 was observed primarily as a singly charged parent ion at $\mathrm{m} / \mathrm{z} 392.20$ (Fig. 2.7A). Retention time for BI-D1870 was 2.06 min using LC/MS (Fig. 2.7B). 
Subsequently, we conducted tolerability and PK/PD studies. We injected BI-D1870 (I.P.) at two concentrations in CD-1 mice: $50 \mathrm{mg} / \mathrm{kg}$ and $100 \mathrm{mg} / \mathrm{kg}$. After $24 \mathrm{~h}$, we found the mice did not display any signs of acute toxicity at either drug concentration. We continued to dose at $100 \mathrm{mg} / \mathrm{kg}$ for procurement of $1,2,4$, and $6 \mathrm{~h}$ timepoint samples. Brain, lungs, spleen, kidneys, and liver and plasma were collected. BI-D1870 extraction efficiency from tissues was approximately $60 \%$. We are the first group to report that BI$\mathrm{D} 1870$ crosses the $\mathrm{BBB}$ and drug concentrations in the brain dropped from $3.38 \mu \mathrm{M}$ to $0.07 \mu \mathrm{M}$ over $24 \mathrm{~h}$ (Fig. 2.7C). Knowing that extraction efficiency is only $60 \%$, we postulated that the actual concentration achieved in the brain is $0.1 \mu \mathrm{M}$. This concentration of BI-D1870 did not exert any effect on Daoy cells (Fig. 2.7D).

Upon analysis of plasma samples, we found that BI-D1870 decreased from $516 \mu \mathrm{M}$ to $0.51 \mu \mathrm{M}$ around $4 \mathrm{~h}$ (Fig. 2.7E). This drop is most likely attributed to distribution into tissues. Extraction efficiency of BI-D1870 from serum was 100\%. As posited, we detected BI-D1870 in the rest of the tissues (Fig. 2.7E). Lungs saw a similar PK profile to that of the brain. In liver, BI-D1870 decreased from $51 \mu \mathrm{M}$ to $4 \mu \mathrm{M}$. In kidneys, it decreased from $56 \mu \mathrm{M}$ to $0.6 \mu \mathrm{M}$. Spleen saw a drop of BI-D1870 from $116 \mu \mathrm{M}$ to 0.6 $\mu \mathrm{M}$ over $24 \mathrm{~h}$. We measured metabolite production in case decline of the compound was due to conversion into active metabolites similar to pro-drugs such as temozolomide (TMZ), which have shown promise in clinical trials (Rautio et al., 2008). TMZ is used in GBM and is rapidly metabolized into active compound at physiological pH (Bei et al., 2010). However, we detected low levels of the glucaronide and reduced metabolites (Supplemental Fig. 2.5). These findings underscore the need for the synthesis of more stable RSK inhibitors.

\subsection{DISCUSSION}

In this study, we propose that RSK is a novel MB target in cells that are resistant to SMO inhibitors. RSK has been described as important for embryonic development and its expression intrinsically shuts off after birth (Dugani et al., 2010; Zeniou et al., 2002). This makes RSK an attractive target especially since BI-D1870 is 1) a readily available in 
vitro inhibitor, 2) effective at low concentrations, and 3) not toxic to hNSCs. This work has demonstrated that RSK silencing or inhibition is a new way to circumvent SMO inhibitor resistance by re-sensitizing these SHH MB cell lines. Another exciting observation is the detection of RSK transcripts in actual patients. This strongly suggests that RSK potentially plays a functional role in humans as it does in vitro.

A potential relationship between RSK2 and GLI2 has been established (Liu et al., 2012). Liu et al. has previously shown that RSK phosphorylates GSK3ß, resulting in its inactivation. Thereby GSK3ß can no longer constitutively phosphorylate GLI transcription factors for degradation (Liu et al., 2012). Extending this idea to BI-D1870, inhibiting RSK theoretically would free GSK3ß to tag GLI for degradation. It is common for resistant $\mathrm{SHH} \mathrm{MB}$ to have mutations in $S M O$, defective $\mathrm{PTCH}$, or more frequently GLI amplifications. The protection from degradation which RSK imparts to GLI is another potential mechanism contributing to chemotherapeutic and SHH resistance. This supports previous literature identifying that most MB is driven by ligand-independent SHH pathway activation (Lin and Matsui, 2012; Slade et al., 2011; Taylor et al., 2002).

We have demonstrated the in vitro efficacy of BI-D1870; thus, we hope to improve on its in vivo stability. As indicated by our data, we observe appreciable uptake and distribution into the brain $(3 \mu \mathrm{M})$. This concentration provides effective drug activity; however, after $24 \mathrm{~h}$, levels rapidly drop to $0.07 \mu \mathrm{M}$. Repeat dosing of BI-D1870 is likely to be necessary to maintain steady state drug concentrations. The highlight of the PK/PD study is that we were able to discern the ability of BI-D1870 to cross the BBB. BI-D1870 is a promising drug candidate displaying no acute toxicity at high dosing concentrations; however, perhaps modifying it structurally by integrating different chemical moieties would enhance stability allowing for prolonged effects. This study highlights the need for the synthesis of stable RSK inhibitors.

While BI-D1870 was relatively straightforward to synthesize, we were met with challenges in formulating it for animal studies. Further, the rapid elimination in mice precluded subsequent efficacy testing. We found that it was only soluble at very low or 
very high $\mathrm{pH}$, which severely limited our ability to deliver it in a suitable solvent. This problem was overcome by milling BI-D1870 into fine particulates. We also had difficulties fully extracting BI-D1870 from tissues. Therefore, while in vitro we are able to routinely inhibit RSK kinase activity with an $\mathrm{IC}_{50}=16 \mathrm{nM}$, and in cell based assays the agent is active in the low micromolar range there are still obstacles to be overcome. Future work will be necessary to optimize this compound such that anti-tumour studies can be conducted in mice bearing human tumour xenografts.

In summary, inhibiting RSK1 and RSK2 with siRNA or BI-D1870 suppresses signaling through YB-1, tumour cell proliferation, self-renewal and anchorage-independent growth. These changes manifest in triggering apoptosis. Notably this occurred in MB cells that were resistant to SMO antagonists. In patients, the RSK2 isoform in particular correlates with primary SHH MB. Further studies are encouraged given that BI-D1870 crosses the BBB. We therefore conclude that RSK inhibition offers an opportunity to potentially improve the treatment of pediatric MB. 


\subsection{FIGURES}

A.
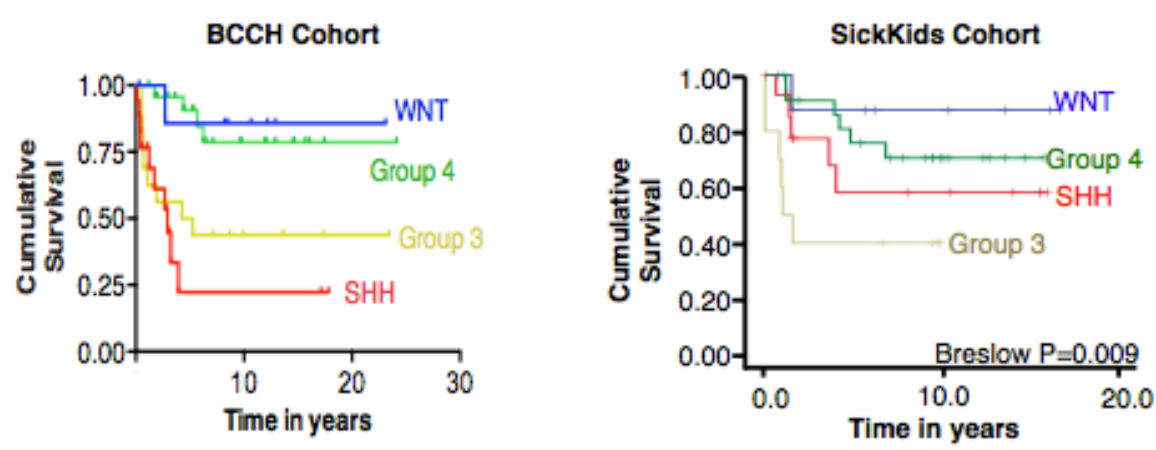

B.

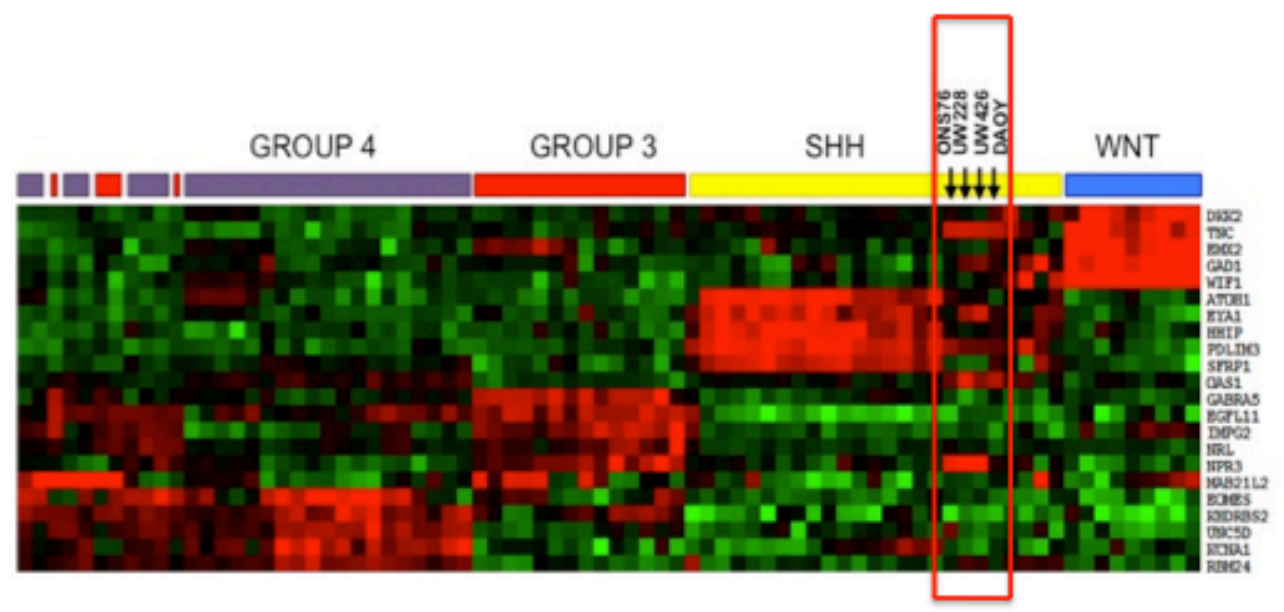

Figure 2.1 The foundation for focusing on SHH MB. A) Kaplan-Meier survival curves indicating SHH MB does as poorly as Group $3 \mathrm{MB}$ in the $\mathrm{BCCH}$ cohort $(n=65)$ whereas in SickKids, they have an equivalent outcome $(n=55)$. B) Hierarchical clustering of $M B$ cell lines cultured as neurospheres illustrating that they fall most closely in the SHH signature. Red=high, Green=low. Data provided by Joanna Triscott. 
A.

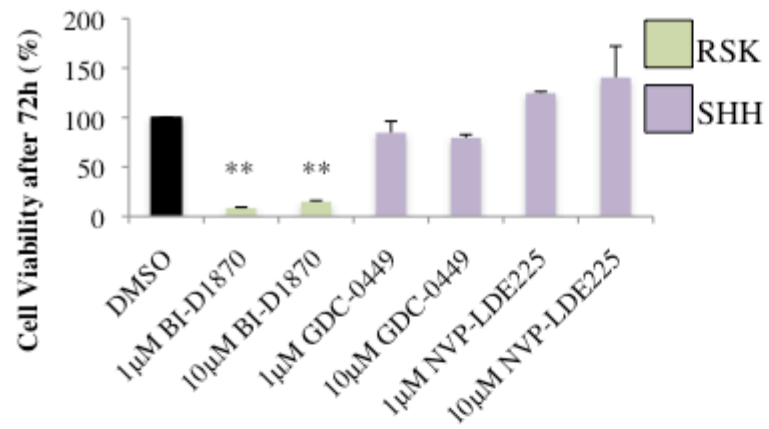

B.

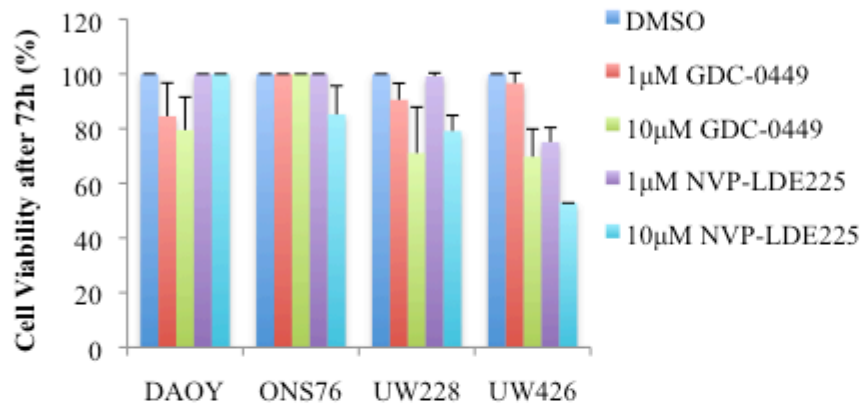

C.

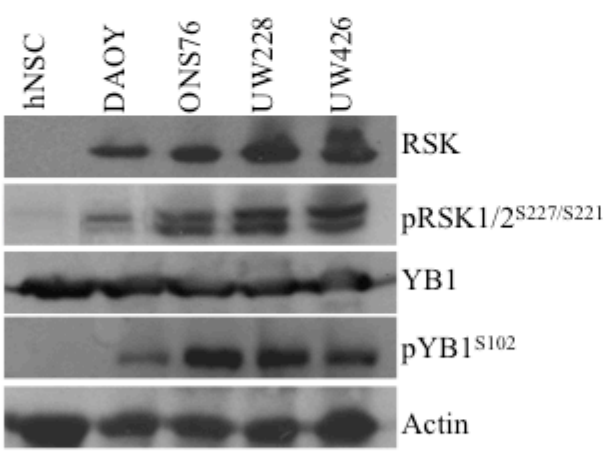

Figure 2.2 Identification of RSK as a novel target in resistant SHH MB cell lines. A) Screen of 129 small molecule library against Daoy cells for $72 \mathrm{~h}$ at 1 and $10 \mu \mathrm{M}$. B) Four SHH MB cell lines treated at 1 and $10 \mu \mathrm{M}$ of SMO inhibitors in clinical trials for $72 \mathrm{~h}$. C) Immunoblotting shows the RSK axis is active as indicated by $\mathrm{pYB}-1^{\mathrm{S} 102}$ in $\mathrm{SHH} \mathrm{MB}$ cell lines, but not in hNSC. 

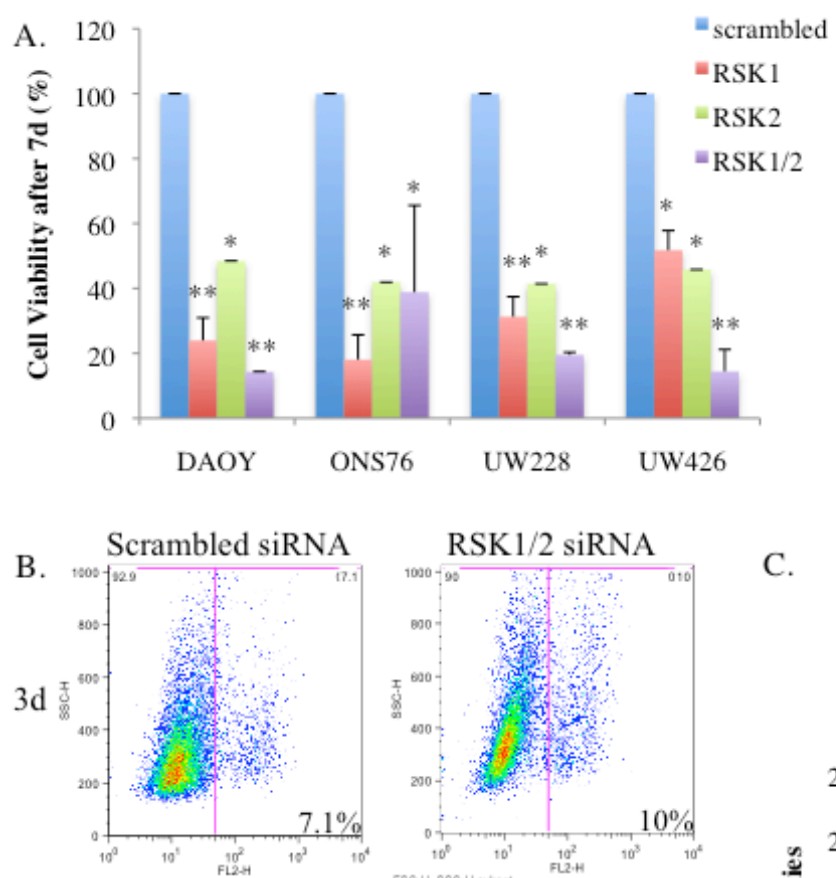

C.
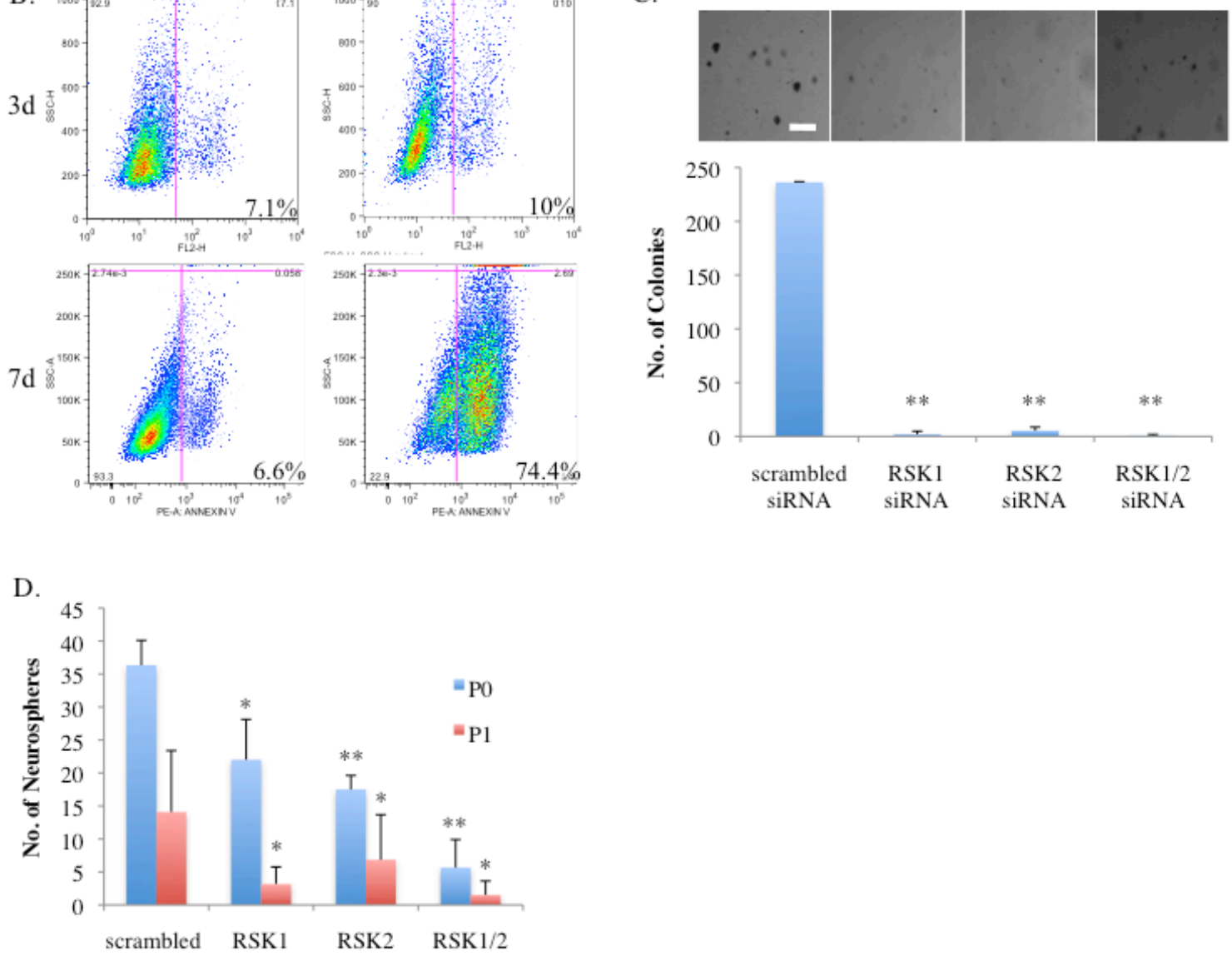

Figure 2.3 Establishing the role of RSK in SHH MB cell growth. A) RSK1/2 siRNA together inhibit cell proliferation to a greater extent compared to individually after $7 \mathrm{~d}$ in all MB lines. B) A larger rightward shift in Annexin V indicates apoptosis after $7 \mathrm{~d}$ compared to 3 d of RSK1/2 siRNA in Daoy cells. C,D) Daoy cells treated with RSK siRNA prior to agar and neurosphere assays leads to decreased colony formation and self-renewal respectively. 

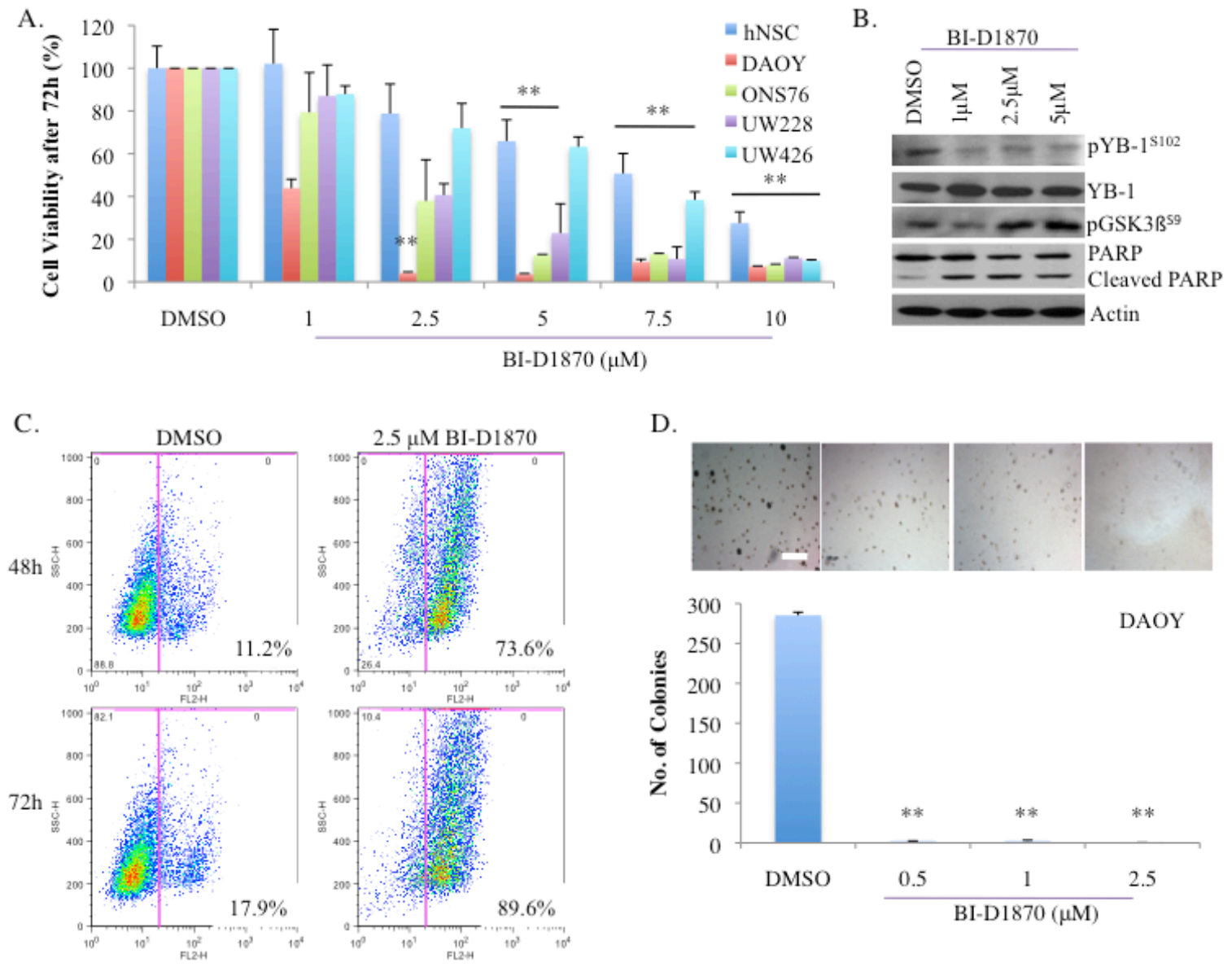

D.
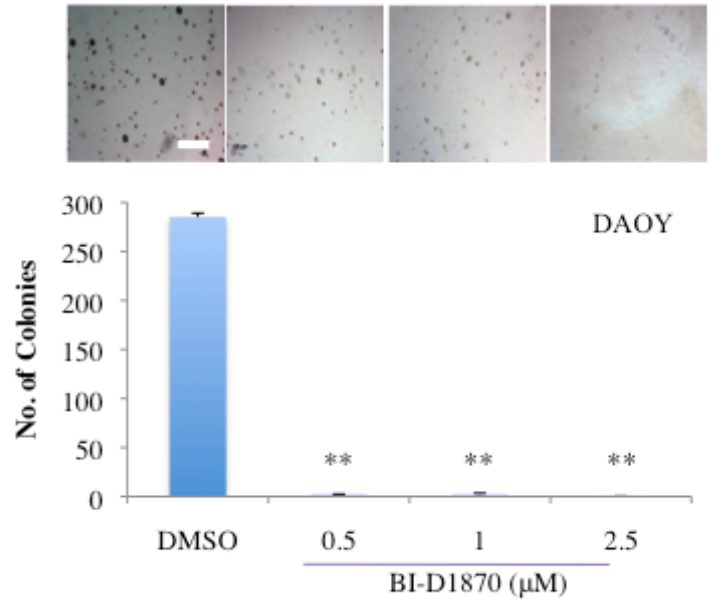

E.

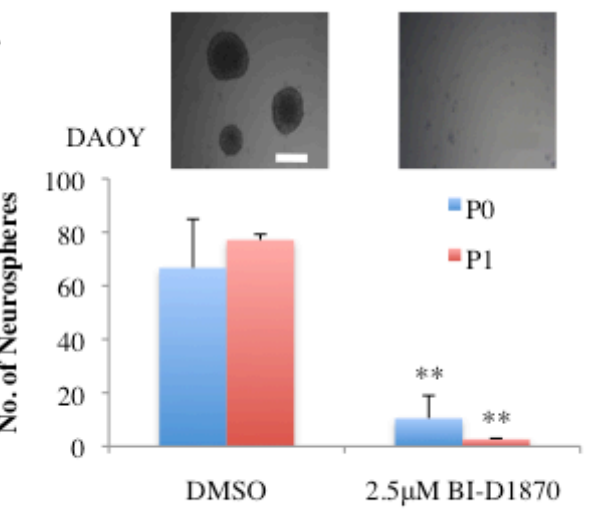

F.

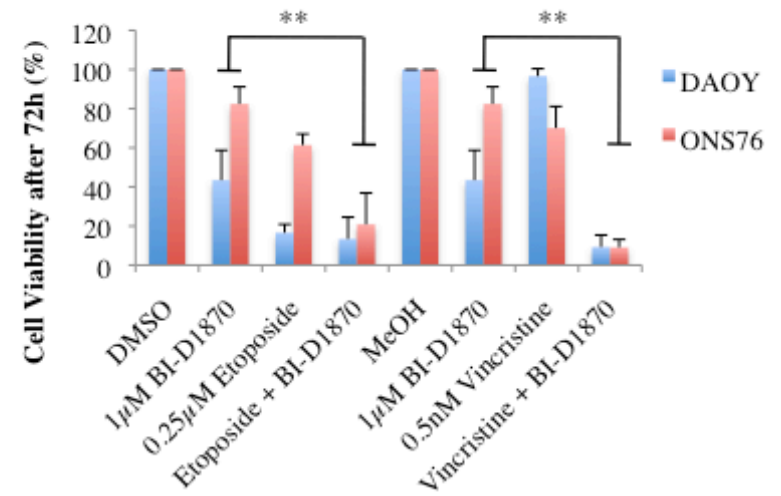

Figure 2.4 Evaluation of the efficacy of BI-D1870 in SHH MB. A) BI-D1870

significantly inhibits growth at low concentrations $(\leq 5 \mu \mathrm{M})$ with no toxicity in hNSCs. B) BI-D1870 inhibits the RSK axis and begins to induce apoptosis via PARP cleavage in Daoy cells. C) Rightward shift in Annexin V detected by flow cytometry indicates induction of apoptosis in Daoy cells after 3 d BI-D1870 treatment. D,E) Low concentrations of BI-D1870 prevent colony and neurosphere formation in Daoy cells. F) BI-D1870 combined with conventional chemotherapeutics is more potent together than individually. 

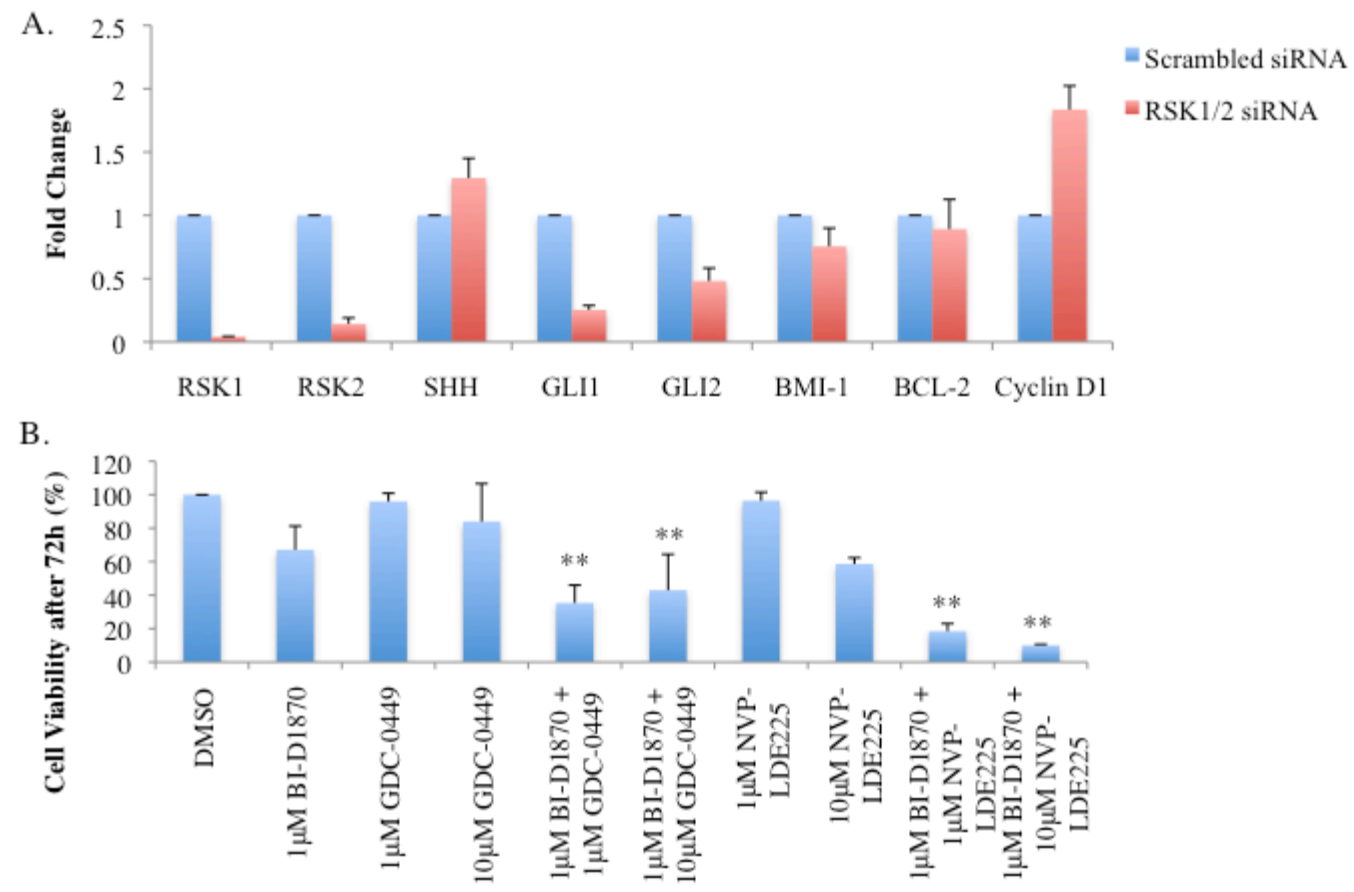

C.

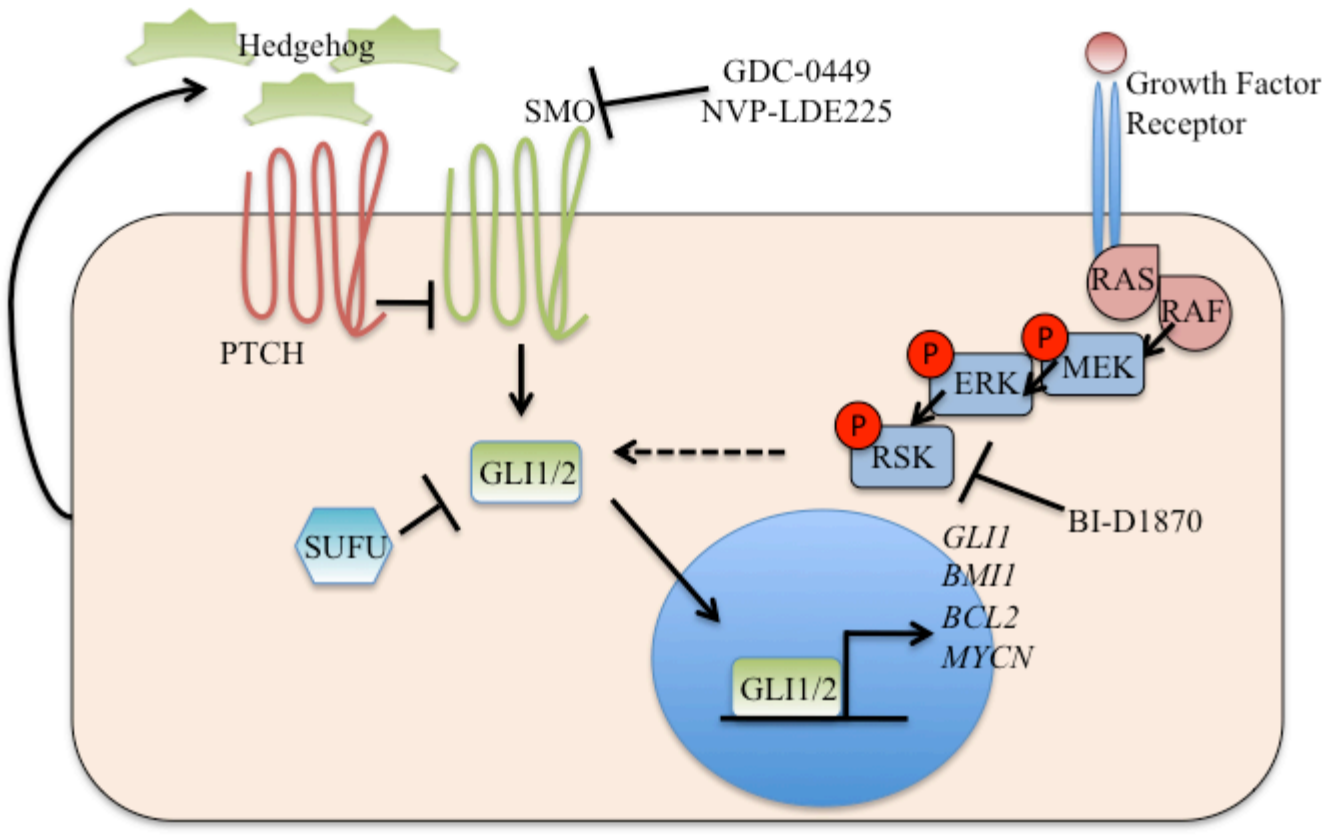

Figure 2.5 Targeting RSK to circumvent SHH resistance. A) RSK1/2 knockdown after $96 \mathrm{~h}$ correlates with decreased GLI1/2 transcripts as well as modest decreases in BMI-1 and BCL2 in Daoy cells. B) Low concentrations of BI-D1870 combined with SMO inhibitors in clinical trials decrease cell viability in Daoy cells. C) Proposed mechanism of RSK-SHH pathway communication. 

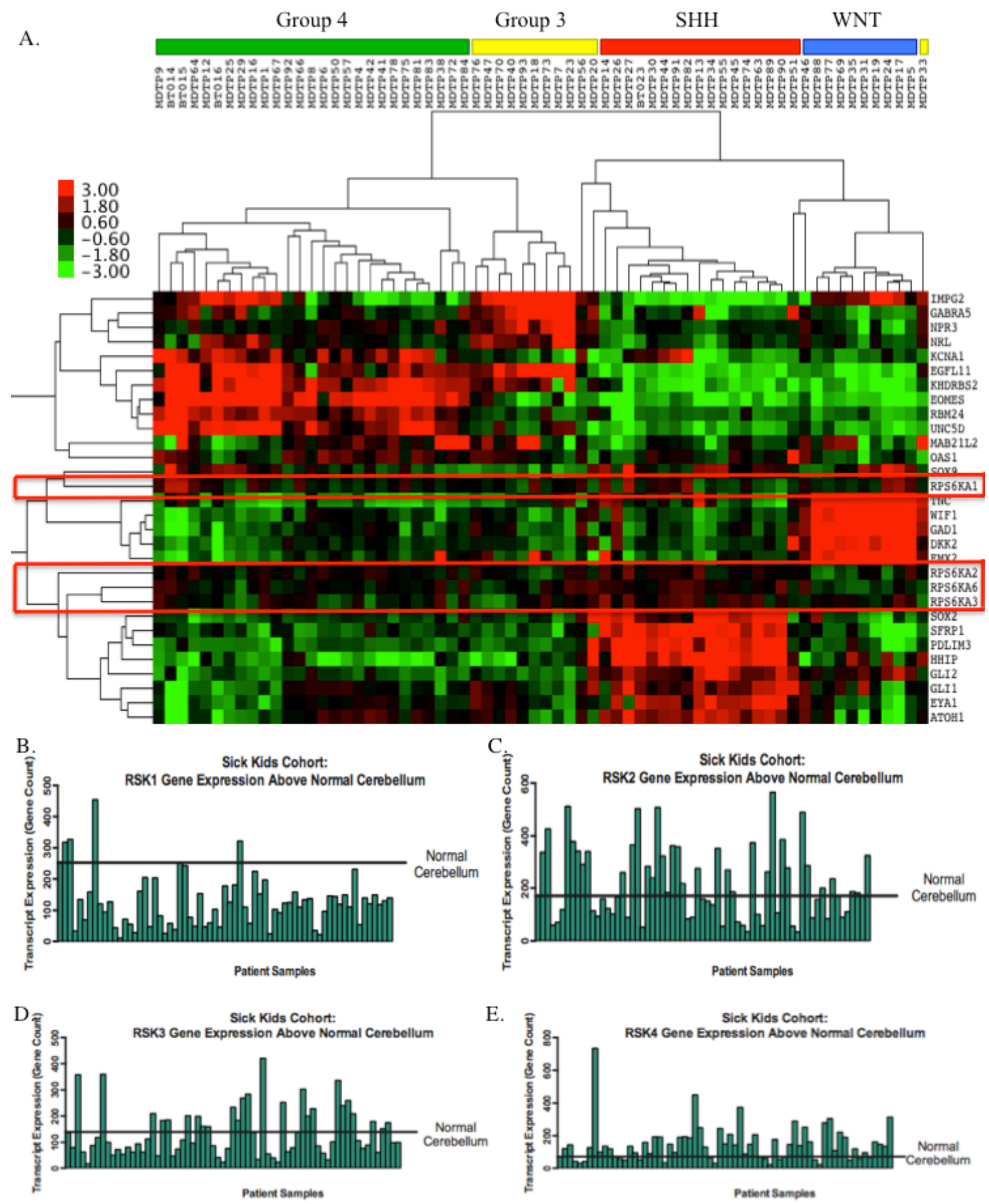

Figure 2.6 Clinical relevance of RSK. A) Hierarchical clustering of RSK isoform and MB subtyping gene expression in patients. Dendogram illustrates degree of similarity in expression pattern. Red=high, Green=low. Expression of B) RSK1/RPS6KA1 C) RSK2/RPS6KA3 D) RSK3/RPS6KA2 E) RSK4/RPS6KA6 in individuals relative to levels measured in normal cerebellum. Data provided by Joanna Triscott. 
A

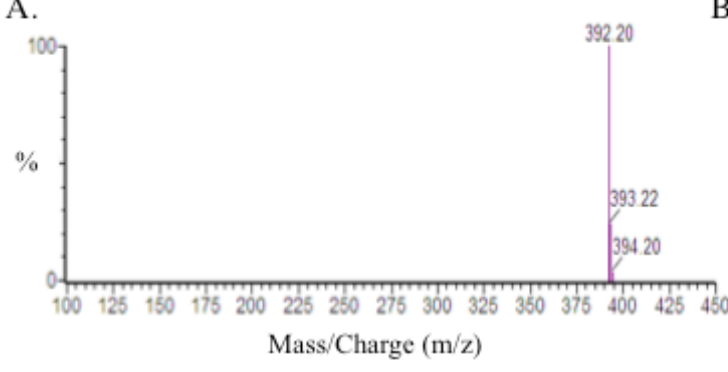

C.

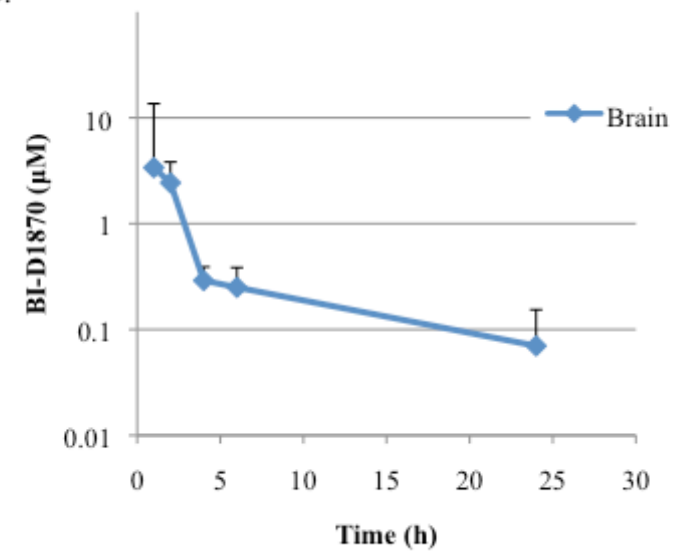

E.

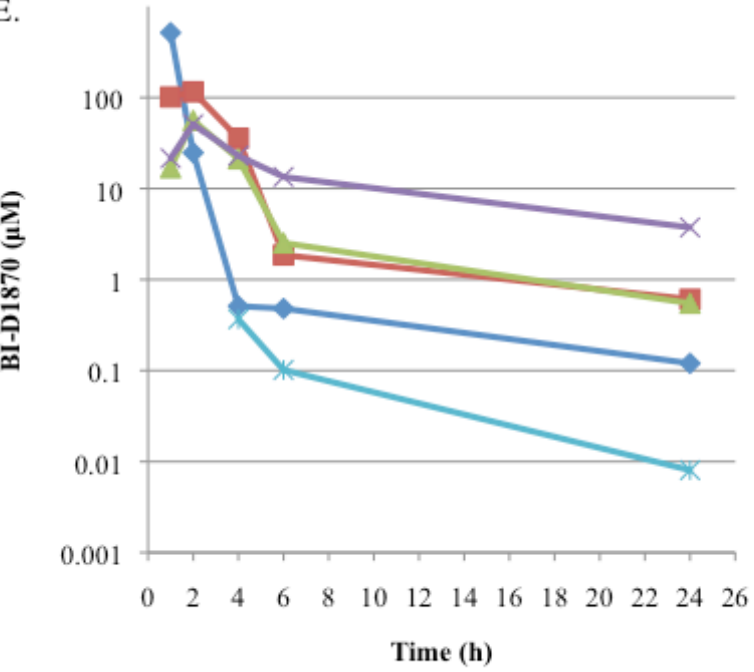

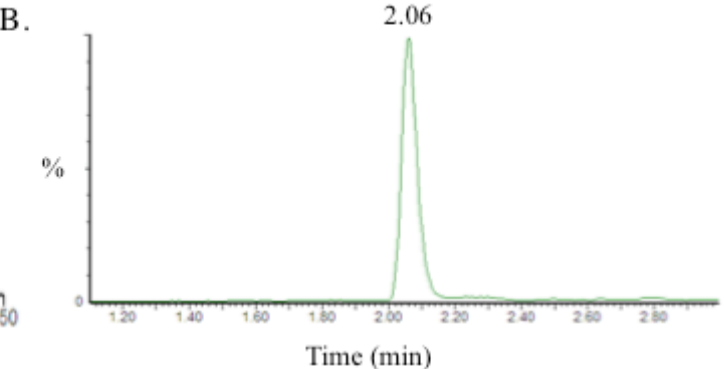

D.

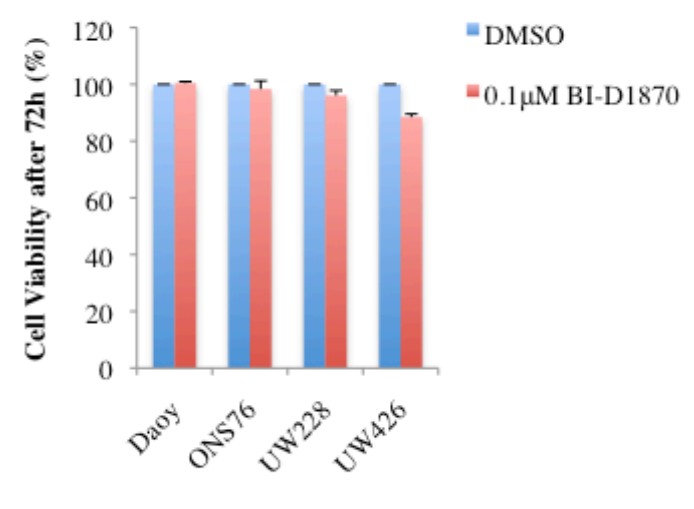

F.

MDV3100
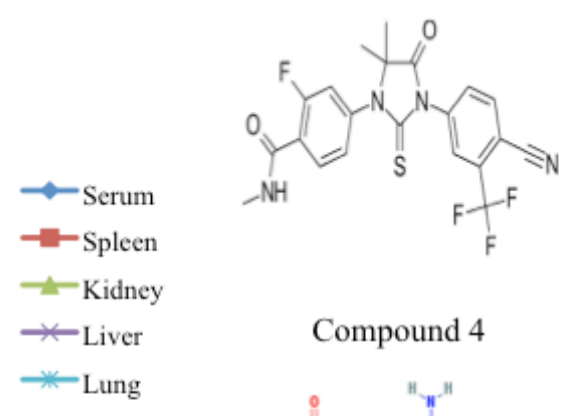

Compound 4

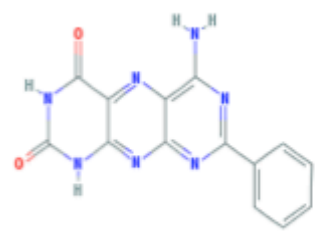

Figure 2.7 Profiling BI-D1870 for pre-clinical use. A) Electrospray+ scan of BID1870. B) Chromatogram using $\mathrm{m} / \mathrm{z}$ 392>322 identifying $5 \mu \mathrm{L}$ of $10 \mathrm{nM} \mathrm{BI-D1870} \mathrm{as} \mathrm{a}$ single pure peak. C) After injecting $100 \mathrm{mg} / \mathrm{kg}$ of BI-D1870 into mice, the plot graph is the BI-D1870 concentration extracted from the brain at 1, 2, 4, 6, and $24 \mathrm{~h}$ corrected for blood volume. D) The estimated BI-D1870 concentration of $0.1 \mu \mathrm{M}$ does not affect the MB cell lines. E) The PK profile for the remaining tissues and plasma at various timepoints. F) Structures of the controls for LC/MS, MDV3100 and Compound 4. 


\subsection{SUPPLEMENTARY FIGURES \\ SHH}
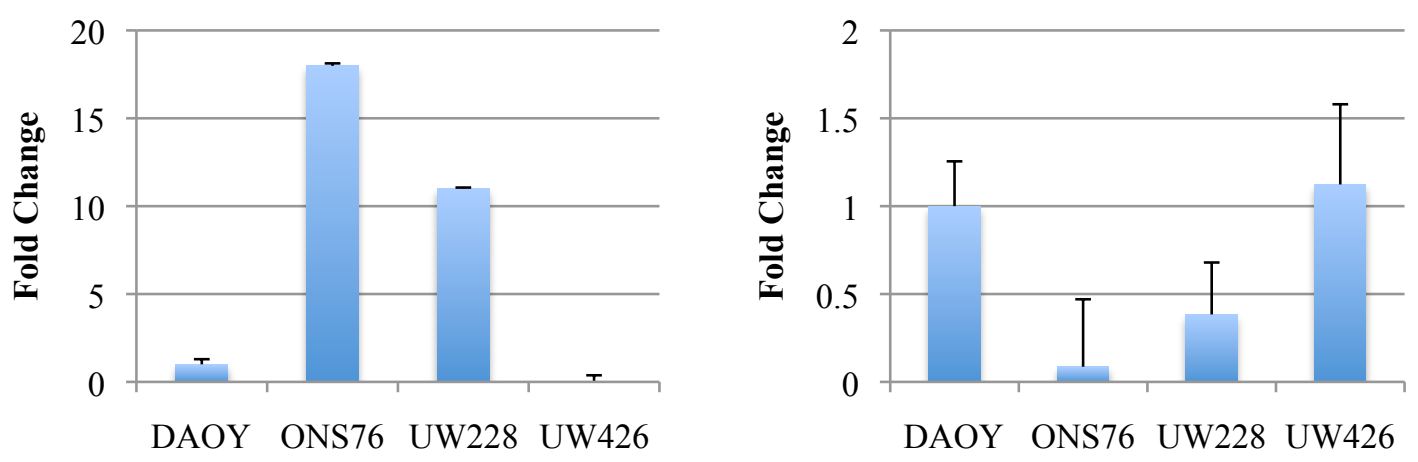

\section{GLI2}

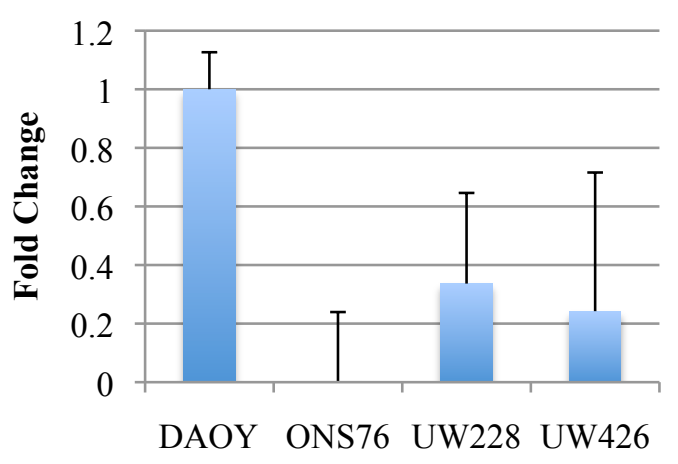

Supplemental Figure 2.1 Characterization of SHH pathway components in MB cell lines using qRT-PCR. SHH ligand, GLI1, and GLI2 were semi-quantitatively measured relative to the Daoy cell line.

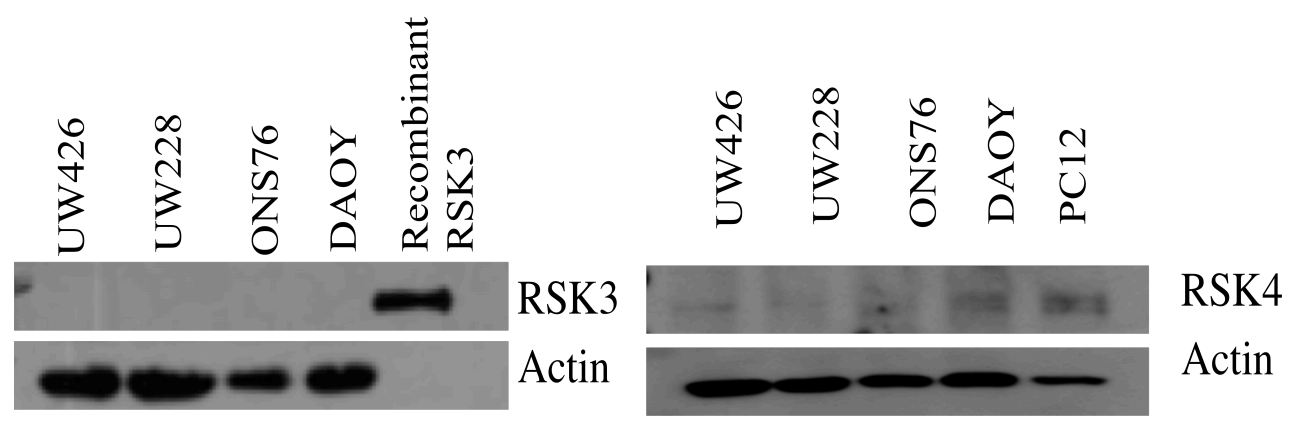

Supplemental Figure 2.2 Characterization of RSK3 and 4 in SHH MB cell lines via immunoblotting. The SHH MB lines do not express RSK3 nor RSK4 as compared to the positive controls. 


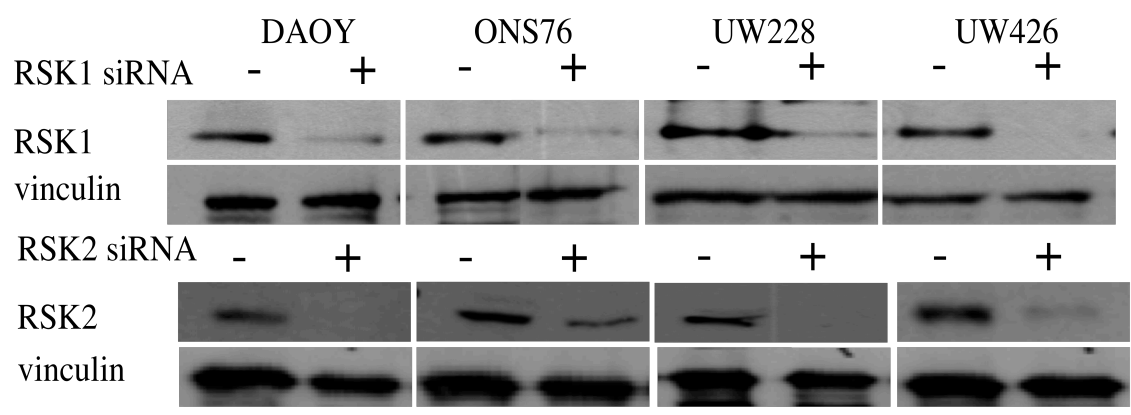

Supplemental Figure 2.3 Validation of RSK knockdown. Knockdown was achieved in all four SHH MB cell lines for the RSK1 and RSK2 isoforms.

A. ONS76 UW228

UW426
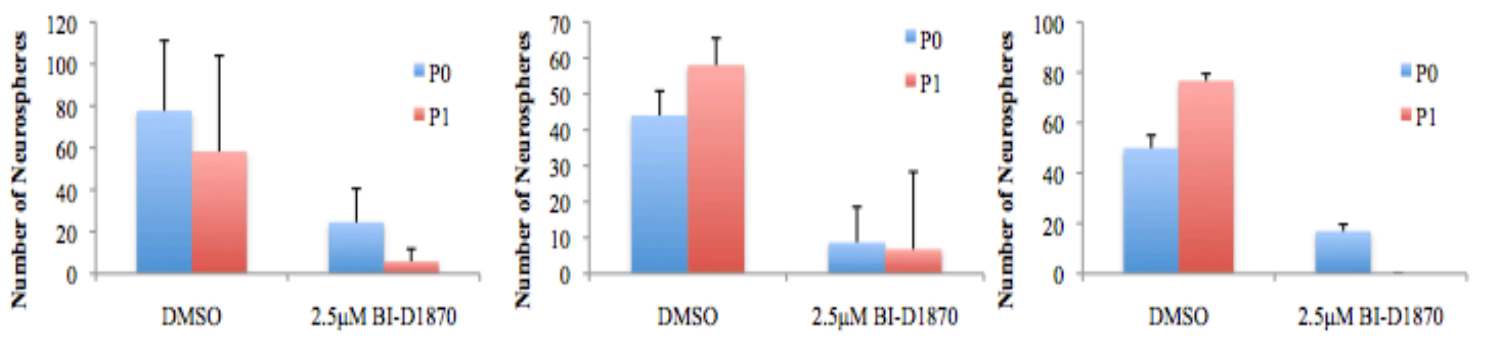

B.

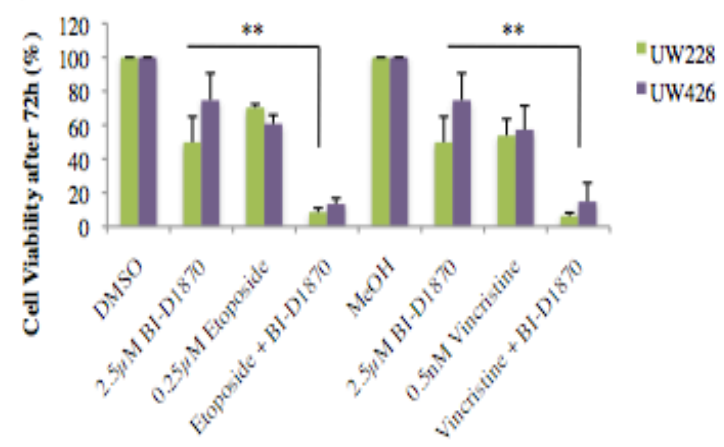

Supplemental Figure 2.4 Further effects of BI-D1870 on remaining SHH MB cell lines. A) BI-D1870 prevents self-renewal in the 3 SHH MB cell lines. B) BI-D1870 and chemotherapy together have an enhanced effect on the other SHH MB cell lines. 
A.

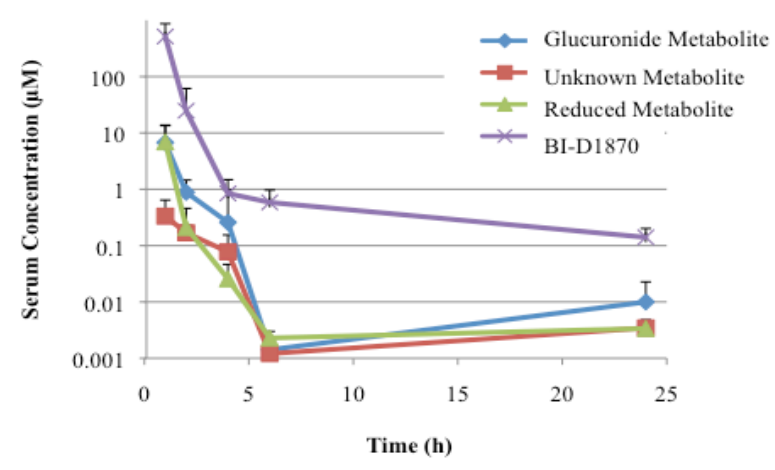

B.

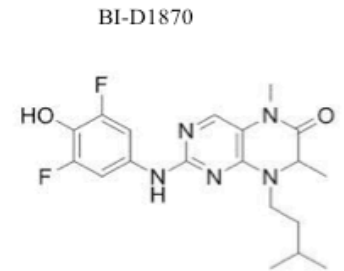

Glucuronide Metabolite

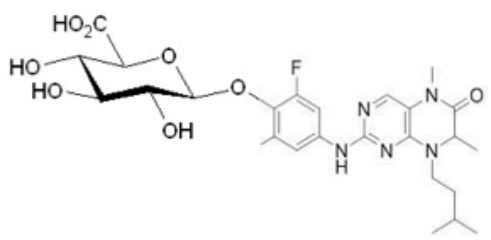

Reduced Metabolite

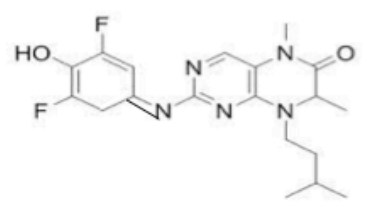

Supplemental Figure 2.5 Metabolite concentrations relative to BI-D1870 in plasma.

A) The three identified metabolites are at low abundance compared to the parent compound. B) The predicted metabolite structures of BI-D1870. 


\subsection{SUPPLEMENTARY TABLES}

Supplemental Table 2.1 Summary of the pediatric MB patients from BCCH included in the Discovery cohort.

\begin{tabular}{|c|c|c|c|c|c|}
\hline Characteristic: & & WNT & SHH & Group 3 & Group 4 \\
\hline $\begin{array}{l}\text { Total Number of Patients } \\
\text { Between 1986-2012: }\end{array}$ & 74 & $9(12 \%)$ & $21(29 \%)$ & $18(24 \%)$ & $26(35 \%)$ \\
\hline $\begin{array}{l}\text { Excluded from Survival } \\
\text { Analyais: }\end{array}$ & $g^{* x}$ & 1 & 4 & 2 & 2 \\
\hline Number of Patients: & 65 & $8(12 \%)$ & $17(26 \%)$ & $16(25 \%)$ & $24(37 \%)$ \\
\hline \multicolumn{6}{|l|}{ Age } \\
\hline$<3$ years & $16(25 \%)$ & $0(0 \%)$ & $10(59 \%)$ & $6(37 \%)$ & $0(0 \%)$ \\
\hline Between 3 to 8 years & $30(46 \%)$ & $2(25 \%)$ & $6(35 \%)$ & $7(44 \%)$ & $15(62 \%)$ \\
\hline Between 8 to 12 years & $12(18 \%)$ & $2(25 \%)$ & $0(0 \%)$ & $3(19 \%)$ & $7(30 \%)$ \\
\hline $12-18$ years & $7(11 \%)$ & $4(50 \%)$ & $1(6 \%)$ & $0(0 \%)$ & $2(8 \%)$ \\
\hline Average (years) & 6.3 & 11.2 & 3.0 & 4.6 & 7.8 \\
\hline Range (years) & 1.18 to 15.4 & 6.1 to 14.7 & 1.18 to 7.7 & 1.5 to 10.2 & 3.8 to 15.4 \\
\hline \multicolumn{6}{|l|}{ Sex } \\
\hline Female & $25(38 \%)$ & $7(88 \%)$ & $8(47 \%)$ & $7(44 \%)$ & $3(12 \%)$ \\
\hline Male & $40(62 \%)$ & $1(12 \%)$ & $9(53 \%)$ & $9(56 \%)$ & $21(88 \%)$ \\
\hline \multicolumn{6}{|l|}{ Metastasis } \\
\hline Mo & $31(48 \%)$ & $4(50 \%)$ & $9(53 \%)$ & $6(37 \%)$ & $12(50 \%)$ \\
\hline M1 & $14(22 \%)$ & $1(12 \%)$ & $3(17 \%)$ & $5(32 \%)$ & $5(21 \%)$ \\
\hline M2 & $4(6 \%)$ & $0(0 \%)$ & $2(12 \%)$ & $1(6 \%)$ & $1(4 \%)$ \\
\hline M3 & $10(15 \%)$ & $1(12 \%)$ & $1(6 \%)$ & $3(19 \%)$ & $5(21 \%)$ \\
\hline Unknown & $6(9 \%)$ & $2(25 \%)$ & $2(12 \%)$ & $1(6 \%)$ & $1(4 \%)$ \\
\hline \multicolumn{6}{|l|}{ Extent of Resection } \\
\hline Gross Total Resection & $43(66 \%)$ & $5(62 \%)$ & $11(65 \%)$ & $10(63 \%)$ & $17(70 \%)$ \\
\hline Subtotal or lees & $20(31 \%)$ & $3(38 \%)$ & $6(35 \%)$ & $4(25 \%)$ & $7(30 \%)$ \\
\hline Unknown & $2(3 \%)$ & $0(0 \%)$ & $0(0 \%)$ & $2(12 \%)$ & $0(0 \%)$ \\
\hline \multicolumn{6}{|l|}{ Treatment } \\
\hline Chemotherapy Only & $16(25 \%)$ & $0(0 \%)$ & $9(53 \%)$ & $3(19 \%)$ & $4(17 \%)$ \\
\hline Radiation Only & $4(6 \%)$ & $3(38 \%)$ & $0(0 \%)$ & $0(0 \%)$ & $1(4 \%)$ \\
\hline Both Chemo and Radiation & $43(66 \%)$ & $5(62 \%)$ & $7(41 \%)$ & $12(75 \%)$ & $19(79 \%)$ \\
\hline No Treatment or Incomplete & $2(3 \%)$ & $0(0 \%)$ & $1(6 \%)$ & $1(6 \%)$ & $0(0 \%)$ \\
\hline
\end{tabular}

"9 Patients were excluded from survival analysis due to inhomogeneity of treatment regime Note: of 75 original blocks with follow up 1 was not a MB sample and therefore excluded 
Supplemental Table 2.2 Summary of the pediatric MB patients from SickKids Hospital included in the Validation cohort.

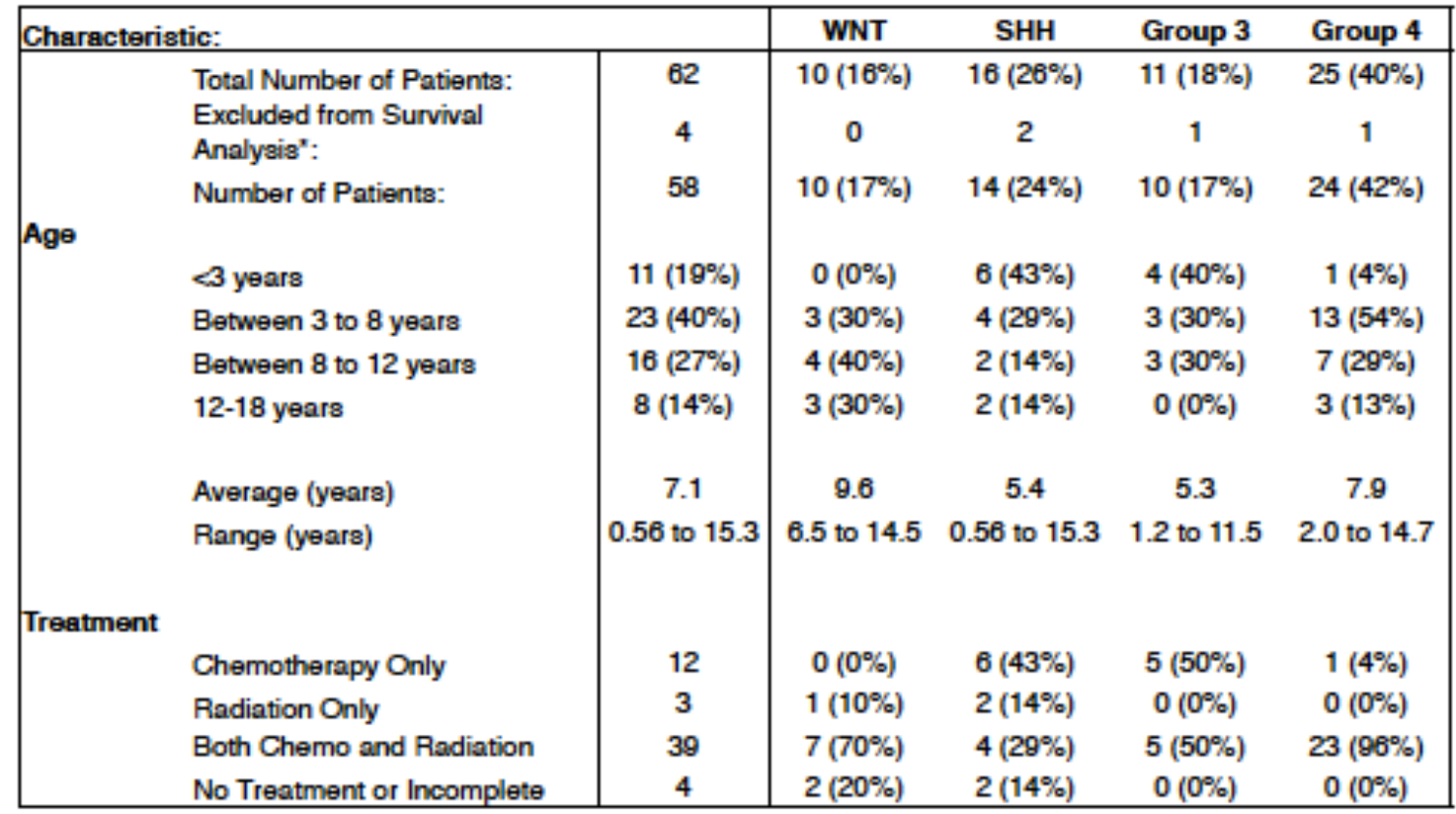

"4 Patients were excluded from aurvival analysis due to inhomogeneity of treatment regime Note: only 55/58 patients with aurvival outcomes had information on disease progreseion 
Supplemental Table 2.3 Complete list of compounds in the ChemieTek Library.

\begin{tabular}{|c|c|}
\hline Inhibitor & Activity \\
\hline GSK690693 & Akt \\
\hline MK-2206 & Akt \\
\hline AZD1152 & AURK \\
\hline VX-680 & AURK \\
\hline ZM447439 & AURK \\
\hline ABT-263 & BCL-2 \\
\hline ABT-737 & BCL-2 \\
\hline PLX4032 (Votrient) & B-Raf \\
\hline PLX4720 & B-Raf \\
\hline TM30098 & CRTH2R \\
\hline Ramatroban (Bay u3405) & CRTH2R \\
\hline ARQ 197 (Tivatinib) & cMET \\
\hline BMS-777607 & cMET \\
\hline EMD1214063 & cMET \\
\hline PF-04217903 & cMET \\
\hline PF-2341066 & cMET \\
\hline LBH-589 (Panobinostat) & HDAC \\
\hline MGCD0103 & HDAC \\
\hline Vorinostat (SAHA) & HDAC \\
\hline MS-275 & HDAC \\
\hline Tubacin & HDAC \\
\hline Tubastatin A & HDAC \\
\hline Belinostat (PXD101) & HDAC \\
\hline 17-AAG & HSP90 \\
\hline 17-DMAG & HSP90 \\
\hline NVP-AUY922 (VER-52296) & HSP90 \\
\hline OSI-906 & IGF1R \\
\hline BMS-754807 & IGF1R \\
\hline CP-690550 & JAK \\
\hline AZD1480 & JAK \\
\hline CYT-387 & JAK \\
\hline INCB018424 (Ruxolitinib) & JAK \\
\hline TG101348 & JAK \\
\hline RDEA119 & MEK \\
\hline AZD6244 (ARRY-142886) & MEK \\
\hline ARRY -162 & MEK \\
\hline GSK1120212 & MEK \\
\hline AS703026 (MSC1936369B) & MEK \\
\hline PD0325901 & MEK \\
\hline
\end{tabular}




\begin{tabular}{|c|c|}
\hline Inhibitor & Activity \\
\hline Pp242 & mTOR \\
\hline Rapamycin (Sirolimus) & mTOR \\
\hline AZD8055 & mTOR \\
\hline INK128 & mTOR \\
\hline OSI- 027 & mTOR \\
\hline Capecitabine (Xeloda) & NA synthesis \\
\hline Pemetrexed Disodium (Alimta) & NA synthesis \\
\hline Gemcitabine, $\mathrm{HCl}$ (Gemzar) & NA synthesis \\
\hline Doxorubicin (Adriamycin) & NA synthesis \\
\hline ABT-888 (Veliparib) & PARP \\
\hline AZD 2281 (Olaparib) & PARP \\
\hline BSI-201 (Iniparib) & PARP \\
\hline AG014699 (PF-01367338) & PARP \\
\hline MK-4827 & PARP \\
\hline Sunitinib & PDGFR \\
\hline Tandutinib & PDGFR \\
\hline Imatinib & PDGFR \\
\hline PIK-75, $\mathrm{HCl}$ & PI3K \\
\hline GDC-0941 & PI3K \\
\hline CAL-101 & PI3K \\
\hline LY294002 & PI3K \\
\hline PF-04691502 & $\mathrm{PI} 3 \mathrm{~K} / \mathrm{mTOR}$ \\
\hline TG100-115 & PI3K \\
\hline XL-147 & PI3K \\
\hline TGX-221 & PI3K \\
\hline BI2536 & PLK \\
\hline BI6727 (Volasertib) & PLK \\
\hline GSK461364 & PLK \\
\hline GDC-0449 & SMO \\
\hline NVP-LDE225 & SMO \\
\hline AZD05030 (Saracatinib) & Src \\
\hline Dasatanib & $\mathrm{Src}$ \\
\hline AV-951 (Tivozanib) & VEGFR \\
\hline Axitinib (AG-013736) & VEGFR \\
\hline Pazopanib (Votrient) & VEGFR \\
\hline Motesanib (AMG-706) & VEGFR \\
\hline XL-184 (Cabozantinib) & VEGFR \\
\hline Vandetanib (Zactima) & VEGFR \\
\hline Vatalanib Dihydrochloride & VEGFR \\
\hline
\end{tabular}




\begin{tabular}{|c|c|}
\hline Inhibitor & Activity \\
\hline FK-506 & Immunosuppressant \\
\hline FTY720, $\mathrm{HCl}$ & Immunosuppressant \\
\hline Erlotinib, $\mathrm{HCl}$ & EGFR \\
\hline WZ4002 & EGFR \\
\hline AZD4547 & FGFR \\
\hline CUDC-101 & HDAC/EGFR/HER2 \\
\hline Lapatinib & HER1/2, EGFR \\
\hline A-769662 & AMPK \\
\hline AC220 (Quizartinib) & CD135 \\
\hline CVT-6883 & Adenosine receptor \\
\hline CGS 21680 & Adenosine receptor \\
\hline Bicalutamide (Casodex) & Androgen receptor \\
\hline Topotecan (Hycamtin) & Topoisomerase I \\
\hline $\mathrm{SN}-38$ & Topoisomerase I \\
\hline Etoposide & Topoisomerase II \\
\hline Lenalidomide (CC-5013) & Immunomodulator \\
\hline Carfilzomib (PR-171) & Proteasome \\
\hline Bortezomib (Velcade) & Proteasome \\
\hline VX-950 (Telaprevir) & Protease \\
\hline YM155 & Survivin suppressant \\
\hline Varespladib (LY315920) & Phospholipase A2 \\
\hline VX-675 & ICE/Caspase 1 \\
\hline Raltegravir & HIV integrase \\
\hline Rofecoxib (Vioxx) & COX-2 \\
\hline VX702 & p38 MAPK \\
\hline PD-0332991 & CDK \\
\hline Atorvastatin Calcium (Lipitor) & HMG-CoA reductase \\
\hline Odanacatib (MK-0822) & Cathepsin \\
\hline NVP-TAE684 & NPM-ALK \\
\hline Dutasteride (Avodart) & $5 \alpha$ reductase \\
\hline BMS-599626 & HER2 \\
\hline BIBW 2992 (Tovok) & HER2/EGFR \\
\hline Gefitinib (Iressa) & EGFR \\
\hline Sorafenib & RAS/RAF \\
\hline Canertinib (CI-1033) & ERBB-R \\
\hline Bosutinib (SKI-606) & ABL,SRC \\
\hline Nilotinib & BCR-ABL \\
\hline Docetaxel & Tubulin \\
\hline Ponatinib (AP24534) & BCR-ABL \\
\hline Regorafenib (BAY 73-4506) & Multi kinase \\
\hline
\end{tabular}




\begin{tabular}{|c|c|}
\hline Inhibitor & Activity \\
\hline SR1 & $\begin{array}{l}\text { Aryl hydrocarbon } \\
\text { receptor }\end{array}$ \\
\hline Montelukast Sodium (Singulair) & Leukotriene \\
\hline Maraviroc (UK-427857) & $\begin{array}{l}\text { C-C chemokine receptor } \\
5\end{array}$ \\
\hline AN2728 & Phosphodiesterase 4 \\
\hline Laropiprant & Prostaglandin 2 receptor \\
\hline Paclitaxel (Taxol) & Tubulin stabilizer \\
\hline Bexarotene (Targetrin) & $\begin{array}{l}\text { Retinoid X receptor } \\
\text { activator }\end{array}$ \\
\hline Eprosartan Mesylate (Teveten) & Angiotensin receptor \\
\hline Hypothemycin & $\mathrm{T}$ cell activation \\
\hline Dimebolin Hydrochloride & Antihistamine \\
\hline BI-D1870 & p90 RSK \\
\hline
\end{tabular}




\section{CHAPTER THREE: CLOSING REMARKS}

\subsection{DISCUSSION \& FUTURE DIRECTIONS}

With a myriad of studies allowing for clearer stratification of patients into subtypes, it is paramount that we mine through the data, pinpoint key genes, and harness these findings to synthesize inhibitors that will eliminate disease completely. The landscape of MB has changed from a hostile frontier in the 1900s when Cushing first classified it, to four foreseeably manageable sects of disease (Bailey and Cushing, 1925; Kool et al., 2012).

The idea of personalized medicine is slowly coming to fruition in MB. Recently, the SHH subtype has been further divided into four distinct subtypes through methylation and gene expression profiling of $>250 \mathrm{MB}$ samples (Remke et al., 2013). The Kool group also found that the SHH subtype can be divided into two subtypes through methylation arrays (Kool et al., 2013). It will be of interest to see what role RSK plays within this unfolding story.

Recurrence in children with MB is an inevitable challenge as demonstrated by the progression free survival from two different institutions (Fig. 3.1A). When looking into individual subtypes, the SHH subtype appears to recur at an equivalent propensity as Group 3 subtypes in the BCCH cohort (Fig. 3.1B). As mentioned earlier, the differences in treatment regimens could account for discrepancies between the outcomes of BCCH and SickKids cohorts. It is important to identify what is driving recurrence, since mortality rates are high for recurrent $\mathrm{MB}$, specifically a three-year survival rate of $22 \%$ (Massimino et al., 2013). Recently, subtypes have been found to remain stable in both primary and recurrent tumours - ie. SHH MB tumours do not switch to Group 3 tumours when they recur (Ramaswamy et. al, 2013).

The MAPK pathway has been identified as a key player in driving brain tumours including glioma, medulloblastoma, and pilocytic astrocytoma (the most common nonmalignant brain tumour) (Huse and Holland, 2010), and it has been implicated in metastatic MB. The MacDonald group reported that PDGFR (platelet-derived growth 
factor) is highly expressed in metastatic MB compared to primary MB (MacDonald, 2001). PDGFR is known to activate the MAPK signaling cascade. Interestingly, they found that RSK1 was not a driver of metastatic MB. They did not include other RSK isoforms in their study, and they had a small cohort pre-subtyping era; thus perhaps they did not capture the full extent of the expression of RSK. They did find that inhibiting MEK with U0126 led to decreased migration; however, they did not survey cell proliferation. To date, there are no clinical trials for MEK inhibitors in MB (NCI clinical trials website). Also, MEK inhibitors have been poorly tolerated, thus clinical trials have been halted in other solid cancers (Akinleye et al., 2013). In our screen, Daoy cells did not respond to B-Raf nor MEK inhibitors (Table 3.1).

Perhaps, MB is driven by RSK, a further downstream component, which we demonstrated is active in MB cells. RSK could be constitutively active independent of ERK via mutations or there could be a loss-of-function of its phosphatase, protein phosphatase-2C $\delta$ (Sapkota et al., 2007). However, mutations occur infrequently in MB at a rate of 0.35 non-silent mutations per megabase (Parsons et al., 2011; Pugh et al., 2012). One way to test whether mutated RSK is driving SHH inhibitor resistance would be to sequence the RSK gene in all four MB cell lines as well as patient samples against hNSC to ascertain if there are point mutations that would confer constitutive activity. To analyze RSK and SMO crosstalk conferring resistance, we could obtain a SMO inhibitor responsive cell line and transfect in RSK. One such cell line was outlined in the Yauch paper where they transfected either WT SMO into GLI-luciferase reporter C3H10T1/2 cells (Yauch et al., 2009). Following treatment with SMO inhibitors, we expect to see a decrease in cell viability in the WT-SMO cell line whereas RSK-transfected cell lines would not be affected.

Here in our study, we provide a new opportunity to circumvent SHH inhibitor resistance in MB. The first major finding was delineating that RSK is crucial for resistant SHH MB cell growth. In Fig. 2.3A, there is still a residual population following siRNA treatment. Studies have found that heterogeneity occurs in cultured cell lines (Keller et al., 2010; Stockholm et al., 2007). These side populations change gene expression patterns due to 
cells adapting to their microenvironment including confluency, passage number, and media conditions. Potentially, the cells that did survive siRNA treatment had elevated RSK or a compensatory pathway took over to promote growth. Another way to test this conferred resistance is to subculture cells with siRNA or low dose BI-D1870 and allow for the side population of resistant cells to recover from treatment. Following this, we could harvest mRNA or protein and measure RSK levels and other postulated pathways.

Interestingly, when we silenced YB-1, the downstream target of RSK, we observed decreased cell viability, colony growth, and neurosphere formation (Fig. 3.2A-C). YB-1 is an oncogenic transcription/translation factor associated with a variety of cancers such as ovarian, breast, and prostate cancer (Wu et al., 2007). Our lab has also demonstrated that YB-1 is highly expressed in GBM, but not normal tissue, thus making it an ideal therapeutic candidate (Fotovati et al., 2011). It is known to drive proliferation and multidrug resistance by transcriptionally regulating a plethora of oncogenes including Cyclins, MDR-1, and BMI-1 (Wu et al., 2007).

BMI-1 is a chromatin-modifier, which regulates self-renewal of hematopoietic and NSC populations (Valk-Lingbeek et al., 2004; Wang et al., 2012). It is part of the Polycomb Repressor Complex 1 (PRC1), which permits changes in the epigenome. PRC1 recognizes H3 lysine 27 mark, which is placed by the other Polycomb Group complex, PRC2, which consists of histone deacetylases and methyltransferases. Together, these complexes repress the senescence pathways, $\mathrm{p} 16^{\mathrm{Ink} 4 \mathrm{a}}$ and $\mathrm{p} 19^{\mathrm{Arf}}$ (Valk-Lingbeek et al., 2004). The first direct evidence that BMI-1 and SHH cooperate came from the Singh group (Wang et al., 2012). They demonstrated that GLI1 binds to the promoter of BMI1, thus promoting a NSC phenotype in MB. Perhaps, YB-1 and GLI1 or 2 cooperate to allow for transcriptional activity of BMI-1. Following this, BMI-1 silences tumour suppressors, thus possibly fueling the SHH MB phenotype.

When assessing the efficacy of BI-D1870, we noticed that the UW426 cell line was least sensitive to the RSK inhibitor (Fig. 2.4A). Curiously, it responded to siRNA. Perhaps, this cell line requires a higher concentration of BI-D1870 as it has the highest RSK level 
compared to the other three MB cell lines (Fig. 2.2C). Another reason for its resistance against BI-D1870 could be that it is a more drug resistant cell line. Perhaps it has increased efflux pumps such as P-gp, which can be surveyed using immunoblotting.

In Fig. 2.4F, there was still a remaining population after chemotherapy treatment. However, chemotherapy together with BI-D1870 led to a more pronounced inhibitory growth effect. There are several chemoresistance mechanisms such as decreased uptake, increased efflux, and decreased metabolism (Zahreddine and Borden, 2013; Gottesman et al., 2002). SHH MB has been characterized as being chemoresistant through tetraploidy (Castedo et al., 2006). Another perspective to consider is the unraveling of how the DNA damage response (DDR) can be responsible for chemotherapeutic resistance (Zhou and Bartek, 2004). One component of the DDR is the ATR-CHK1 pathway. ATR phosphorylates CHK1 in response to DNA damage at Ser317 and Ser345. Activated CHK1 leads to CDC25 phosphatase degradation allowing for DNA repair and mitosis. Conversely, RSK confers an inhibitory phosphorylation on CHK1 at Ser280 (Li et al., 2012; Ray-David et al., 2012). This facilitates G2 DNA damage checkpoint slippage. In melanoma, chemoresistance was overcome by treatment with SL0101 (Ray-David et al., 2012). In our model, we treated Daoy cells with DNA damaging agents and found that BI-D1870 decreased pCHK $1^{\text {S280 }}$ (Fig. 3.3). This demonstrates that BI-D1870 has the ability to restore this cell cycle checkpoint. This is preliminary evidence of how RSK exacerbates resistance to chemotherapy and SMO inhibitors.

Following silencing of RSK, transcript levels of downstream effectors GLI1/2 decrease (Fig. 2.5A). As aforementioned, GSK3ß was a proposed mechanism for protecting degradation of GLI1/2 in multiple myeloma. However, this proposal did not apply to our SHH MB models. We inhibited RSK and observed that $\mathrm{pGSK} 3 \beta^{\mathrm{S} 9}$ did not change (Fig. 2.4B). This was counterintuitive as BI-D1870 inhibits RSK activity from phosphorylating downstream targets, which include GSK3ß. Perhaps, another pathway is compensating and phosphorylating GSK3ß such as the PI3K/Akt pathway (Cross et al., 1995). In Fig. 2.6A, RSK2-4 have been identified under the SHH MB subtype. Since BI-D1870 is a pan-RSK inhibitor, it seems beneficial that it can target these implicated SHH genes. 
The second major finding was that BI-D1870 could cross the BBB, but at limited concentrations (Fig. 2.7C). Its delivery needs optimization as not much crossed the BBB. Newly synthesized RSK inhibitors can be delivered intrathecally, IP, IV, or orally. There are invasive approaches including intra-cerebro-ventricular infusion and biodegradable chemotherapeutic wafers in tumour resection cavities such as BCNU (bischloroethylnitrosurea) (Gabathuler, 2010). However, we aim to treat patients in the least invasive way possible. Pharmacological methods employ the synthesis of inhibitors that are less than $500 \mathrm{Da}$, low hydrogen bonding capabilities, and high lipophilicity (Gabathuler, 2010). BI-D1870 fulfills these requirements with a molecular weight of 391.42 Da (Sapkota et al., 2007).

Despite this, we encountered stability issues with BI-D1870. It requires formulation at a physiologically unachievable $\mathrm{pH}$. Chemically modifying BI-D1870 with different structural moieties has potential to increase stability. We also could attempt delivering BI-D1870 using physiological methods called molecular Trojan horses (MTH; Gabathuler, 2010). Borrowing the idea from the Greeks, drugs disguise themselves using ligand properties so that cell surface receptors bind to and increase their uptake of the ligand-disguised drug. For example, iron is the natural substrate of the receptor transferrin. Some drugs are tagged with an iron-like property which tricks the cell into taking up the drug (Gabathuler, 2010). Antibodies are also conjugated to liposomes directing the inhibitors to undergo transcytosis.

Once more stable analogs of BI-D1870 are synthesized, they will need to be tested in vitro for specificity and efficacy. To test for specificity, one could obtain a RSK deficient cell line or knockdown RSK and then treat with BI-D1870 analogs. Following this, they could ascertain whether these new inhibitors inhibit previously identified off-targets of BI-D1870 (Sapkota et al., 2007). One such target is Polo-Like Kinase 1 (PLK1). PLK1 activity can be measured by phosphorylation of $\mathrm{CDC} 25 \mathrm{C}$ through immunoblotting. We could also conduct a kinase screen against AGC kinases for specificity. Another assay to verify specificity would be to use RSK siRNA and compare the effects with the new 
inhibitors. Lastly, a rescue experiment to ascertain specificity could be performed where we transfect a RSK over-expression plasmid into cells.

After establishing efficacy and stability of the new compounds, we are able to test them in vivo. We have a Daoy mouse model ready, which molecularly subtypes with SHH MB and histologically has features of LC/A. There are other readily available mouse models for SHH MB (Goodrich et al., 1997; Hatton et al., 2008). In addition, we have an excellent rapport with $\mathrm{BCCH}$ where we receive fresh $\mathrm{MB}$ samples for culture. Taking primary and recurrent samples that have been subtyped via NanoString as SHH MB and injecting them stereotactically into mice would be the ideal model. Another avenue that could be explored is the use of a stable lentiviral RSK shRNA (Premsrirut et al., 2011). We could transfect and stably knockdown RSK in Daoy cells to ascertain whether this silencing would prevent tumours from forming or delay tumour growth in mice. Using transient RSK siRNA, our group has recently demonstrated that silencing RSK delays tumour growth in a triple-negative breast cancer model (Reipas et al., 2013). We hope that our MB model transfected with RSK shRNA would reflect the findings of this breast cancer model. In addition, we tested a range of BI-D1870 concentrations on normal hematopoietic stem cells as well as mammary cells and observed neither growth inhibition nor apoptosis on these normal tissues (Reipas et al., 2013).

Since we are striving to treat children, it is important to properly establish the role of RSK in the mature human brain. We know from previous work that certain RSK isoforms are important for embryogenesis and are no longer expressed postnatally. The Allen Human Brain Atlas is an online database, which has outlined the expression of RSK using microarrays of human samples. RSK1/2 were detected from low-moderate levels in children. In adults, RSK1/2 are expressed in various regions of the brain including the corpus callosum and the frontal lobe. In light of CLS and RSK2 deficiency, there might be issues inhibiting RSK. To ensure that RSK inhibitors can be feasible for clinical studies, we must demonstrate the function of RSK in the mature brain. As such, immunoblotting and IHC should be used to ascertain the RSK activity and protein 
expression of various tissues of the central nervous system such as the brainstem, cerebellum, and cortex from the developed human brain.

We identified that YB-1 is present in MB patients at varying levels (Fig. 3.4A). Using these low and high YB-1 samples, we strove to find the ideal antibody dilution for $\mathrm{pYB}$ $1^{\mathrm{S} 102}$ in IHC, which is 1:200 in our preliminary study (Fig. 3.4B). Once we treat our mouse models with RSK inhibitor, we can use $\mathrm{pYB}-1^{\mathrm{S} 102}$ as an indicator of RSK inhibition. There are caveats associated with pYB-1 ${ }^{\text {S102 }}$ IHC. As indicated by Fig. 3.4A, there is a 5-fold difference in YB-1 transcript. One can only detect qualitative rather than quantitative levels of $\mathrm{pYB}-1^{\mathrm{S} 102}$ by IHC. Another difficulty is that $\mathrm{pYB}-1^{\mathrm{S} 102}$ is a fairly new antibody for IHC. To ensure that there is no non-specific binding, the proper controls would be applied as follows. We could knock down YB-1 in cells and probe for pYB$1^{\mathrm{S} 102}$ via immunoblot. No band should be detected in the treated cells. A second experiment could be to prepare IHC without the primary antibody. There should be no staining. Lastly, a blocking peptide could be applied in the IHC preparation. The primary antibody would bind to this blocking peptide, resulting in no binding to the actual tissue.

With the foundation set for RSK as a novel target for SHH MB, we looked into whether RSK plays a role in Group 3 and 4 MB. Surprisingly, we found that BI-D1870 elicited a profound inhibitory growth effect in Group 3 MED8A cells (Fig. 3.5A). Using qRT-PCR, we found that both RSK1 and RSK2 transcripts are expressed in MED8A cells (Fig. 3.5C). There are no other verified Group $3 \mathrm{MB}$ cell lines; however, there are $M Y C$ amplified cell lines such as the D283 and D341 cell lines. Also, there are Group 3-like mouse models, which we could test with BI-D1870. This group of MB has the worst survival rates and requires new treatment strategies.

The first clue that RSK was involved with Group 4 MB was identified in our patient cohort. We found that RSK1 RNA is detected and clusters most closely under the Group 4 subtype (Ch. 2, Fig. 2.6A). We obtained a primary sample, BT016, which has been characterized as Group 4 by NanoString, from BCCH and tested BI-D1870. It formed well-rounded neurospheres and responded quite well to treatment (Fig. 3.5B). It was 
interesting to find that BT016 has low RSK transcript levels compared to hNSC (Fig. 3.5C). Thus, we looked at YB-1 and observed that it was modestly higher than hNSC. Perhaps, it is the activity that Group $4 \mathrm{MB}$ relies on rather than simply transcript level. Further investigation will be required to query the role of RSK in these subtypes.

In our lab, we also study GBM and triple-negative breast cancer (TNBC). We assessed BI-D1870 activity in these systems. Since there are no RSK inhibitors available clinically, we addressed whether off-patent drugs hold promise in this regard. Off-patent drugs such as luteolin and apigenin are easily accessible and are present in celery, carrots, and chamomile tea. They are ideal in that their safety profiles and dosing schedules are established, thus they can be fast-tracked into clinic. Further, flavonoids such as quercetin have demonstrated the ability to cross the BBB using an in vitro model (Youdim et al., 2003). Ellipticine is another off-patent RSK2 inhibitor, which could be tested. Since apigenin and luteolin have identical backbones to quercetin (Fig. 3.6A), we can infer that they have similar, or perhaps better, BBB permeability.

In Fig. 3.6B, we observed that off-patent RSK inhibitors, luteolin and apigenin, decreased cell viability in pediatric (SF188) and adult GBM (U251) cell lines at high concentrations. Fig. 3.6C suggests that the tumour cells are differentiating into astrocytes as indicated by glial fibrillary acidic protein (GFAP) positive staining. Differentiation therapy has been used to halt uncontrolled proliferation including retinoids used for acute promyelocytic leukemia (Brown and Hughes, 2012). In a previous study, we identified that YB-1 acts as a differentiation switch between GBM and astrocytes (Fotovati et al., 2011).

Our group has previously shown that TNBC cell lines rely on RSK and YB-1 (Reipas et al., 2013; Stratford et al., 2012). We screened SUM149 cells with the ChemieTek library, which replicated the decrease in cell viability (Fig. 3.6D) that has been published upon RSK inhibition. Thus, RSK inhibition has broad implications in other cancers. 
Resistance has emerged against SMO inhibitors and chemotherapy, thus it may arise against RSK inhibitors. Since RSK is at the distal end of the MAPK signaling pathway, it has a lower propensity of accumulating downstream mutations. A strategy to prevent resistance from occurring is to treat cancer similarly to AIDS and tuberculosis (Dye, 2009). Treatment involves cycles of different inhibitors at low doses to prevent or delay the onset of new disease, thus allowing patients to live life with a manageable disease.

In summary, this project has identified and established RSK as a novel target for MB. New RSK antagonists with increased delivery and stability will be required to pursue this therapeutic avenue. With the tight symbiosis between scientists and clinicians, RSK inhibitors are coming ever closer to translating to the bedside and ridding children of $\mathrm{MB}$. 


\subsection{FIGURES}

A.

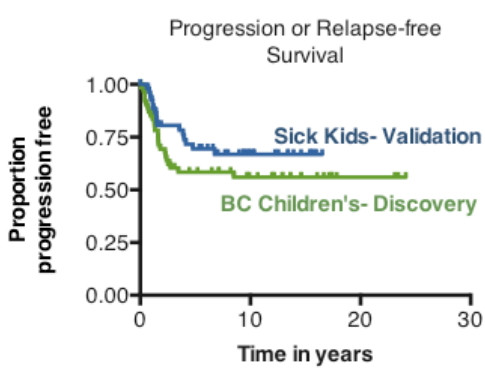

B.
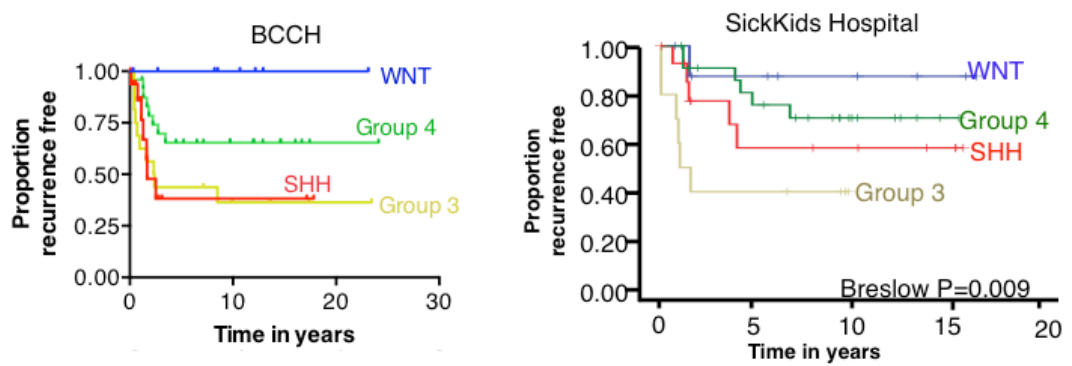

Figure 3.1 Relapse-free survival across MB. A) Kaplan-Meier curves representing recurrence free survival from BCCH $(n=65)$ and SickKids $(n=55)$. B) Kaplan-Meier survival curves depicting recurrence free survival across subtypes. The SHH subtype does as poorly as Group $3 \mathrm{MB}$ when it recurs at $\mathrm{BCCH}$, whereas Group 3 does worse than $\mathrm{SHH}$ at SickKids. Data provided by Joanna Triscott. 
A.

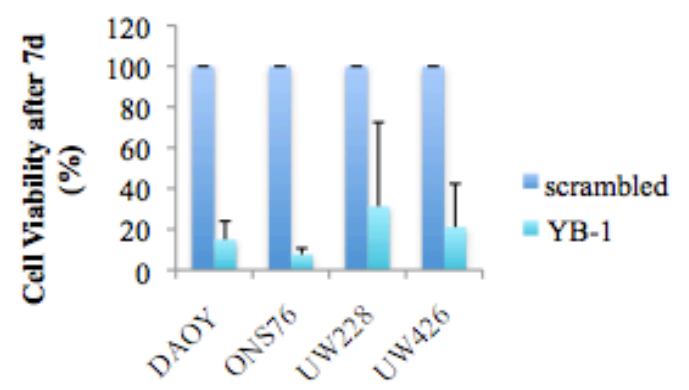

C.

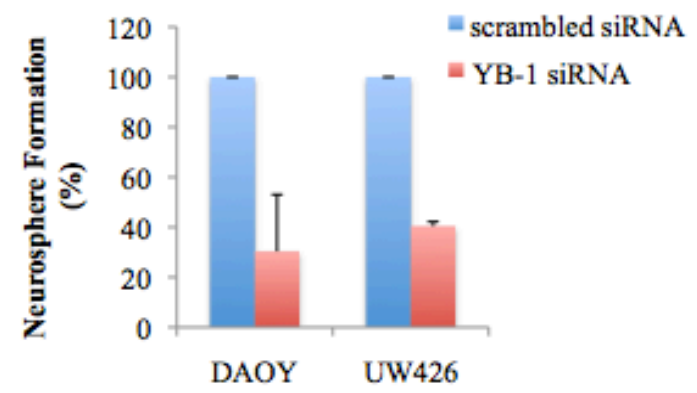

B.

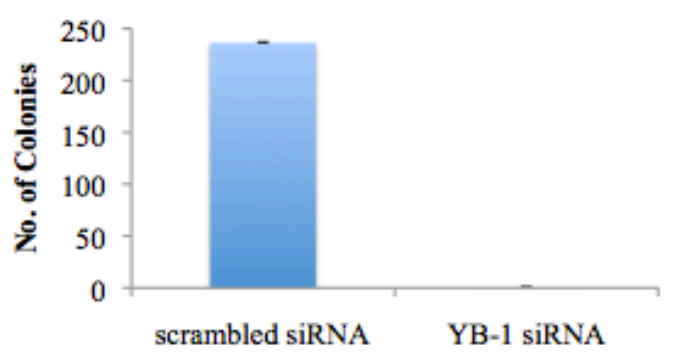

Figure 3.2 Effects of silencing YB-1 in SHH MB. A) SHH MB cell lines were treated with YB-1 siRNA for 7 days, which led to a decrease in cell viability. B) Daoy cells were treated with YB-1 siRNA for two days and then plated into the soft agar assay. No colonies were formed. C) Daoy and UW426 cells were treated with YB-1 siRNA for two days and then seeded into neurosphere assays. Through silencing YB-1, neurosphere formation decreased.

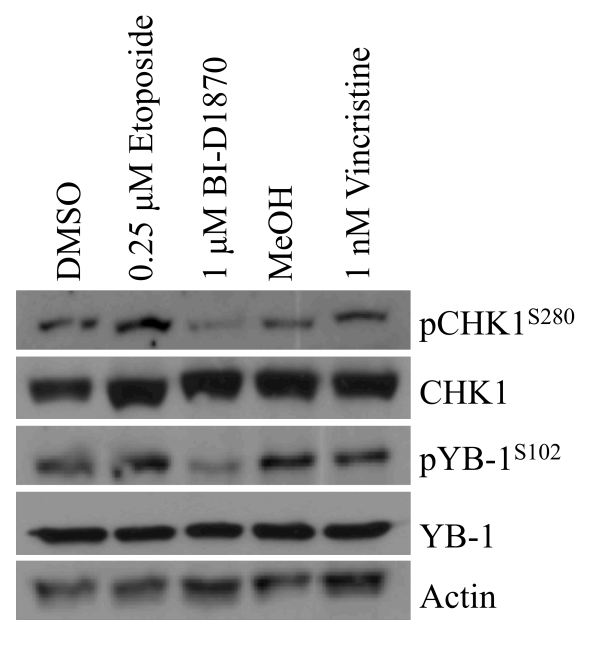

Figure 3.3 BI-D1870 and the DNA damage response. RSK-mediated phosphorylation and subsequent deactivation of CHK1 is inhibited by $1 \mu \mathrm{M}$ BI-D1870, whereas DNA damaging chemotherapeutics induced RSK to phosphorylate CHK1 to allow for checkpoint slippage and continued proliferation. 


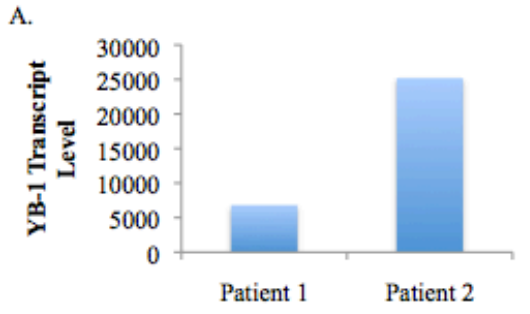

B.

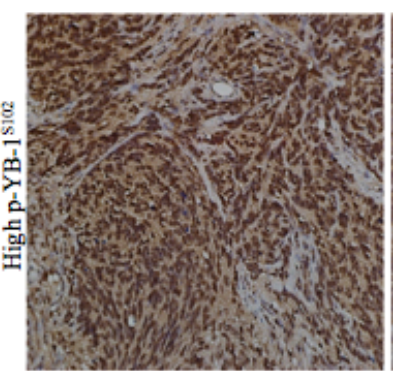

$1: 400$

$1: 600$
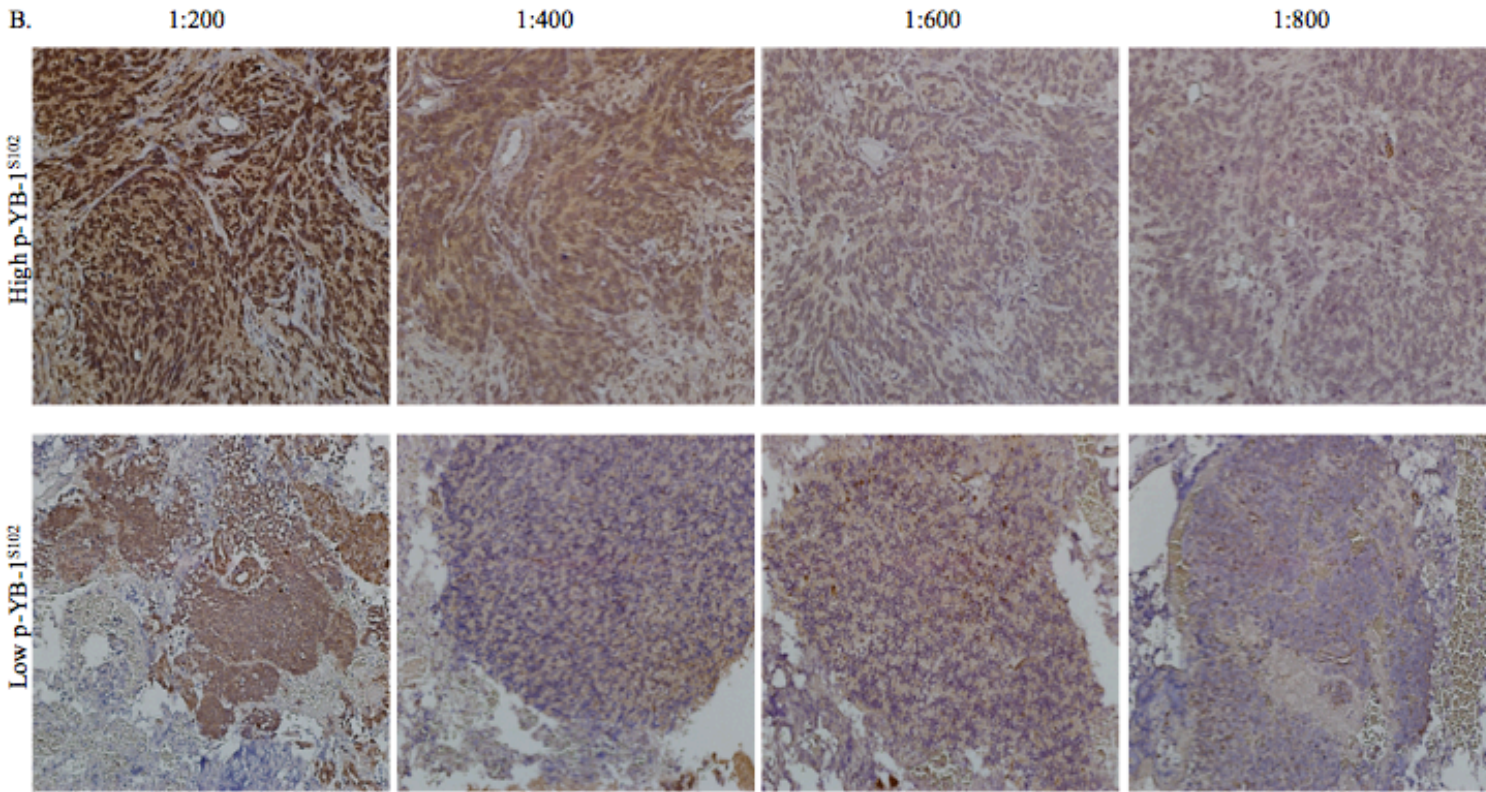

Figure 3.4 IHC optimization for future RSK inhibitor studies. A) YB-1 transcript levels of patient tumour sections from BCCH. B) The optimum pYB-1 ${ }^{\text {s102 }}$ antibody dilution from preliminary IHC is 1:200. Images are at 10x magnification. 

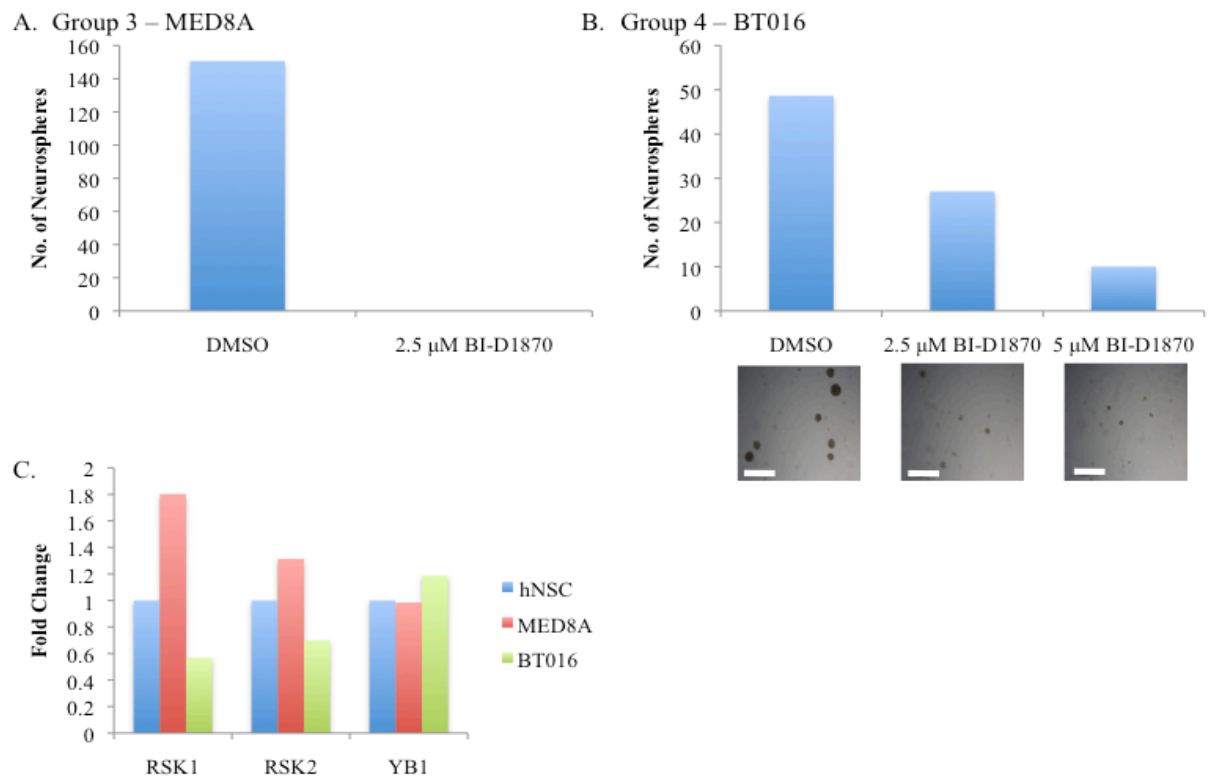

Figure 3.5 The efficacy of BI-D1870 in other MB subtypes. A) Group 3 cell line MED8A treated with $2.5 \mu \mathrm{M}$ BI-D1870 in neurosphere media prevents neurosphere formation after $7 \mathrm{~d}$. B) Primary Group 4 sample BT016 treated with range of BI-D1870 concentrations in neurosphere media curbing neurosphere formation after $7 \mathrm{~d}$. C) RSK and YB-1 levels in MED8A and BT016 cells via qRT-PCR. No error bars included as this data set was performed at $n=1$. 
A.

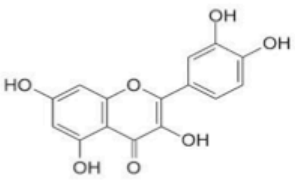

Quercetin

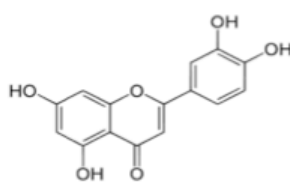

Luteolin

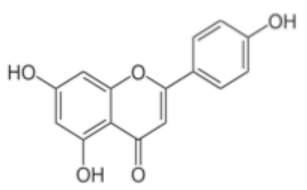

Apigenin

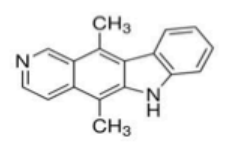

Ellipticine
B

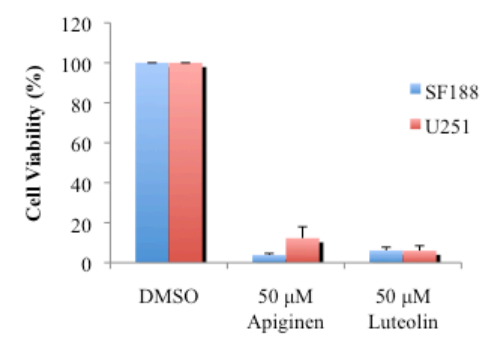

D.

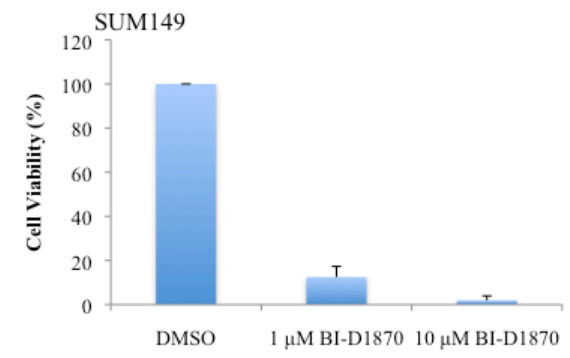

c.

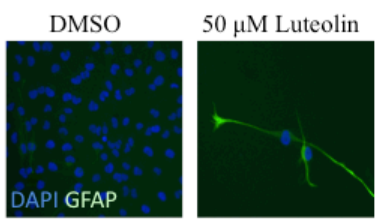

Figure 3.6 Broad implications of RSK inhibitors in other cancers. A) The structures of off-patent compounds that target RSK. B) Off-patent compounds, luteolin and apigenin, exert a strong inhibitory effect on adult and pediatric GBM cell lines after $72 \mathrm{~h}$. C) A change in morphology to a stellate form and staining positive for GFAP after $72 \mathrm{~h}$ of luteolin treatment in pediatric SF188 GBM cells indicates differentiation. D) Low concentrations of BI-D1870 inhibit the TNBC line SUM149 at low concentrations. 


\subsection{TABLES}

TABLE 3.1 ChemieTek screen of 129 small molecule inhibitors against SHH MB cell line Daoy and triple-negative breast cancer cell line SUM149. Y indicates $>70 \%$ growth inhibition at $1 \mu \mathrm{M}$.

\begin{tabular}{|c|c|c|c|}
\hline Target & Inhibitor & DAOY & SUM149 \\
\hline \multirow{2}{*}{ Akt } & GSK690693 & $\mathrm{N}$ & $\mathrm{N}$ \\
\hline & MK-2206 & $\mathrm{N}$ & $\mathrm{N}$ \\
\hline \multirow{3}{*}{ AURK } & AZD1152 & $\mathrm{Y}$ & $\mathrm{Y}$ \\
\hline & VX-680 & $\mathrm{Y}$ & Y \\
\hline & ZM447439 & $\mathrm{Y}$ & $\mathrm{Y}$ \\
\hline \multirow{2}{*}{ BCL-2 } & ABT-263 & $\mathrm{N}$ & $\mathrm{N}$ \\
\hline & ABT-737 & $\mathrm{N}$ & $\mathrm{N}$ \\
\hline \multirow{2}{*}{ B-Raf } & PLX4032 (Votrient) & $\mathrm{N}$ & $\mathrm{N}$ \\
\hline & PLX4720 & $\mathrm{N}$ & $\mathrm{N}$ \\
\hline \multirow{2}{*}{ CRTH2R } & TM30098 & $\mathrm{N}$ & $\mathrm{N}$ \\
\hline & Ramatroban (Bay u3405) & $\mathrm{N}$ & $\mathrm{N}$ \\
\hline \multirow{5}{*}{$\mathrm{cMET}$} & ARQ 197 (Tivatinib) & $\mathrm{Y}$ & $\mathrm{Y}$ \\
\hline & BMS-777607 & $\mathrm{N}$ & $\mathrm{N}$ \\
\hline & EMD1214063 & $\mathrm{N}$ & $\mathrm{N}$ \\
\hline & PF-04217903 & $\mathrm{N}$ & $\mathrm{N}$ \\
\hline & PF-2341066 & $\mathrm{N}$ & $\mathrm{N}$ \\
\hline \multirow{7}{*}{ HDAC } & LBH-589 (Panobinostat) & $\mathrm{Y}$ & $\mathrm{Y}$ \\
\hline & MGCD0103 & $\mathrm{N}$ & $\mathrm{Y}$ \\
\hline & Vorinostat (SAHA) & $\mathrm{N}$ & $\mathrm{N}$ \\
\hline & MS-275 & $\mathrm{N}$ & $\mathrm{N}$ \\
\hline & Tubacin & $\mathrm{N}$ & $\mathrm{N}$ \\
\hline & Tubastatin A & $\mathrm{N}$ & $\mathrm{N}$ \\
\hline & Belinostat (PXD101) & $\mathrm{N}$ & $\mathrm{N}$ \\
\hline \multirow{3}{*}{ HSP90 } & $17-\mathrm{AAG}$ & $\mathrm{Y}$ & $\mathrm{Y}$ \\
\hline & 17-DMAG & $\mathrm{Y}$ & $\mathrm{Y}$ \\
\hline & NVP-AUY922 (VER-52296) & $\mathrm{Y}$ & $\mathrm{Y}$ \\
\hline \multirow{2}{*}{ IGF1R } & OSI-906 & $\mathrm{N}$ & $\mathrm{N}$ \\
\hline & BMS-754807 & $\mathrm{N}$ & $\mathrm{N}$ \\
\hline \multirow{5}{*}{ JAK } & CP-690550 & $\mathrm{N}$ & $\mathrm{N}$ \\
\hline & AZD1480 & $\mathrm{N}$ & $\mathrm{N}$ \\
\hline & CYT-387 & $\mathrm{N}$ & $\mathrm{N}$ \\
\hline & INCB018424 (Ruxolitinib) & $\mathrm{N}$ & $\mathrm{N}$ \\
\hline & TG101348 & $\mathrm{N}$ & $\mathrm{N}$ \\
\hline
\end{tabular}




\begin{tabular}{|c|c|c|c|}
\hline Target & Inhibitor & DAOY & SUM149 \\
\hline \multirow{6}{*}{ MEK } & RDEA119 & $\mathrm{N}$ & $\mathrm{N}$ \\
\hline & AZD6244 (ARRY-142886) & $\mathrm{N}$ & $\mathrm{N}$ \\
\hline & ARRY-162 & $\mathrm{N}$ & $\mathrm{N}$ \\
\hline & GSK1120212 & $\mathrm{N}$ & $\mathrm{Y}$ \\
\hline & AS703026 (MSC1936369B) & $\mathrm{N}$ & $\mathrm{N}$ \\
\hline & PD0325901 & $\mathrm{N}$ & $\mathrm{N}$ \\
\hline \multirow{5}{*}{ mTOR } & Pp242 & $\mathrm{N}$ & $\mathrm{N}$ \\
\hline & Rapamycin (Sirolimus) & $\mathrm{Y}$ & $\mathrm{N}$ \\
\hline & AZD8055 & $\mathrm{N}$ & $\mathrm{N}$ \\
\hline & INK128 & $\mathrm{Y}$ & $\mathrm{N}$ \\
\hline & OSI-027 & $\mathrm{N}$ & $\mathrm{N}$ \\
\hline \multirow{4}{*}{ Nucleic acid synthesis } & Capecitabine (Xeloda) & $\mathrm{N}$ & $\mathrm{N}$ \\
\hline & Pemetrexed Disodium (Alimta) & $\mathrm{Y}$ & $\mathrm{Y}$ \\
\hline & Gemcitabine, $\mathrm{HCl}$ (Gemzar) & $\mathrm{Y}$ & $\mathrm{Y}$ \\
\hline & Doxorubicin (Adriamycin) & $\mathrm{Y}$ & Y \\
\hline \multirow{5}{*}{ PARP } & ABT-888 (Veliparib) & $\mathrm{N}$ & $\mathrm{N}$ \\
\hline & AZD 2281 (Olaparib) & $\mathrm{N}$ & $\mathrm{N}$ \\
\hline & BSI-201 (Iniparib) & $\mathrm{N}$ & $\mathrm{N}$ \\
\hline & AG014699 (PF-01367338) & $\mathrm{N}$ & $\mathrm{N}$ \\
\hline & MK- 4827 & $\mathrm{~N}$ & $\mathrm{~N}$ \\
\hline \multirow{3}{*}{ PDGFR } & Sunitinib & $\mathrm{N}$ & $\mathrm{N}$ \\
\hline & Tandutinib & $\mathrm{N}$ & $\mathrm{N}$ \\
\hline & Imatinib & $\mathrm{N}$ & $\mathrm{N}$ \\
\hline \multirow{8}{*}{ PI3K } & PIK-75, $\mathrm{HCl}$ & Y & Y \\
\hline & GDC-0941 & $\mathrm{N}$ & $\mathrm{N}$ \\
\hline & CAL-101 & $\mathrm{N}$ & $\mathrm{N}$ \\
\hline & LY294002 & $\mathrm{N}$ & $\mathrm{N}$ \\
\hline & PF-04691502 & $\mathrm{N}$ & $\mathrm{N}$ \\
\hline & TG100-115 & $\mathrm{N}$ & $\mathrm{N}$ \\
\hline & XL-147 & $\mathrm{N}$ & $\mathrm{N}$ \\
\hline & TGX-221 & $\mathrm{N}$ & $\mathrm{N}$ \\
\hline \multirow{3}{*}{ PLK } & BI2536 & $\mathrm{Y}$ & $\mathrm{Y}$ \\
\hline & BI6727 (Volasertib) & Y & $\mathrm{Y}$ \\
\hline & GSK461364 & $\mathrm{Y}$ & $\mathrm{Y}$ \\
\hline \multirow{2}{*}{ SMO } & GDC-0449 & $\mathrm{N}$ & $\mathrm{N}$ \\
\hline & NVP-LDE225 & $\mathrm{N}$ & $\mathrm{N}$ \\
\hline \multirow{2}{*}{ Src } & AZD05030 (Saracatinib) & $\mathrm{N}$ & $\mathrm{N}$ \\
\hline & Dasatanib & $\mathrm{N}$ & $\mathrm{N}$ \\
\hline
\end{tabular}




\begin{tabular}{|c|c|c|c|}
\hline Target & Inhibitor & DAOY & SUM149 \\
\hline \multirow{7}{*}{ VEGFR } & AV-951 (Tivozanib) & $\mathrm{N}$ & $\mathrm{N}$ \\
\hline & Axitinib (AG-013736) & $\mathrm{N}$ & $\mathrm{N}$ \\
\hline & Pazopanib (Votrient) & $\mathrm{N}$ & $\mathrm{N}$ \\
\hline & Motesanib (AMG-706) & $\mathrm{N}$ & $\mathrm{N}$ \\
\hline & XL-184 (Cabozantinib) & $\mathrm{N}$ & $\mathrm{N}$ \\
\hline & Vandetanib (Zactima) & $\mathrm{N}$ & $\mathrm{N}$ \\
\hline & Vatalanib Dihydrochloride & $\mathrm{N}$ & $\mathrm{N}$ \\
\hline \multirow{2}{*}{ Immunosuppressant } & FK-506 & $\mathrm{N}$ & $\mathrm{N}$ \\
\hline & FTY720, $\mathrm{HCl}$ & $\mathrm{N}$ & $\mathrm{N}$ \\
\hline \multirow{2}{*}{ EGFR } & Erlotinib, $\mathrm{HCl}$ & $\mathrm{N}$ & $\mathrm{N}$ \\
\hline & WZ4002 & $\mathrm{N}$ & $\mathrm{N}$ \\
\hline \multirow{2}{*}{ Proteasome } & Carfilzomib (PR-171) & $\mathrm{Y}$ & $\mathrm{Y}$ \\
\hline & Bortezomib (Velcade) & $\mathrm{Y}$ & $\mathrm{Y}$ \\
\hline \multirow{2}{*}{ Adenosine receptor } & CVT-6883 & $\mathrm{N}$ & $\mathrm{N}$ \\
\hline & CGS 21680 & $\mathrm{~N}$ & $\mathrm{~N}$ \\
\hline \multirow{3}{*}{ Topoisomerase } & Topotecan (Hycamtin) & $\mathrm{Y}$ & $\mathrm{Y}$ \\
\hline & SN-38 & Y & $\mathrm{Y}$ \\
\hline & Etoposide & $\mathrm{Y}$ & $\mathrm{Y}$ \\
\hline FGFR & AZD4547 & $\mathrm{N}$ & $\mathrm{N}$ \\
\hline HDAC/EGFR/HER2 & CUDC-101 & $\mathrm{N}$ & $\mathrm{Y}$ \\
\hline HER1/2, EGFR & Lapatinib & $\mathrm{N}$ & $\mathrm{N}$ \\
\hline AMPK & A-769662 & $\mathrm{N}$ & $\mathrm{N}$ \\
\hline FLT3 & AC220 (Quizartinib) & $\mathrm{N}$ & $\mathrm{N}$ \\
\hline Androgen receptor & Bicalutamide (Casodex) & $\mathrm{N}$ & $\mathrm{N}$ \\
\hline Immunomodulator & Lenalidomide (CC-5013) & $\mathrm{N}$ & $\mathrm{N}$ \\
\hline Protease & VX-950 (Telaprevir) & $\mathrm{N}$ & $\mathrm{N}$ \\
\hline Survivin suppressant & YM155 & $\mathrm{N}$ & $\mathrm{N}$ \\
\hline Phospholipase A2 & Varespladib (LY315920) & $\mathrm{N}$ & $\mathrm{N}$ \\
\hline ICE/Caspase 1 & VX-765 & $\mathrm{N}$ & $\mathrm{N}$ \\
\hline HIV integrase & Raltegravir & $\mathrm{N}$ & $\mathrm{N}$ \\
\hline $\mathrm{COX}-2$ & Rofecoxib (Vioxx) & $\mathrm{N}$ & $\mathrm{N}$ \\
\hline p38 MAPK & VX702 & $\mathrm{N}$ & $\mathrm{N}$ \\
\hline CDK & PD-0332991 & $\mathrm{N}$ & $\mathrm{N}$ \\
\hline HMG-CoA reductase & Atorvastatin Calcium (Lipitor) & $\mathrm{N}$ & $\mathrm{N}$ \\
\hline Cathepsin & Odanacatib (MK-0822) & $\mathrm{N}$ & $\mathrm{N}$ \\
\hline NPM-ALK & NVP-TAE684 & $\mathrm{N}$ & $\mathrm{N}$ \\
\hline $5 \alpha$ reductase & Dutasteride (Avodart) & $\mathrm{N}$ & $\mathrm{N}$ \\
\hline HER2 & BMS-599626 & $\mathrm{N}$ & $\mathrm{N}$ \\
\hline HER2/EGFR & BIBW 2992 (Tovok) & $\mathrm{N}$ & $\mathrm{N}$ \\
\hline
\end{tabular}




\begin{tabular}{|c|c|c|c|}
\hline Target & Inhibitor & DAOY & SUM149 \\
\hline EGFR & Gefitinib (Iressa) & N & N \\
\hline RAS/RAF & Sorafenib & N & N \\
\hline ERBB-R & Canertinib (CI-1033) & N & N \\
\hline ABL,SRC & Bosutinib (SKI-606) & N & N \\
\hline BCR-ABL & Nilotinib & N & N \\
\hline Tubulin & Docetaxel & Y & Y \\
\hline BCR-ABL & Ponatinib (AP24534) & N & N \\
\hline Multi kinase & Regorafenib (BAY 73-4506) & N & N \\
\hline AHR & SR1 & N & N \\
\hline LTR & Montelukast Sodium (Singulair) & Y & N \\
\hline CCR5 & Maraviroc (UK-427857) & N & N \\
\hline PDE4 & AN2728 & N & N \\
\hline PGD2R & Laropiprant & N & N \\
\hline Tubulin stabilizer & Paclitaxel (Taxol) & Y & Y \\
\hline RXR activator & Bexarotene (Targetrin) & N & N \\
\hline Angiotensin receptor & Eprosartan Mesylate (Teveten) & Y & N \\
\hline T cell activation & Hypothemycin & N & N \\
\hline Antihistamine & Dimebolin Hydrochloride & N & N \\
\hline p90 RSK & BI-D1870 & Y & Y \\
\hline
\end{tabular}




\section{REFERENCES}

Ahlfeld, J., Favaro, R., Pagella, P., Kretzschmar, H. A., Nicolis, S., and Schuller, U. (2013). Sox 2 requirement in Sonic hedgehog-associated medulloblastoma. Cancer Res, ePub.

Akinleye A., Furqan, M., Mukhi, N., Ravella, P., and Liu, D. (2013). MEK and the inhibitors: from bench to bedside. J Hematol Oncol 6, 27.

Anjum, R., and Blenis, J. (2008). The RSK family of kinases: emerging roles in cellular signalling. Nat Rev Mol Cell Biol 9, 747-758.

Astanehe, A., Finkbeiner, M. R., Hojabrpour, P., To, K., Fotovati, A., Shadeo, A., Stratford, A. L., Lam, W. L., Berquin, I. M., Duronio, V., and Dunn, S. E. (2009). The transcriptional induction of PIK3CA in tumour cells is dependent on the oncoprotein Ybox binding protein-1. Oncogene 28, 2406-2418.

Bailey, P., and Cushing, H. (1925). Medulloblastoma cerebelli. A common type of midcerebellar glioma of childhood. Arch Neurol Psychiatry 14, 192-224.

Bandopadhayay, P., Nguyen, B., Masoud, S., Vuc, N., Gholamin, S., Yu, F., Schubert, S., Bergthold, G., Mitra, S., Qi, J., et al. (2013). 0135. BET bromodomain inhibition of MYC-amplified medulloblastoma. Neuro-Oncology 15, i36.

Bartlett, F., Kortmann, R., and Saran, F. (2013). Medulloblastoma. Clin Oncol (R Coll Radiol) 25, 36-45.

Bastida, M.F., Sheth R., and Ros, M.A. (2009). A BMP-Shh negative-feedback loop restricts $S h h$ expression during limb development. Development 136, 3779-3789.

Bei, R., Marzocchella, L., and Turriziani, M. (2010). The use of temozolomide for the treatment of malignant tumours: clinical evidence and molecular mechanisms of action. Recent Pat Anticancer Drug Discov 5, 172-187.

Bignone, P. A., Lee, K. Y., Liu, Y., Emilion, G., Finch, J., Soosay, A. E., Charnock, F. M., Beck, S., Dunham, I., Mungall, A. J., and Ganesan, T. S. (2007). RPS6KA2, a putative tumour suppressor gene at $6 \mathrm{q} 27$ in sporadic epithelial ovarian cancer. Oncogene 26, 683-700.

Brown, G., and Hughes, P. (2012). Retinoid differentiation therapy for common types of acute myeloid leukemia. Leuk Res Treatment, ePub.

Brugieres, L., Remenieras, A., Pierron, G., Varlet, P., Forget, S., Byrde, V., Bombled, J., Puget, S., Caron, O., Dufour, C., et al. (2012). High frequency of germline SUFU 
mutations in children with desmoplastic/nodular medulloblastoma younger than 3 years of age. J Clin Oncol 30, 2087-2093.

Buonamici, S., Williams, J., Morrissey, M., Wang, A., Guo, R., Vattay, A., Hsiao, K., Yuan, J., Green, J., Ospina, B., et al. (2010). Interfering with resistance to smoothened antagonists by inhibition of the PI3K pathway in medulloblastoma. Sci Transl Med 2, 5170 .

Cargnello, M., and Roux, P. P. (2011). Activation and function of the MAPKs and their substrates, the MAPK-activated protein kinases. Microbiol Mol Biol Rev 75, 50-83.

Castedo, M., Coquelle, A., Vitale, I., Vivet, S., Mouhamad, S., Viaud, S., Zitvogel, L., and Kroemer, G. (2006). Selective resistance of tetraploid cancer cells against DNA damage-induced apoptosis. Ann N Y Acad Sci 1090, 35-49.

Cecchelli, R., Berezowski, V., Lundquist, S., Culot, M., Renftel, M., Dehouck, M. P., and Fenart, L. (2007). Modelling of the blood-brain barrier in drug discovery and development. Nat Rev Drug Discov 6, 650-661.

Cho, Y. J., Tsherniak, A., Tamayo, P., Santagata, S., Ligon, A., Greulich, H., Berhoukim, R., Amani, V., Goumnerova, L., Eberhart, C. G., et al. (2011). Integrative genomic analysis of medulloblastoma identifies a molecular subgroup that drives poor clinical outcome. J Clin Oncol 29, 1424-1430.

Clifford, S., Gustafsson, G., Ellison, D., Figarella-Branger, D., Doz, F., Rutkowski, S., Lannering, B., and Pietsch, T. (2013). 0047. Biomarker-driven stratification of diseaserisk in non-metastatic medulloblastoma: the SIOP-Europe PNET4 clinical trial. NeuroOncology 15, i11.

Clifford, S. C., Lusher, M. E., Lindsey, J. C., Langdon, J. A., Gilbertson, R. J., Straughton, D., and Ellison, D. W. (2006). Wnt/Wingless pathway activation and chromosome 6 loss characterize a distinct molecular sub-group of medulloblastomas associated with a favorable prognosis. Cell Cycle 5, 2666-2670.

Cross, D. A., Alessi, D. R., Cohen, P., Andjelkovich, M., and Hemmings, B. A. (1995). Inhibition of glycogen synthase kinase-3 by insulin mediated by protein kinase B. Nature 378, 785-789.

Dhall, G., Grodman, H., Ji, L., Sands, S., Gardner, S., Dunkel, I. J., McCowage, G. B., Diez, B., Allen, J. C., Gopalan, A., et al. (2008). Outcome of children less than three years old at diagnosis with non-metastatic medulloblastoma treated with chemotherapy on the "Head Start" I and II protocols. Pediatr Blood Cancer 50, 1169-1175.

Dijkgraaf, G. J., Alicke, B., Weinmann, L., Januario, T., West, K., Modrusan, Z., Burdick, D., Goldsmith, R., Robarge, K., Sutherlin, D., et al. (2011). Small molecule 
inhibition of GDC-0449 refractory smoothened mutants and downstream mechanisms of drug resistance. Cancer Res 71, 435-444.

Doucette, T. A., Yang, Y., Pedone, C., Kim, J. Y., Dubuc, A., Northcott, P. D., Taylor, M. D., Fults, D. W., and Rao, G. (2012). WIP1 enhances tumour formation in a sonic hedgehog-dependent model of medulloblastoma. Neurosurgery 70, 1003-1010.

Dugani, C. B., Paquin, A., Kaplan, D. R., and Miller, F. D. (2010). Coffin-Lowry syndrome: a role for RSK2 in mammalian neurogenesis. Dev Biol 347, 348-359.

Dye, C. (2009). Doomsday postponed? Preventing and reversing epidemics of drugresistant tuberculosis. Nat Rev Microbiol 7, 81-87.

Eberhart, C. G., Tihan, T., and Burger, P. C. (2000). Nuclear localization and mutation of beta-catenin in medulloblastomas. J Neuropathol Exp Neurol 59, 333-337.

Ellison, D. W., Dalton, J., Kocak, M., Nicholson, S. L., Fraga, C., Neale, G., Kenney, A. M., Brat, D. J., Perry, A., Yong, W. H., et al. (2011). Medulloblastoma:

clinicopathological correlates of SHH, WNT, and non-SHH/WNT molecular subgroups. Acta Neuropathol 121, 381-396.

Ellison, D. W., Onilude, O. E., Lindsey, J. C., Lusher, M. E., Weston, C. L., Taylor, R. E., Pearson, A. D., and Clifford, S. C. (2005). beta-Catenin status predicts a favorable outcome in childhood medulloblastoma: the United Kingdom Children's Cancer Study Group Brain Tumour Committee. J Clin Oncol 23, 7951-7957.

Evans, D. G., Farndon, P. A., Burnell, L. D., Gattamaneni, H. R., and Birch, J. M. (1991). The incidence of Gorlin syndrome in 173 consecutive cases of medulloblastoma. $\mathrm{Br} \mathrm{J}$ Cancer 64, 959-961.

Finkbeiner, M. R., Astanehe, A., To, K., Fotovati, A., Davies, A. H., Zhao, Y., Jiang, H., Stratford, A. L., Shadeo, A., Boccaccio, C., et al. (2009). Profiling YB-1 target genes uncovers a new mechanism for MET receptor regulation in normal and malignant human mammary cells. Oncogene 28, 1421-1431.

Forment, J. V., Kaidi, A., and Jackson, S. P. (2012). Chromothripsis and cancer: causes and consequences of chromosome shattering. Nat Rev Cancer 12, 663-670.

Fotovati, A., Abu-Ali, S., Wang, P. S., Deleyrolle, L. P., Lee, C., Triscott, J., Chen, J. Y., Franciosi, S., Nakamura, Y., Sugita, Y., et al. (2011). YB-1 bridges neural stem cells and brain tumour-initiating cells via its roles in differentiation and cell growth. Cancer Res 71, 5569-5578.

Fryer, R. M., Muthukumarana, A., Chen, R. R., Smith, J. D., Mazurek, S. N., Harrington, K. E., Dinallo, R. M., Burke, J., DiCapua, F. M., Guo, X., et al. (2012). Mitigation of off- 
target adrenergic binding and effects on cardiovascular function in the discovery of novel ribosomal S6 kinase 2 inhibitors. J Pharmacol Exp Ther 340, 492-500.

Fuccillo, M., Joyner, A. L., and Fishell, G. (2006). Morphogen to mitogen: the multiple roles of hedgehog signalling in vertebrate neural development. Nat Rev Neurosci 7, 772783.

Gabathuler, R. (2010). Approaches to transport therapeutic drugs across the blood-brain barrier to treat brain diseases. Neurobiol Dis 37, 48-57.

Gajjar, A., Packer, R. J., Foreman, N. K., Cohen, K., Haas-Kogan, D., and Merchant, T. E. (2012). Children's Oncology Group's 2013 blueprint for research: Central nervous system tumours. Pediatr Blood Cancer 60, 1022-1026.

Gibson, P., Tong, Y., Robinson, G., Thompson, M. C., Currle, D. S., Eden, C., Kranenburg, T. A., Hogg, T., Poppleton, H., Martin, J., et al. (2010). Subtypes of medulloblastoma have distinct developmental origins. Nature 468, 1095-1099.

Goodrich, L. V., Milenkovic, L., Higgins, K. M., and Scott, M. P. (1997). Altered neural cell fates and medulloblastoma in mouse patched mutants. Science 277, 1109-1113.

Gottesman, M. M., Fojo, T., and Bates, S. E. (2002). Multidrug resistance in cancer: role of ATP-dependent transporters. Nat Rev Cancer 2, 48-58.

Grammel, D., Warmuth-Metz, M., von Bueren, A. O., Kool, M., Pietsch, T., Kretzschmar, H. A., Rowitch, D. H., Rutkowski, S., Pfister, S. M., and Schuller, U. (2012). Sonic hedgehog-associated medulloblastoma arising from the cochlear nuclei of the brainstem. Acta Neuropathol 123, 601-614.

Hamilton, S. R., Liu, B., Parsons, R. E., Papadopoulos, N., Jen, J., Powell, S. M., Krush, A. J., Berk, T., Cohen, Z., Tetu, B., et al. (1995). The molecular basis of Turcot's syndrome. N Engl J Med 332, 839-847.

Hanahan, D., and Weinberg, R. A. (2011). Hallmarks of cancer: the next generation. Cell 144, 646-674.

Hatton, B. A., Villavicencio, E. H., Tsuchiya, K. D., Pritchard, J. I., Ditzler, S., Pullar, B., Hansen, S., Knoblaugh, S. E., Lee, D., Eberhart, C. G., et al. (2008). The Smo/Smo model: hedgehog-induced medulloblastoma with $90 \%$ incidence and leptomeningeal spread. Cancer Res 68, 1768-1776.

Hilinski, M. K., Mrozowski, R. M., Clark, D. E., and Lannigan, D. A. (2012). Analogs of the RSK inhibitor SL0101: optimization of in vitro biological stability. Bioorg Med Chem Lett 22, 3244-3247. 
Huse, J. T., and Holland, E. C. (2010). Targeting brain cancer: advances in the molecular pathology of malignant glioma and medulloblastoma. Nat Rev Cancer 10, 319-331.

Hyman, J. M., Firestone, A. J., Heine, V. M., Zhao, Y., Ocasio, C. A., Han, K., Sun, M., Rack, P. G., Sinha, S., Wu, J. J., et al. (2009). Small-molecule inhibitors reveal multiple strategies for Hedgehog pathway blockade. Proc Natl Acad Sci U S A 106, 14132-14137.

Kawauchi, D., Robinson, G., Uziel, T., Gibson, P., Rehg, J., Gao, C., Finkelstein, D., Qu, C., Pounds, S., Ellison, D. W., et al. (2012). A mouse model of the most aggressive subgroup of human medulloblastoma. Cancer Cell 21, 168-180.

Keller, P. J., Lin, A. F., Arendt, L. M., Klebba, I., Jones, A. D., Rudnick, J. A., DiMeo, T. A., Gilmore, H., Jefferson, D. M., Graham, R. A., et al. (2010). Mapping the cellular and molecular heterogeneity of normal and malignant breast tissues and cultured cell lines. Breast Cancer Res 12, R87.

Kieran, M. W., Walker, D., Frappaz, D., and Prados, M. (2010). Brain tumours: from childhood through adolescence into adulthood. J Clin Oncol 28, 4783-4789.

Kim, J., Aftab, B. T., Tang, J. Y., Kim, D., Lee, A. H., Rezaee, M., Chen, B., King, E. M., Borodovsky, A., Riggins, G. J., et al. (2013). Itraconazole and arsenic trioxide inhibit Hedgehog pathway activation and tumour growth associated with acquired resistance to smoothened antagonists. Cancer Cell 23, 23-34.

Kim, J., Kato, M., and Beachy, P. A. (2009). Gli2 trafficking links Hedgehog-dependent activation of Smoothened in the primary cilium to transcriptional activation in the nucleus. Proc Natl Acad Sci U S A 106, 21666-21671.

Kimura, H., Ng, J. M., and Curran, T. (2008). Transient inhibition of the Hedgehog pathway in young mice causes permanent defects in bone structure. Cancer Cell 13, 249260.

Kool, M., Jones, D. T. W., Jaeger, N., Northcott, P. A., Pugh, T., Hovestadt, V., Markant, S. L., Esparza, L. A., Bourdeaut, F., Remke, M., et al. (2013). 0041. Genome sequencing of SHH medulloblastoma predicts age-dependent response to smoothened-inhibition and rational therapeutic combinations. Neuro-Oncology $15, \mathrm{i} 10$.

Kool, M., Korshunov, A., Remke, M., Jones, D. T., Schlanstein, M., Northcott, P. A., Cho, Y. J., Koster, J., Schouten-van Meeteren, A., van Vuurden, D., et al. (2012).

Molecular subgroups of medulloblastoma: an international meta-analysis of transcriptome, genetic aberrations, and clinical data of WNT, SHH, Group 3, and Group 4 medulloblastomas. Acta Neuropathol 123, 473-484.

Lauth, M., Bergstrom, A., Shimokawa, T., and Toftgard, R. (2007). Inhibition of GLImediated transcription and tumour cell growth by small-molecule antagonists. Proc Natl Acad Sci U S A 104, 8455-8460. 
Lee, C., Triscott, J., Foster, C., Manoranjan, B., Pambid, M. R., Fotovati, A., Berns, R., Venugopal, C., O'Hallaran, K., Narendran, A., et al. (2013). 0012. Personalizing the treatment for medulloblastoma: polo-like kinase 1 (PLK1) as a molecular target for the sonic hedgehog (SHH) subtype. Neuro-Oncology 15, i2.

Lee, C., Fotovati, A., Triscott, J., Chen, J., Venugopal, C., Singhal, A., Dunham, C., Kerr, J. M., Verreault, M., Yip, S., et al. (2012). Polo-like kinase 1 inhibition kills glioblastoma multiforme brain tumour cells in part through loss of SOX2 and delays tumour progression in mice. Stem Cells 30, 1064-1075.

Li, P., Goto, H., Kasahara, K., Matsuyama, M., Wang, Z., Yatabe, Y., Kiyono, T., and Inagaki, M. (2012). P90 RSK arranges Chk1 in the nucleus for monitoring of genomic integrity during cell proliferation. Mol Biol Cell 23, 1582-1592.

Lin, T. L., and Matsui, W. (2012). Hedgehog pathway as a drug target: Smoothened inhibitors in development. Onco Targets Ther 5, 47-58.

Lindsey, J. C., Hill, R. M., Megahed, H., Lusher, M. E., Schwalbe, E. C., Cole, M., Hogg, T. L., Gilbertson, R. J., Ellison, D. W., Bailey, S., and Clifford, S. C. (2011). TP53 mutations in favorable-risk Wnt/Wingless-subtype medulloblastomas. J Clin Oncol 29, e344-346; author reply e347-348.

Liu, Z., Li, T., Reinhold, M. I., and Naski, M. C. (2012). MEK1-RSK2 contributes to hedgehog signaling by stabilizing GLI2 transcription factor and inhibiting ubiquitination. Oncogene, ePub.

Loscher, W., and Potschka, H. (2005). Drug resistance in brain diseases and the role of drug efflux transporters. Nat Rev Neurosci 6, 591-602.

Louis, D. N., Ohgaki, H., Wiestler, O. D., Cavenee, W. K., Burger, P. C., Jouvet, A., Scheithauer, B. W., and Kleihues, P. (2007). The 2007 WHO classification of tumours of the central nervous system. Acta Neuropathol 114, 97-109.

MacDonald, T. J., Brown, K. M., LaFleur, B., Peterson, K., Lawlor, C., Chen, Y., Packer, R. J., Cogen, P., and Stephan, D. A. (2001). Expression profiling of medulloblastoma:

PDGFRA and the RAS/MAPK pathway as therapeutic targets for metastatic disease. Nat Gen 29, 143-152.

Mahringer, A., Ott, M., Reimold, I., Reichel, V., and Fricker, G. (2011). The ABC of the blood-brain barrier - regulation of drug efflux pumps. Curr Pharm Des 17, 2762-2770.

Mangelberger, D., Kern, D., Loipetzberger, A., Eberl, M., and Aberger, F. (2012).

Cooperative Hedgehog-EGFR signaling. Front Biosci 17, 90-99. 
Manoranjan, B., Venugopal, C., McFarlane, N., Doble, B. W., Dunn, S. E., Scheinemann, K., and Singh, S. K. (2012). Medulloblastoma stem cells: where development and cancer cross pathways. Pediatr Res 71, 516-522.

Manoranjan, B., Wang, X., Hallett, R. M., Venugopal, C., Mack, S. C., McFarlane, N., Nolte, S. M., Scheinemann, K., Gunnarsson, T., Hassell, J. A., et al. (2013). FoxG1 interacts with Bmil to regulate self-renewal and tumorigenecity of medulloblastoma stem cells. Stem Cells, ePub.

Marks, A. M., and Packer, R. J. (2012). A review of secondary central nervous system tumours after treatment of a primary pediatric malignancy. Semin Pediatr Neurol 19, 4348.

Massimino, M., Casanova, M., Polastri, D., Biassoni, V., Modena, P., Pecori, E., Schiavello, E., De Pava, M. V., Indini, A., Rampini, P., et al. (2013). Relapse in medulloblastoma: what can be done after abandoning high-dose chemotherapy? A monoinstitutional experience. Childs Nerv Syst, ePub.

Mendrzyk, F., Radlwimmer, B., Joos, S., Kokocinski, F., Benner, A., Stange, D. E., Neben, K., Fiegler, H., Carter, N. P., Reifenberger, G., et al. (2005). Genomic and protein expression profiling identifies CDK6 as novel independent prognostic marker in medulloblastoma. J Clin Oncol 23, 8853-8862.

Mrozowski, R. M., Vemula, R., Wu, B., Zhang, Q., Schroeder, B. R., Hilinski, M. K., Clark, D. E., Hecht, S. M., O'Doherty, G. A., and Lannigan, D. A. (2012). Improving the affinity of SL0101 for RSK using structure-based design. ACS Med Chem Lett 4, 175 179.

Ng, J. M., and Curran, T. (2011). The Hedgehog's tale: developing strategies for targeting cancer. Nat Rev Cancer 11, 493-501.

Nguyen, T. L. (2008). Targeting RSK: an overview of small molecule inhibitors. Anticancer Agents Med Chem 8, 710-716.

Northcott, P. A., Jones, D. T., Kool, M., Robinson, G. W., Gilbertson, R. J., Cho, Y. J., Pomeroy, S. L., Korshunov, A., Lichter, P., Taylor, M. D., and Pfister, S. M. (2012a). Medulloblastomics: the end of the beginning. Nat Rev Cancer 12, 818-834.

Northcott, P. A., Korshunov, A., Witt, H., Hielscher, T., Eberhart, C. G., Mack, S., Bouffet, E., Clifford, S. C., Hawkins, C. E., French, P., et al. (2011). Medulloblastoma comprises four distinct molecular variants. J Clin Oncol 29, 1408-1414.

Northcott, P. A., Nakahara, Y., Wu, X., Feuk, L., Ellison, D. W., Croul, S., Mack, S., Kongkham, P. N., Peacock, J., Dubuc, A., et al. (2009). Multiple recurrent genetic events converge on control of histone lysine methylation in medulloblastoma. Nat Genet 41, 465-472. 
Northcott, P. A., Shih, D. J., Peacock, J., Garzia, L., Morrissy, A. S., Zichner, T., Stutz, A. M., Korshunov, A., Reimand, J., Schumacher, S. E., et al. (2012b). Subgroup-specific structural variation across 1,000 medulloblastoma genomes. Nature 488, 49-56.

Northcott, P. A., Shih, D. J., Remke, M., Cho, Y. J., Kool, M., Hawkins, C., Eberhart, C. G., Dubuc, A., Guettouche, T., Cardentey, Y., et al. (2012c). Rapid, reliable, and reproducible molecular sub-grouping of clinical medulloblastoma samples. Acta Neuropathol 123, 615-626.

Packer, R. J., and Vezina, G. (2008). Management of and prognosis with medulloblastoma: therapy at a crossroads. Arch Neurol 65, 1419-1424.

Parsons, D. W., Li, M., Zhang, X., Jones, S., Leary, R. J., Lin, J. C., Boca, S. M., Carter, H., Samayoa, J., Bettegowda, C., et al. (2011). The genetic landscape of the childhood cancer medulloblastoma. Science 331, 435-439.

Pei, Y., Moore, C. E., Wang, J., Tewari, A. K., Eroshkin, A., Cho, Y. J., Witt, H., Korshunov, A., Read, T. A., Sun, J. L., et al. (2012). An animal model of MYC-driven medulloblastoma. Cancer Cell 21, 155-167.

Pereira, P. M., Schneider, A., Pannetier, S., Heron, D., and Hanauer A. (2010). CoffinLowry syndrome. Eur J Hum Gen 18, 627-633.

Pfaff, E., Remke, M., Sturm, D., Benner, A., Witt, H., Milde, T., von Bueren, A. O., Wittmann, A., Schottler, A., Jorch, N., et al. (2010). TP53 mutation is frequently associated with CTNNB1 mutation or MYCN amplification and is compatible with longterm survival in medulloblastoma. J Clin Oncol 28, 5188-5196.

Pietsch, T., Waha, A., Koch, A., Kraus, J., Albrecht, S., Tonn, J., Sorensen, N., Berthold, F., Henk, B., Schmandt, N., et al. (1997). Medulloblastomas of the desmoplastic variant carry mutations of the human homologue of Drosophila patched. Cancer Res 57, 20852088.

Pillai, S., Metrie, M., Dunham, C., Sargent, M., Hukin, J., and Steinbok, P. (2012). Intracranial tumors in infants: long-term functional outcome, survival, and its predictors. Childs Nerv Syst 28, 547-555.

Polkinghorn, W. R., and Tarbell, N. J. (2007). Medulloblastoma: tumourigenesis, current clinical paradigm, and efforts to improve risk stratification. Nat Clin Pract Oncol 4, 295304.

Pollack, I. F., and Jakacki, R. I. (2011). Childhood brain tumours: epidemiology, current management and future directions. Nat Rev Neurol 7, 495-506.

Premsrirut, P. K., Dow, L. E., Kim, S. Y., Camiolo, M., Malone, C. D., Miething, C., Scuoppo, C., Zuber, J., Dickins, R. A., Kogan, S. C., et al. (2011). A rapid and scalable 
system for studying gene function in mice using conditional RNA interference. Cell 145 , 145-158.

Pugh, T. J., Weeraratne, S. D., Archer, T. C., Pomeranz Krummel, D. A., Auclair, D., Bochicchio, J., Carneiro, M. O., Carter, S. L., Cibulskis, K., Erlich, R. L., et al. (2012). Medulloblastoma exome sequencing uncovers subtype-specific somatic mutations. Nature 488, 106-110.

Ramaswamy, V., Remke, M., Bouffet, E., Faria, C., Shih, D., Gururangan, S., McLendon, R., Schuller, U., Ligon, K., Pomeroy, S., et al. (2013). 0085. Subgroup specific patterns of recurrence in medulloblastoma. Neuro-Oncology, 15, i22.

Rausch, T., Jones, D. T., Zapatka, M., Stutz, A. M., Zichner, T., Weischenfeldt, J., Jager, N., Remke, M., Shih, D., Northcott, P. A., et al. (2012). Genome sequencing of pediatric medulloblastoma links catastrophic DNA rearrangements with TP53 mutations. Cell 148, $59-71$.

Rautio, J., Kumpulainen, H., Heimbach, T., Oliyai, R., Oh, D., Jarvinen, T., and Savolainen, J. (2008). Prodrugs: design and clinical applications. Nat Rev Drug Discov 7 , 255-270.

Ray-David, H., Romeo, Y., Lavoie, G., Deleris, P., Tcherkezian, J., Galan, J. A., and Roux, P. P. (2012). RSK promotes G2 DNA damage checkpoint silencing and participates in melanoma chemoresistance. Oncogene, ePub.

Reipas, K. M., Law, J. H., Couto, N., Islam, S., Li, Y., Li, H., Cherkasov, A., Jung, K., Cheema, A. S., Jones, S. J., et al. (2013). Luteolin is a novel p90 ribosomal S6 kinase (RSK) inhibitor that suppresses Notch4 signaling by blocking the activation of Y-box binding protein-1 (YB-1). Oncotarget 4, 329-345.

Remke, M., Cavalli, F. M. G., Northcott, P. A., Kool, M., Pfister, S. M., Taylor, M. D., and M.A.G.I.C. (2013). 0144. Integrative clustering reveals four clinically and molecularly distinct subtypes of SHH medulloblastoma. Neuro-Oncology 15, i39.

Remke, M., Hielscher, T., Korshunov, A., Northcott, P. A., Bender, S., Kool, M., Westermann, F., Benner, A., Cin, H., Ryzhova, M., et al. (2011). FSTL5 is a marker of poor prognosis in non-WNT/non-SHH medulloblastoma. J Clin Oncol 29, 3852-3861.

Robinson, G., Parker, M., Kranenburg, T. A., Lu, C., Chen, X., Ding, L., Phoenix, T. N., Hedlund, E., Wei, L., Zhu, X., et al. (2012). Novel mutations target distinct subgroups of medulloblastoma. Nature 488, 43-48.

Romeo, Y., Zhang, X., and Roux, P. P. (2012). Regulation and function of the RSK family of protein kinases. Biochem J 441, 553-569. 
Rudin, C. M., Hann, C. L., Laterra, J., Yauch, R. L., Callahan, C. A., Fu, L., Holcomb, T., Stinson, J., Gould, S. E., Coleman, B., et al. (2009). Treatment of medulloblastoma with hedgehog pathway inhibitor GDC-0449. N Engl J Med 361, 1173-1178.

Sahebjam, S., Siu, L. L., and Razak, A. A. (2012). The utility of hedgehog signaling pathway inhibition for cancer. Oncologist 17, 1090-1099.

Samkari, A., Hwang, E., and Packer, R. J. (2012). Medulloblastoma/Primitive neuroectodermal tumour and germ cell tumours: the uncommon but potentially curable primary brain tumours. Hematol Oncol Clin North Am 26, 881-895.

Sapkota, G. P., Cummings, L., Newell, F. S., Armstrong, C., Bain, J., Frodin, M., Grauert, M., Hoffmann, M., Schnapp, G., Steegmaier, M., et al. (2007). BI-D1870 is a specific inhibitor of the p90 RSK (ribosomal S6 kinase) isoforms in vitro and in vivo. Biochem J 401, 29-38.

Schnidar, H., Eberl, M., Klingler, S., Mangelberger, D., Kasper, M., Hauser-Kronberger, C., Regl, G., Kroismayr, R., Moriggl, R., Sibilia, M., and Aberger, F. (2009). Epidermal growth factor receptor signaling synergizes with Hedgehog/GLI in oncogenic transformation via activation of the MEK/ERK/JUN pathway. Cancer Res 69, 12841292.

Schuller, U., Heine, V. M., Mao, J., Kho, A. T., Dillon, A. K., Han, Y. G., Huillard, E., Sun, T., Ligon, A. H., Qian, Y., et al. (2008). Acquisition of granule neuron precursor identity is a critical determinant of progenitor cell competence to form Shh-induced medulloblastoma. Cancer Cell 14, 123-134.

Scotting, P. J., Walker, D. A., and Perilongo, G. (2005). Childhood solid tumours: a developmental disorder. Nat Rev Cancer 5, 481-488.

Serra, V., Eichhorn, P. J., Garcia-Garcia, C., Ibrahim, Y. H., Prudkin, L., Sanchez, G., Rodriguez, O., Anton, P., Parra, J. L., Marlow, S., et al. (2013). RSK3/4 mediate resistance to PI3K pathway inhibitors in breast cancer. J Clin Invest 123, 2551-2563.

Shahi, M. H., Rey, J. A., and Castresana, J. S. (2012). The sonic hedgehog-GLI1 signaling pathway in brain tumour development. Expert Opin Ther Targets 16, 12271238.

Siegel, R., Naishadham, D., and Jemal, A. (2013). Cancer statistics, 2013. CA Cancer J Clin 63, 11-30.

Slade, I., Murray, A., Hanks, S., Kumar, A., Walker, L., Hargrave, D., Douglas, J., Stiller, C., Izatt, L., and Rahman, N. (2011). Heterogeneity of familial medulloblastoma and contribution of germline PTCH1 and SUFU mutations to sporadic medulloblastoma. Fam Cancer 10, 337-342. 
Stockholm, D., Benchaouir, R., Picot, J., Rameau, P., Neildez, T. M., Landini, G., Laplace-Builhe, C., and Paldi, A. (2007). The origin of phenotypic heterogeneity in a clonal cell population in vitro. PLoS One 2, e394.

Stratford, A. L., Fry, C. J., Desilets, C., Davies, A. H., Cho, Y. Y., Li, Y., Dong, Z., Berquin, I. M., Roux, P. P., and Dunn, S. E. (2008). Y-box binding protein-1 serine 102 is a downstream target of p90 ribosomal S6 kinase in basal-like breast cancer cells. Breast Cancer Res 10, R99.

Stratford, A. L., Reipas, K., Hu, K., Fotovati, A., Brough, R., Frankum, J., Takhar, M., Watson, P., Ashworth, A., Lord, C. J., et al. (2012). Targeting p90 ribosomal S6 kinase eliminates tumour-initiating cells by inactivating Y-box binding protein-1 in triplenegative breast cancers. Stem Cells 30, 1338-1348.

Sun, Y., Cao, S., Yang, M., Wu, S., Wang, Z., Lin, X., Song, X., and Liao, D. J. (2012). Basic anatomy and tumour biology of the RPS6KA6 gene that encodes the p90 ribosomal S6 kinase-4. Oncogene 32, 1794-1810.

Swartling, F. J., Savov, V., Persson, A. I., Chen, J., Hackett, C. S., Northcott, P. A., Grimmer, M. R., Lau, J., Chesler, L., Perry, A., et al. (2012). Distinct neural stem cell populations give rise to disparate brain tumours in response to N-MYC. Cancer Cell 21, 601-613.

Taylor, M. D., Liu, L., Raffel, C., Hui, C. C., Mainprize, T. G., Zhang, X., Agatep, R., Chiappa, S., Gao, L., Lowrance, A., et al. (2002). Mutations in SUFU predispose to medulloblastoma. Nat Genet 31, 306-310.

Taylor, M. D., Mainprize, T. G., and Rutka, J. T. (2000). Molecular insight into medulloblastoma and central nervous system primitive neuroectodermal tumour biology from hereditary syndromes: a review. Neurosurgery 47, 888-901.

Thompson, M. C., Fuller, C., Hogg, T. L., Dalton, J., Finkelstein, D., Lau, C. C., Chintagumpala, M., Adesina, A., Ashley, D. M., Kellie, S. J., et al. (2006). Genomics identifies medulloblastoma subgroups that are enriched for specific genetic alterations. J Clin Oncol 24, 1924-1931.

Utepbergenov, D., and Derewenda, Z. S. (2013). The unusual mechanism of inhibition of the p90 ribosomal S6 kinase (RSK) by flavonol rhamnosides. Biochim Biophys Acta. Valk-Lingbeek, M. E., Bruggeman, S. W., and van Lohuizen, M. (2004). Stem cells and cancer; the polycomb connection. Cell 118, 409-418.

Wang, X., Venugopal, C., Manoranjan, B., McFarlane, N., O'Farrell, E., Nolte, S., Gunnarsson, T., Hollenberg, R., Kwiecien, J., Northcott, P., et al. (2012). Sonic hedgehog regulates Bmil in human medulloblastoma brain tumour-initiating cells. Oncogene 31, 187-199. 
Wu, J., Lee, C., Yokom, D., Jiang, H., Cheang, M. C., Yorida, E., Turbin, D., Berquin, I. M., Mertens, P. R., Iftner, T., et al. (2006). Disruption of the Y-box binding protein-1 results in suppression of the epidermal growth factor receptor and HER-2. Cancer Res 66, 4872-4879.

Wu, J., Stratford, A. L., Astanehe, A., and Dunn, S. E. (2007). YB-1 is a Transcription/Translation Factor that Orchestrates the Oncogenome by Hardwiring Signal Transduction to Gene Expression. Transl Oncogenomics 2, 49-65.

Yang, Z. J., Ellis, T., Markant, S. L., Read, T. A., Kessler, J. D., Bourboulas, M., Schuller, U., Machold, R., Fishell, G., Rowitch, D. H., et al. (2008). Medulloblastoma can be initiated by deletion of Patched in lineage-restricted progenitors or stem cells. Cancer Cell 14, 135-145.

Yauch, R. L., Dijkgraaf, G. J., Alicke, B., Januario, T., Ahn, C. P., Holcomb, T., Pujara, K., Stinson, J., Callahan, C. A., Tang, T., et al. (2009). Smoothened mutation confers resistance to a Hedgehog pathway inhibitor in medulloblastoma. Science 326, 572-574.

Youdim, K. A., Dobbie, M. S., Kuhnie, G., Proteggent, A. R., Abbott, N. J., and RiceEvans, C. (2003). Interaction between flavonoids and the blood-brain barrier: in vitro studies. J Neurochem 85, 180-192.

Yuasa, T., Kataoka, H., Kinto, N., Iwamoto, M., Enomoto-Iwamoto, M., Iemura, S., Ueno, N., Shibata, Y., Kurosawa, H., and Yamaguchi, A. (2002). Sonic hedgehog is involved in osteoblast differentiation by cooperating with BMP-2. J Cell Physiol 193, 225-232.

Yu, F., Masoud, S., Nguyen, B., Vue, N., Schubert, S., Tolliday, N., Sengupta, S., Weeraratne, D., Shreiber, S., and Cho, Y. J. (2013). 0188. High-throughput chemical biology screen identifies ROS intolerance as a vulnerability of MYC-amplified/Group 3 medulloblastomas. Neuro-Oncology 15, i50.

Zahreddine, H., and Borden, K. L. (2013). Mechanisms and insights into drug resistance in cancer. Front Pharmacol 4, 28.

Zeniou, M., Ding, T., Trivier, E., and Hanauer, A. (2002). Expression analysis of RSK gene family members: the RSK2 gene, mutated in Coffin-Lowry syndrome, is prominently expressed in brain structures essential for cognitive function and learning. Hum Mol Genet 11, 2929-2940.

Zhou, B. B., and Bartek, J. (2004). Targeting the checkpoint kinases: chemosensitization versus chemoprotection. Nat Rev Cancer 4, 216-225.

Zurawel, R. H., Chiappa, S. A., Allen, C., and Raffel, C. (1998). Sporadic medulloblastomas contain oncogenic beta-catenin mutations. Cancer Res 58, 896-899. 